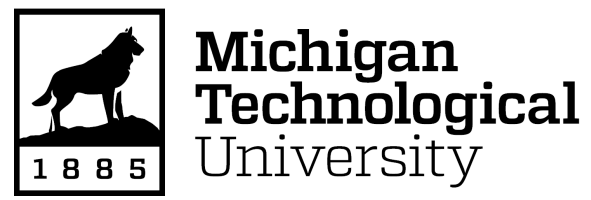

Michigan Technological University Digital Commons @ Michigan Tech

Experimental investigations of temperature controlled innovative annular flow-boiling of FC-72 in millimeter scale ducts - steady and enhanced pulsatile realizations

Patcharapol Gorgitrattanagul

Michigan Technological University, pgorgitr@mtu.edu

Copyright 2017 Patcharapol Gorgitrattanagul

Recommended Citation

Gorgitrattanagul, Patcharapol, "Experimental investigations of temperature controlled innovative annular flow-boiling of FC-72 in millimeter scale ducts - steady and enhanced pulsatile realizations", Open Access Dissertation, Michigan Technological University, 2017.

https://doi.org/10.37099/mtu.dc.etdr/504

Follow this and additional works at: https://digitalcommons.mtu.edu/etdr

Part of the Heat Transfer, Combustion Commons 


\title{
EXPERIMENTAL INVESTIGATIONS OF TEMPERATURE CONTROLLED INNOVATIVE ANNULAR FLOW-BOILING OF FC-72 IN MILLIMETER SCALE DUCTS - STEADY AND ENHANCED PULSATILE REALIZATIONS
}

\author{
By \\ Patcharapol Gorgitrattanagul
}

\begin{abstract}
A DISSERTATION
Submitted in a partial fulfillment of the requirements for the degree of DOCTOR OF PHILOSOPHY
\end{abstract}

In Mechanical Engineering-Engineering Mechanics

MICHIGAN TECHNOLOGICAL UNIVERSITY

2017

(C) 2017 Patcharapol Gorgitrattanagul 
This dissertation has been approved in partial fulfillment of the requirements for the Degree of DOCTOR OF PHILOSOPHY in Mechanical Engineering-Engineering Mechanics.

Department of Mechanical Engineering-Engineering Mechanics

\author{
Dissertation Advisor: $\quad$ Dr. Amitabh Narain \\ Committee Member: Dr. Sajjad Bigham \\ Committee Member: $\quad$ Dr. Scott Miers \\ Committee Member: Dr. Radheshyam Tewari \\ Committee Member: Dr. Scott Wagner \\ Department Chair: Dr. William Predebon
}




\section{Dedication}

I humbly dedicate this work to king Bhumibol, the king of Thailand - who recently passed away in October of last year. He was my inspiration for this study aboard directed at bringing knowledge back to my home country and using it for its development. Also, king Bhumibol has always been my role model for hard-work. This thesis is also dedicated to the royal Thai government which provided this opportunity for studying abroad in the U.S., and for financially supporting me during my study. Finally, this thesis is dedicated to my parents, who have been nurturing, educating, and supporting me ever since I was born. Without all the aforementioned support, I would not be able to come this far. 


\section{Table of Contents}

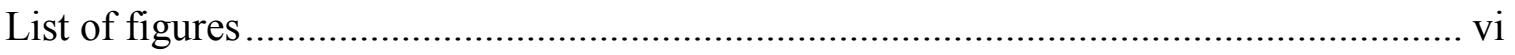

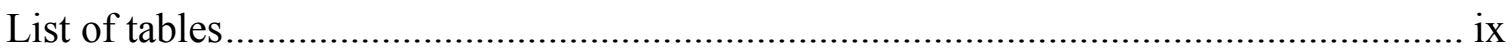

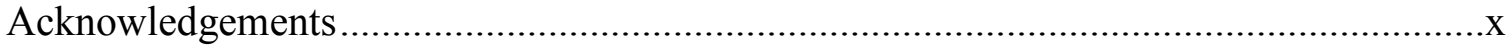

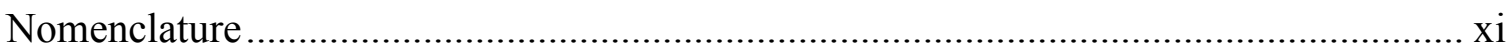

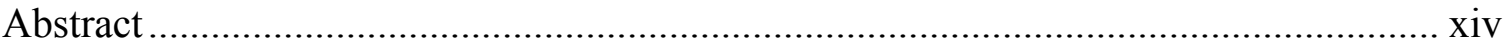

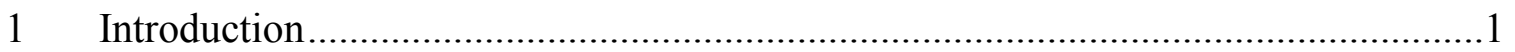

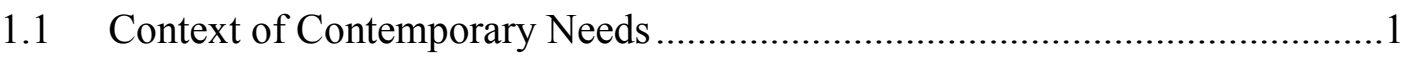

1.2 Established Technologies and their Limitations in Addressing Contemporary Needs 2

1.3 Innovative Annular Flow-boiling Operation ...................................................

1.4 Relationship to Background/Available Knowledge ............................................

1.5 Scientific Issues for Traditional and Innovative Operations .............................6

2 Existing Knowledge and Issues with Innovative Annular Flow-boiling ....................8

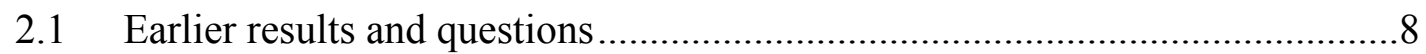

2.1.1 The earlier results.....................................................................

2.1.2 Questions arising from earlier results ...............................................8

2.2 New Experiments to Address the Questions Raised in Section 2.1 ...............10

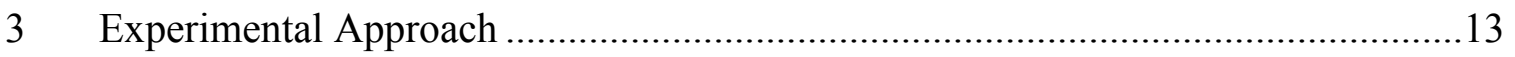

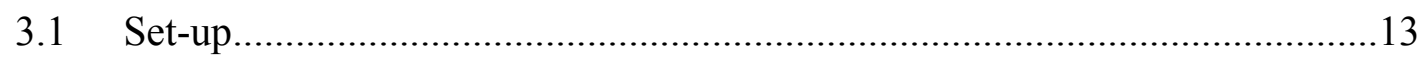

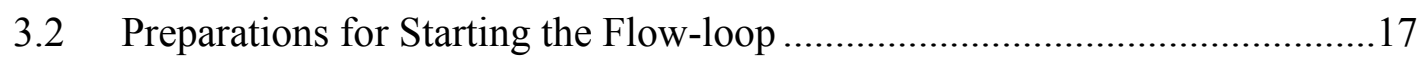

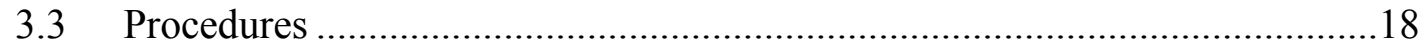

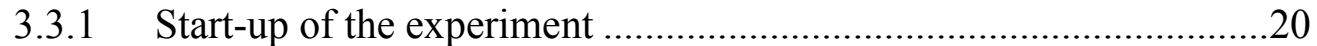

3.3.1.1 Non-pulsatile Steady Annular Flow-boiling....................23

3.3.1.2 Steady-in-the-mean Pulsatile flows Resulting from Imposed Pulsations .........................................................................23

4 Experimental Results and Discussions for Steady and Enhanced Annular Flow-

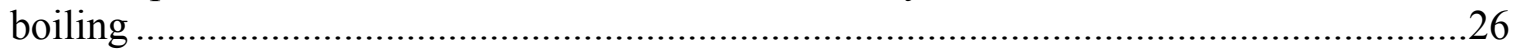

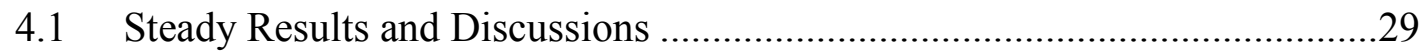

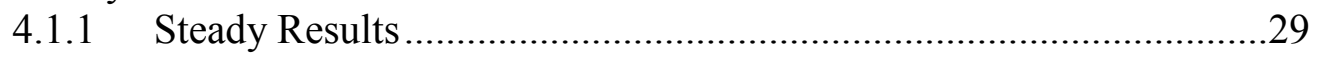

4.1.2 Discussions of Steady Results .............................................................34

4.1.2.1 Role of micro-nucleation ................................................36 
4.1.2.2 Role of experiments in obtaining more flow-regime and parameter-space based HTC correlations ...........................................39

4.2 Pulsatile Enhanced Annular Flow Results and Discussions ............................40

4.2.1 Pulsatile Steady-in-the-Mean Annular Flow Results..........................42

4.2.2 Discussions for the Pulsatile Steady-in-the-Mean Annular Flow Results 53

5 Experiments Enabled Modeling and Simulations that Yield Heat-Transfer Correlations and Assess Role of Micro-nucleation for Steady Annular Flow-boiling ......56

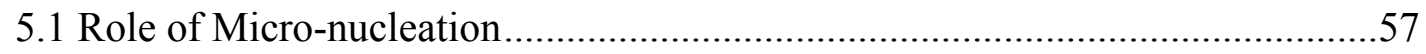

5.2 Parameter-range Specific HTC Correlation for Steady Annular Flow-boiling ..62

6 Alternative More Efficient Ways for Realizing Enhanced Steady-in-the-mean

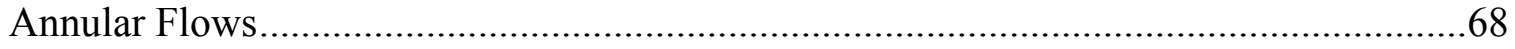

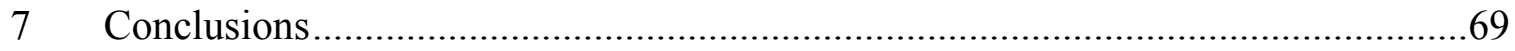

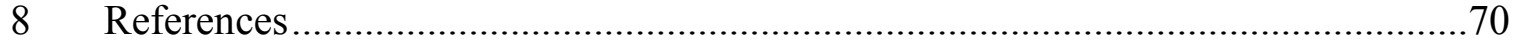

A Appendix A: Flow-loop Modifications Undertaken for this Thesis ..........................74

A.1 Description of Existing Apparatus/Equipment................................................74

A.2 Modified Flow-Loop and Its New Components.............................................77

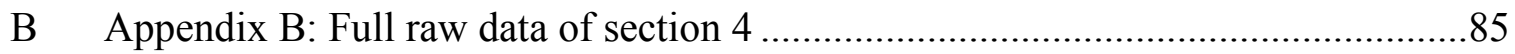

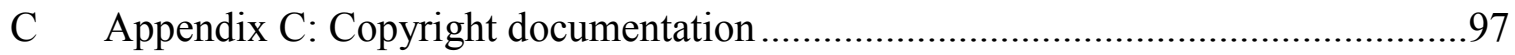




\section{List of figures}

Figure 1.1: (a) Side-view schematic and a representative top-view photograph for a traditional flow-boiler. (b) Mechanism and contact-line physics for nucleate boiling ebullition cycle.

Figure 1.2: (a) Schematic of a typical vapor compression cycle. (b) Thermalmanagement variation of vapor compression cycle. The heat absorption to an evaporator, for electric cooling application, is often restricted to take place with $70-80{ }^{\circ} \mathrm{C}$ constrain on the source temperature.

Figure 1.3: Innovative operations control the inlet quality and duct length - for a range of mass-fluxes and heating conditions - to ensure high heat-flux annular realizations (with 300-50 $\mu \mathrm{m}$ thick liquid films in mm-scale hydraulic diameter ducts) without dry-out. The grey marked zone on the boiling-surface with its depicted local dynamic heat-flux $q_{w}{ }_{w}(t)$ values are indicative of a representative local heat-flux measurement. The photograph below is of an actual annular experimental realization for a low heat-flux case.

Figure 2.1: A side view schematic of an instrumented test-section which has a $15 \mathrm{~mm}$ width (in direction out of the figure plane). The test-section is for new innovative flow boiling investigations (with FC-72 as the working fluid)

Figure 3.1: A side view schematic of an instrumented test-section which has a $15 \mathrm{~mm}$ width (in direction out of the figure plane). The test-section is for innovative flowboiling investigations (with FC-72 as the working fluid).................................. 13

Figure 3.2: A schematic of the experimental flow-loop.......................................... 15

Figure 3.3: A photograph of the experimental test set-up. ..........................................19

Figure 4.1: A side view schematic of an instrumented test-section which has a $15 \mathrm{~mm}$ width (in direction out of the figure plane). The test-section is for innovative flow boiling investigations (with FC-72 as the working fluid).....

Figure 4.2: The above representative non-dimensionlized temperature profile, over $0<\mathrm{x}^{\#} \leq \mathrm{x} \leq \mathrm{x}_{\mathrm{e}}<\mathrm{L}$, specifies the "method of heating" for all the experimental runs in Table 4.1 .

Figure 4.3: This non-dimensionalized temperature profile specifies the "method of heating" for the runs in Table 4.3 .

Figure 4.4: A schematic diagram of the test-section showing a flow realization with large amplitude standing waves on the liquid-vapor interface. The test-section is closed in the vapor flow direction for acoustics enabled formation of interfacial standing 
waves. The zones $\mathrm{x}_{1}, \mathrm{x}_{2}$ and $\mathrm{x}_{3}$ are zones of decreasing film thicknesses, respectively. Bubbles have been represented as "black dots" in zone $\mathrm{x}_{1}$ but are present in the liquid film throughout the test-section, except in the region of suppressed nucleation (zone $\mathrm{x}_{3}$ ). The liquid film thickness, shown as $\mathrm{t}(\mathrm{x})$, varies along the length of the channel, and is measured from the heating surface to the trough of the interfacial wave.

Figure 4.5: (a) The experimentally obtained time-averaged heat-flux values for flowboiling of FC-72 exhibit primary dependence on amplitude of inlet pressure fluctuations. The black curve for $\mathrm{f}_{\mathrm{P}} \approx 3 \mathrm{~Hz}$ represents experimental values (for $\Delta \mathrm{T} \approx 10^{\circ} \mathrm{C}$ ) and the indicated dashed-curve is an expected result from a new enhancement approach. (b) Time-averaged heat-flux values for flow-condensation of FC-72 are experimentally obtained [9] (with $\Delta \mathrm{T} \approx 20^{\circ} \mathrm{C}$ at mass-fluxes and fluid as in (a)) and their primary dependence on amplitude of local (at the Heatflux Sensor location of $\mathrm{x}=40 \mathrm{~cm}$ ) pressure fluctuations are shown above for two frequencies - with the $28.4 \mathrm{~Hz}$ frequency likely being closer to the acousticsenabled dominant frequency for interfacial standing waves. (c) Time-varying heat-flux measurements with and without imposed inlet vapor pulsations, measured by a flush-type dynamic heat-flux sensor at the $40 \mathrm{~cm}$ heat-flux meter location. The experimental arrangement is similar to the innovative arrangement in Fig. 2a (but with dry-out and therefore without the recirculating liquid) [9]. (d) Dynamic and computed time-averaged heat-flux values are shown for steady nonpulsatile and pulsatile cases in Table 4.5. These are obtained for the new flowboiling experiments with $\mathrm{f}_{\mathrm{PL}} \cong \mathrm{f}_{\mathrm{PV}}=5 \mathrm{~Hz}$ and $\mathrm{x}=40 \mathrm{~cm}$ location corresponds to the thicker $\mathrm{x}_{1}$ locations in Fig. 4.4 [Reproduction of Fig. $4.5 \mathrm{~b}-\mathrm{c}$ was granted from Elsevier publishing, see Appendix C]....

Figure 4.6: Heating method (Non-dimensionalized wall temperature profile) of cases in Table 4.5. There is a slight sub-cooling over $\mathrm{x}<\mathrm{x}_{\mathrm{z}}=10.65 \mathrm{~mm}$.

Figure 4.7: For steady and steady-in-the-mean (pulsatile) cases reported in Table 4.5, (a) Sample real time dynamic data record for $\mathrm{p}_{10}(\mathrm{t})$, (b) Low DAQ $\dot{\mathrm{M}}_{\mathrm{L} \text {-in }}(\mathrm{t})$ data of inlet liquid mass flow rate, and (c) Low DAQ $\dot{\mathrm{M}}_{\mathrm{V} \text {-in }}(\mathrm{t})$ data of inlet vapor mass flow rate.

Figure 4.8: The above shows the FFT of $p_{10}(t)$ associated with the steady case in Table 4.5. This and other FFTs confirm a dominant noise frequency of $45 \mathrm{~Hz}$.

Figure 4.9: The above shows the FFT of $\mathrm{q}_{\mathrm{w}-40 \mathrm{~cm}}(\mathrm{t})$ associated with the steady case in Table 4.5. This and other FFTs confirm a dominant noise frequency of $45 \mathrm{~Hz} . . .47$

Figure 4.10: The figure above shows the FFT of $\mathrm{q}_{\mathrm{w}-40 \mathrm{~cm}}(\mathrm{t})$ associated with the pulsatile case in Table 4.5. The externally imposed pulsations frequency $\mathrm{f}_{\mathrm{PL}} \cong \mathrm{f}_{\mathrm{PV}} \cong 5 \mathrm{~Hz}$ clearly dominate the bubble nucleation frequency over the heat-flux sensor at 40 
cm location. However, $5 \mathrm{~Hz}$ is not in sync with the $45 \mathrm{~Hz}$ in Fig. 4.8, hence the dominant subharmonics at $10,15,20$, etc. Hz.................................................4

Figure 4.11: Non dimensional wall temperature profile $\theta_{w}(x), 0<x^{\#} \leq x \leq x_{e}<L$, for the two runs in Table 4.6.

Figure 5.1: An actual experimental realization with known/measured values of $\dot{\mathrm{M}}_{\mathrm{L}-\mathrm{in}}$, $\dot{\mathrm{M}}_{\mathrm{V}-\mathrm{in}}$, wall temperature variation $\mathrm{T}_{\mathrm{w}}(\mathrm{x})$, and some values of $\left.\mathrm{q}_{\mathrm{w}}{ }_{\mathrm{w}}(\mathrm{x})\right|_{\text {Expt }} \ldots \ldots \ldots . . .58$

Figure 5.2: A hypothetical flow realization obtained by a rigorous CFD which employs experimental values (as in Fig. 5.1) of $\dot{\mathrm{M}}_{\mathrm{L}-\mathrm{in}}, \dot{\mathrm{M}}_{\mathrm{V} \text {-in }}$, etc. as inlet condition and experimental values of wall temperature variation $\mathrm{T}_{\mathrm{w}}(\mathrm{x})$ as thermal boundary condition. CFD predicts wall heat-flux $\mathrm{q}_{\mathrm{w} \mid \mathrm{CFD}}(\mathrm{x})$, etc. which are typically different (because micro-nucleation phenomena is not modeled) than corresponding values in Fig. 5.1.

Figure 5.3: A representative and rigorous CFD simulation (that models all flow-physics quite accurately, except for nucleating bubbles) result [41] showing the streamlines for steady annular suppressed nucleation flow-boiling. [Reproduction of the figure was granted from Springer International Publishing, see Appendix C].

Figure 5.4: (a) A representative $X(x)$ calculation for case 3 in Tables 4.1-4.2 is shown. Here $\mathrm{X}(\mathrm{x}=40 \mathrm{~cm})=0.783$ in $\mathrm{Nu}_{\mathrm{x}}$ correlation in [41] yields $\mathrm{h}_{\mathrm{x} \mid \mathrm{cb}-\mathrm{CFD}}=206.1$ $\mathrm{W} /\left(\mathrm{m}^{2}-\mathrm{K}\right)$. (b) The figure shows a graphical comparison between $\mathrm{h}_{\mathrm{x} \mid \mathrm{Expt}}=1072.6$ $\mathrm{W} /\left(\mathrm{m}^{2}-\mathrm{K}\right)$ in Table 4.2 , and $\mathrm{h}_{\mathrm{x} \mid \mathrm{unb}}=866.5 \mathrm{~W} /\left(\mathrm{m}^{2}-\mathrm{K}\right)$ (calculated from Eq. (5.1)). The corresponding $\% \mu \mathrm{nb}-\mathrm{CFD}=80.8 \%$.

Figure 5.5: (a) Variation of quality along the length of the channel from the experiment (Expt) and as predicted by the new proposed correlation $\left(\mathrm{Nu}_{\mathrm{x} \text { |prop }}\right)$ and the original correlation by Kim and Mudawar $\left(\mathrm{Nu}_{\mathrm{x} \mid \mathrm{KM}}\right)$. (b) Variation of Nusselt number along the length of the channel, as predicted by the new proposed correlation $\left(\mathrm{Nu}_{\mathrm{x}}\right.$ prop $)$ and the original correlation proposed by Kim and Mudawar $\left(\mathrm{Nu}_{\mathrm{x} \mid \mathrm{KM}}\right)$. 


\section{List of tables}

Table 4.1: Experimental run results of a set of steady run cases whose "method of heating" is defined by the function in Fig. 4.2

Table 4.2: Calculated parameters computed for the corresponding case-specific values in Table 4.1.

Table 4.3: Experimental run results of steady run cases which different from Table 4.1.33

Table 4.4: Calculated parameters based on values from Table 4.3 …............................33

Table 4.5: Experimental runs associated with Fig. $4.5 \mathrm{~d}$ are characterized by this Table (these are results when the original dynamic heat-flux sensor was available, not broken).

Table 4.6: Time averaged results for pulsatile experimental run cases superposed on a representative steady case.... 


\section{Acknowledgements}

This research work would not have been possible without the grants from NASA (NNX 10AJ59G) and NSF (NNC 04GB52G and NSF-CBET 1033591). These grants, over the past years, provided the support for fabricating the experimental test set-up for my experiments as well as financial supports needed to support the research group (s) I teamed with.

From the bottom of my heart, I am hugely indebted to my academic advisor, Dr. Amitabh Narain. This is not only for his mentoring, guiding, and helping me - that was available throughout my research, but also for his calm one-on-one interactions and willingness to teach over the past 7 years.

I am sincerely grateful to my past colleague, now Dr. Michael T. Kivisalu, for his teaching and for the days and nights we spent together to make progress in our research for close to 5 years. I will never forget that valuable experience.

Next, I am thankful to Prasad Hrishikesh, for his help in planning the runs for the experiments and, also, for the effort that we put together towards making the synthesis of experimental and computational works more meaningful.

Finally, I would like to express my gratitude to my friends - who are numerous and I do not have a chance to list all their names here. I thank them for all of their supports - for both academic and non-academic activities. 


\section{Nomenclature}

\begin{tabular}{|c|c|}
\hline$A_{b s}$ & Boiling-surface area \\
\hline $\mathrm{A}_{\mathrm{cs}}$ & Cross section area \\
\hline$a_{\mathrm{p} 40}$ & Amplitude of pressure at $40 \mathrm{~cm}$ location \\
\hline $\mathrm{C}_{\mathrm{R}}$ & Recirculation compressor \\
\hline$\theta_{\mathrm{w}}(\mathrm{x})$ & Non-dimensionalized wall temperature \\
\hline CFD & Computational fluid dynamics \\
\hline$C_{p}$ & Specific heat \\
\hline DAQ & Data acquisition \\
\hline $\mathrm{D}_{\mathrm{h}}$ & Hydraulic diameter \\
\hline DPT & Differential pressure transducer \\
\hline FFT & Fast Fourier transform \\
\hline $\mathrm{G}$ & Mass-flux \\
\hline HFM-40 & Heat-flux meter at $40 \mathrm{~cm}$ location \\
\hline HTC & Heat transfer coefficient \\
\hline $\mathrm{h}_{\mathrm{x}}$ & Local heat transfer coefficient \\
\hline $\mathrm{h}_{\mathrm{fg}}$ & Heat of vaporization \\
\hline$\dot{\mathrm{M}}_{\mathrm{L}}(\mathrm{x})$ & Liquid mass flow rate \\
\hline$\dot{\mathrm{M}}_{\mathrm{v}}(\mathrm{x})$ & Vapor mass flow rate \\
\hline$\dot{\mathrm{M}}_{\text {total }}$ & Total mass flow rate \\
\hline $\mathrm{Nu}$ & Nusselt number \\
\hline PID & Proportional integral derivative \\
\hline
\end{tabular}




$\begin{array}{ll}\Delta \mathrm{p}_{\mid 10-40} & \text { Pressure difference between } 10 \text { and } 40 \mathrm{~cm} \text { locations } \\ \mathrm{P}_{\mathrm{L}} & \text { A liquid pressure pulsator } \\ \mathrm{P}_{\mathrm{V}} & \text { A vapor pressure pulsator } \\ \mathrm{F}_{\mathrm{C}-1} & \text { Coriolis flow meter (use for measuring vapor) } \\ \mathrm{q}_{\mathrm{w}}^{\prime \prime} & \text { Wall heat-flux } \\ \overline{\mathrm{q}_{\mathrm{w}}^{\prime \prime}} & \text { Averaged wall heat-flux } \\ \mathrm{q}_{\mathrm{total}} & \text { Total heat } \\ \mathrm{TEC} & \text { Thermoelectric cooler } \\ \Delta \mathrm{T} & \text { Temperature difference between averaged wall temperature and saturation } \\ \overline{\mathrm{T}}_{\mathrm{w}} & \text { temperature } \\ \mathrm{T}_{\mathrm{sat}}\left(\mathrm{p}_{0}\right) & \text { Averaged wall temperature } \\ \mathrm{T}_{\mathrm{W}}(\mathrm{x}) & \text { Waturation temperature as a function of inlet pressure } \\ \mathrm{V} \mathrm{P} & \text { Vall temperature } \\ \mathrm{X}(\mathrm{x}) & \text { Vapor quality } \\ \Psi_{\mathrm{q}}(\mathrm{x}) & \text { Non-dimensionalized heat-flux } \\ \rho & \text { Density } \\ \mu & \text { Viscosity }\end{array}$

\section{Subscipts}

$\begin{array}{ll}\text { bf } & \text { Departure bubble frequency } \\ \mathrm{cb} & \text { Convective boiling } \\ \mathrm{nat} & \text { Natural } \\ \mathrm{dom} & \text { Dominant }\end{array}$




\begin{tabular}{ll} 
CFD & Computational fluid dynamics \\
V & Liquid \\
in & Vapor \\
out & Inlet \\
Expt & Outlet \\
st & Experiment \\
Hypoth & Steady \\
prop & Hypothesis \\
$\mu n b$ & Micro nucleate boiling \\
PL & Liquid pulsation \\
PV & Vapor pulsation \\
KM & Kim and Mudawar \\
$\mathrm{x}$ & Local value at particular x location \\
$\mathrm{w}$ & Wall \\
\hline
\end{tabular}




\section{Abstract}

Steady and steady-in-the-mean shear driven annular flow-boiling is experimentally investigated in this thesis. By annular flow-regime one means separated liquid and vapor flows with the flowing liquid film staying on the boiling-surface.

The goals for the steady annular flow-boiling operations are to better understand relative importance of heat-transfer mechanisms (nucleation versus convective phase-change, with convective meaning absence of nucleation) and to develop better quantitative characterizations/correlations for heat-transfer rates. The goals for the steady-in-the-mean annular investigations was to explore improved means of significantly increasing heat transfer rates - while retaining the flow-regime's annularity.

The experimental investigations (with FC-72 as a working fluid) were carried out within a horizontal test-section of $50 \mathrm{~cm}$ length and rectangular cross-section (depth $=15 \mathrm{~mm}$ and height $=2 \mathrm{~mm}$ ). Temperature controlled heating (by using reversed and controllable thermo-electric coolers) at low heat-fluxes (in the range of $0.1-1 \mathrm{~W} / \mathrm{cm}^{2}$ ) were used.

The results establish enhancements between pulsatile (steady-in-the-mean) and corresponding steady cases to be up to $110 \%$ for local heat-flux measurements (at $40 \mathrm{~cm}$ location) and up to $18.3 \%$ for the overall heat-flux. The new physic based decomposition of heat transfer mechanisms - between micro-scale nucleate boiling and convective boiling (assuming no nucleation) - was established by synthesizing experimental data with corresponding data obtained from a very accurate 2D CFD convective modeling (assuming no nucleation) and simulation technique from Dr. Narain's computational team. It is found that invisible micro nucleation plays a very big role in thin liquid film $(400-40 \mu \mathrm{m}$ thick) annular flow-boiling - and is responsible, typically, for removing about 70 to $90 \%$ of the total heat-flux at each location. Experimental data is also used to propose superior heattransfer coefficient correlations.

For steady-in-the-mean cases, it can be concluded that to enhance the heat-flux in an efficient way, inlet liquid flow rate pulsations are best - particularly if the liquid pulsator frequency at suitably small amplitude is set close to the predominant noise frequency (found from the Fast Fourier Transform of the dynamic differential pressure measurement across the test-section) already present in the steady realization. 


\section{Introduction}

\subsection{Context of Contemporary Needs}

Breakthroughs in reliable innovative high heat-flux $\left(>0.5-1 \mathrm{~kW} / \mathrm{cm}^{2}\right)$ millimeter $(\mathrm{mm})$ scale flow-boilers, with appropriate working fluids (R134a, water, etc.,), consistent with the needs of different applications, have long been known [1,2] to be a requirement for removing large amounts of heat from small areas. This thesis makes fluid-physics progress towards addressing the need for removing exponentially increasing amounts of heat (from small or large spaces) associated with electronics used in modern server racks, supercomputers, data centers, as well as other waste-heat recovery and power generation systems. The heat that must be removed has been increasing by a factor of $1.5-2$ every year - although, lately, the rate has started plateauing. Thus, there is a need for steady and costeffective waste heat removal capabilities in excess of $0.5-1 \mathrm{~kW} / \mathrm{cm}^{2}$, while maintaining hardware temperatures at or below $75^{\circ} \mathrm{C}$.

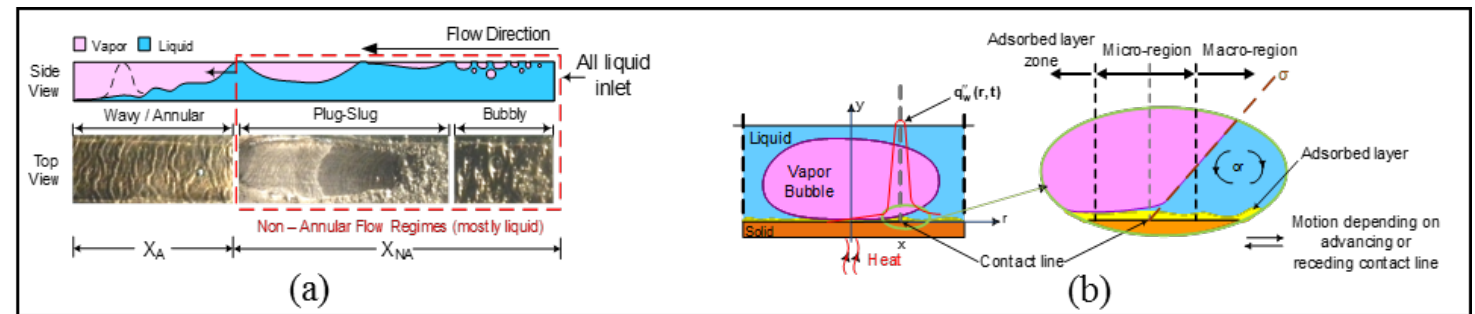

Figure 1.1: (a) Side-view schematic and a representative top-view photograph for a traditional flow-boiler. (b) Mechanism and contact-line physics for nucleate boiling ebullition cycle.

Established technologies, such as an array of small diameter heat pipes (HP) or their Capillary HP and Looped HP variations [3] have limitations that make them inadequate solutions for these applications' increasing high heat-flux and heat-load needs $[4,5]$ that, in turn, need high mass-fluxes in the in-tube boilers. Furthermore, any attempt to use traditional flow-boiling approaches leads to complex and inefficient flow-regimes (see Fig. 1a) - with large pressure-drops - primarily because of shear dominance, easy loss of 
annularity, etc. Also, efficient buoyancy-aided traditional pool-boiling mechanisms (Fig. 1b) are not directly available for such applications, though there are limited opportunities for their use in immersion type electronic cooling approaches [6]. Thus, the physics underlying pool-boiling mechanisms needs to be harnessed (with suitable modifications) to address emerging flow-boiling needs that require lower representative temperature differences $\Delta \mathrm{T}$ (between boiling-surface and saturation temperature) and pressure-drop penalties at high heat-fluxes.

\subsection{Established Technologies and their Limitations in Addressing Contemporary Needs}

A vapor compression cycle (see Fig. 1.2a) transfers heat - e.g. as in heat-pumps and refrigerators - from one temperature (typically lower) to another. As seen in Fig.1.2a, such systems consist of four main components: an evaporator/flow-boiler, a condenser, a compressor, and an expansion/throttling valve. Consider the fluid (or refrigerant) flow process through the evaporator/flow-boiler. In the flow-boiler, the fluid enters as a liquid or a liquid-vapor mixture at a pressure lower than the condenser. Heat is added to this evaporator/flow-boiler and is absorbed by the fluid - evaporating it from liquid to vapor. The vapor exiting the evaporator enters the compressor, where mechanical energy is added and absorbed by the vapor flow. As a result, vapor exits the compressor at a higher pressure. The vapor next enters the condenser where it rejects heat to the condenser surroundings and changes its state to a liquid at higher pressure (than at the evaporator). Then the high pressure liquid flows through the throttling valve - where it experiences frictional drop in pressure - and exits as a saturated liquid or liquid-vapor mixture at lower pressure. The thermal management variation of the vapor compression cycle in Fig. 1.2a is shown in Fig. 1.2b. As shown in Figs.1.2a-b, the fluid re-enters the evaporator and thus repeatedly experiences this cyclic process. It is well known that the transfer of heat (from heat source surrounding the evaporator to the heat sink surrounding the condenser) through such vapor compression cycles have been successfully used - in many applications - that serve society 
and make human life more comfortable. Yet the very same cycle fails to be functional in numerous new applications, particularly those involving thermal management (Fig. 1.2b), where the flow-boiler tube must be small in diameter $(<5 \mathrm{~mm})$, cannot be very long (e.g. as is the case for serpentine coils used in traditional operations), and yet must absorb a large amount of heat through a large mass-flux in the tube. This is because at small diameters and requisite large mass flow rates, high heat-flux traditional flow-boiling operations limit to shear driven situations, modeled as in Fig. 1.1a, which has problems with inefficiencies in flow-boiling brought out by: unmanaged flow-regimes, explosive uncontrolled nucleation rates, increased pressure-drops, etc.

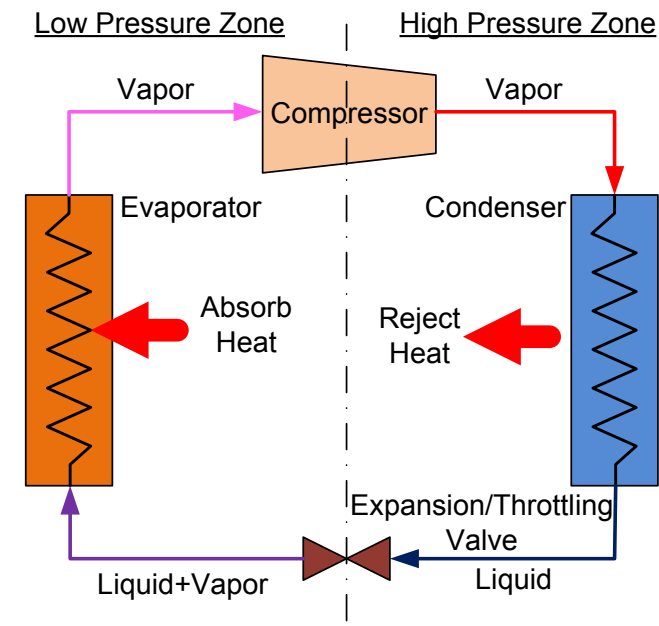

(a)

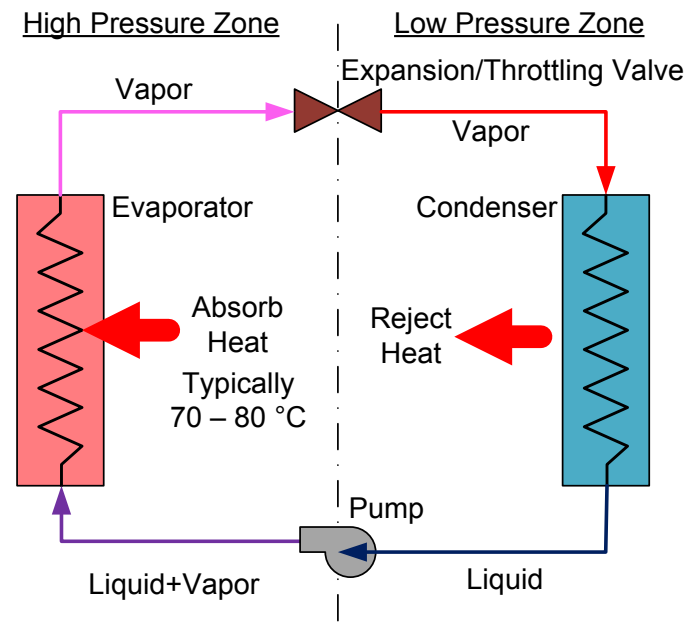

(b)

Figure 1.2: (a) Schematic of a typical vapor compression cycle. (b) Thermal-management variation of vapor compression cycle. The heat absorption to an evaporator, for electric cooling application, is often restricted to take place with $70-80{ }^{\circ} \mathrm{C}$ constrain on the source temperature. 


\subsection{Innovative Annular Flow-boiling Operation}

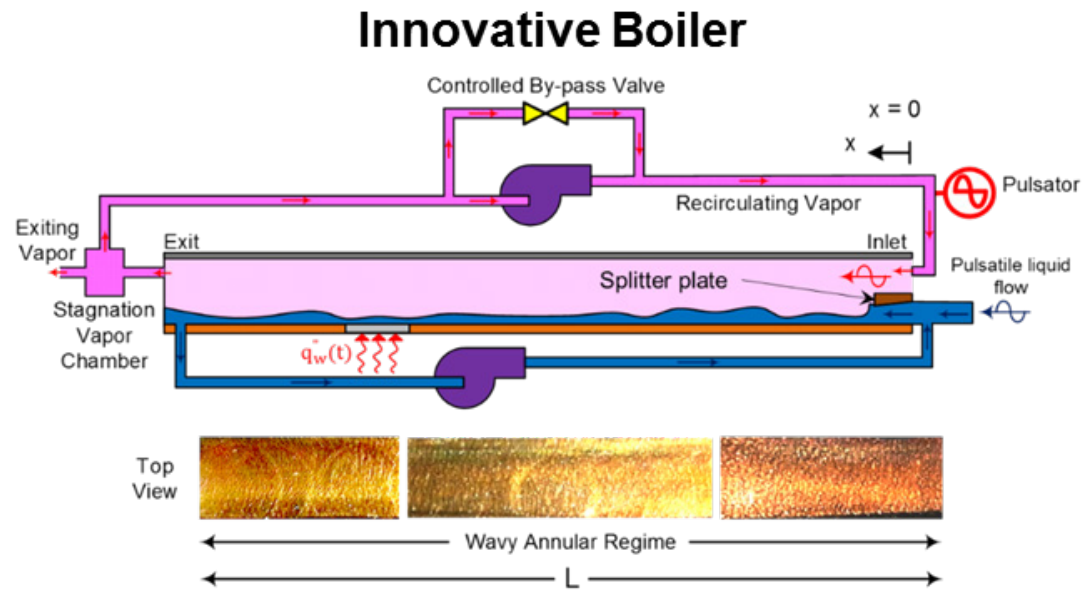

Figure 1.3: Innovative operations control the inlet quality and duct length - for a range of mass-fluxes and heating conditions - to ensure high heat-flux annular realizations (with $300-50 \mu \mathrm{m}$ thick liquid films in mm-scale hydraulic diameter ducts) without dry-out. The grey marked zone on the boiling-surface with its depicted local dynamic heat-flux $q_{w}{ }_{w}(t)$ values are indicative of a representative local heat-flux measurement. The photograph below is of an actual annular experimental realization for a low heat-flux case.

Innovative and effective steady annular flow-boiling operations (Kivisalu et al. 2014) require a change from traditional flow-boiler operations - associated with multiple flowregimes (see Fig. 1.1a for depiction of different flow-regimes in a horizontal duct, and Carey (1992) and Ghiaasiaan (2007) for discussions on different flow-regimes) - to operations such as the ones in Fig. 1.3. These operations control the flow-regimes through control of inlet quality and attain stable and steady annular flow-regime over all of a suitably chosen device length. Furthermore, to propose approaches that address high heatflux needs (500-1000 W/ $/ \mathrm{cm}^{2}$ or greater) in future, as discussed in this thesis, resonant pulsations in the liquid and vapor flows are introduced to create large amplitude standing waves on the interface and investigate its heat-transfer and pressure-drop effects on the highly stabilized thin liquid film (300-200 $\mu \mathrm{m}$ thickness range) annular flow-boiling. Such flows are realized through flow-controls and one or more of the two pulsation input options 
indicated, as sinusoids on the incoming flows, in Fig. 1.3. This is to make liquid film flow as choppy (i.e., up, down, and forward motions) as possible - within the feasibility offered by laminar flow restrictions imposed by the thinness of the liquid film flow (300-200 $\mu \mathrm{m}$ thickness range) on a wetting wall. The choppiness helps in introducing additional microconvection advantages to evaporation at the interface as well as, particularly at higher heatflux values, in altering and increasing the level of contributions from micro-scale nucleate boiling. Both micro-convection and micro-scale nucleate boiling, consisting of micron to submicron diameter bubbles, take advantage of high heat-flux contact-line flow-physics (see Fig. 1.1b) known to play a pivotal role in macro-scale pool-boiling during an ebullition cycle. The size limitations on the nucleating bubbles are imposed by imposed levels of heat-flux, enhancement approaches, liquid film-thicknesses, and accompanying significant changes in hydrodynamic forces relative to those present in pool-boiling (see Dhillon and Buongiorno 2017, Phan et al. 2009, Zeng et al. 1993a, Zeng et al. 1993b, etc.).

\subsection{Relationship to Background/Available Knowledge}

A recent review book chapter [7] from our modeling group discusses the relevant background knowledge for steady annular flow-boiling and enhancement approaches. These are obtained from: Void-fraction and Heat Transfer Empirical Correlations [8-14], Modeling and CFD-Synthesized Improved Empirical Correlations [15, 16], Flow Regime Maps and Associated Instabilities [12, 17-19], Critical Heat-flux Instabilities [20], Pressure-drop Correlations and Pumping Power Penalties [21-23], Effects of Gravity and Tube Geometries [24, 25], and Conventional Enhancement Techniques for Heat Transfer Coefficient (HTC) [26, 27]. This review article also discusses principles and design of flow-boilers' (and flow-condensers') underlying steady operations. These steady operations' design principles are important for further improvements in operations, through existing [28-30] or future proposals for the enhanced steady-in-the-mean realization approaches.

For related and additional discussions on pool-boiling contact-line flow-physics, see Gerardi et al. (2010), Kunkelmann et al. (2012), McHale and Garimella (2010) and 
Raghupathi and Kandlikar (2016). Survey of the available literature on macro- and microscale nucleation is not the focus of this research. Yet it is noted that some heuristic support for the above description of the role played by macro-/micro- nucleation can be obtained by superposition of convection mechanisms and available modeling for nucleating bubble mechanisms based on pool-boiling investigations. Such superposition-based simulations are available on FLUENT (2015). The phase distribution is obtained by solving continuity equations for volume fraction and Navier-Stokes equation for both the phases separately. The simulations use the Rensselaer Polytechnic Institute (RPI) nucleate boiling models as integrated by Kurul and Podowski (1991) and Lavieville et al. (2006). The RPI boiling model partitions the heat-flux from the wall into contributing mechanisms while adding information on models for bubble departure frequency (such as Cole 1960), departure diameter (such as Tolubinsky and Kostanchuk 1970), and nucleation site density (Lemmert and Chawla 1977).

\subsection{Scientific Issues for Traditional and Innovative Operations}

Despite the significant design knowledge/information available in the literature discussed in section 1.3, there is a lack of good and accurate experimental information - and modeling/simulation capabilities - even for the steady annular flow-boiling in Fig. 1.3. To design such flow-boilers, more accurate experiments-modeling synthesis based knowledge and information on: inlet quality restrictions, local heat transfer coefficient, pressure-drop, role of micro-nucleation, avoidance of critical heat-flux, etc. are needed for steady realizations in Fig. 1.3. There is also the question on what will be the differences between this thesis's low heat-flux $\left(0.1-1 \mathrm{~W} / \mathrm{cm}^{2}\right)$ steady annular experiments involving FC-72 as a working fluid and the ongoing high heat-flux $\left(10-500 \mathrm{~W} / \mathrm{cm}^{2}\right)$ steady annular experiments involving water as a working fluid.

For effective development of enhanced annular steady-in-the-mean realizations (such as pulsatile cases discussed in [7,9] there is a concurrent need for better understanding and integration of nucleate-boiling phenomena at single-bubble ([17], [31], etc.) and collective large-scale nucleation [32], [33] levels. In particular, the question relates to understanding 
the significance and mechanisms of micro-nucleation in innovative annular flow-boiling discussed in Fig. 1.3 and ways of controlling (with regard to predominant bubble sizes, nucleation site densities, bubble departure frequencies, etc.) and enhancing its contributions - and then being successful in going from low heat-flux $\left(0.1-1 \mathrm{~W} / \mathrm{cm}^{2}\right)$ to high heat-flux $\left(10-500 \mathrm{~W} / \mathrm{cm}^{2}\right)$ - for steady-in-the-mean realizations utilizing a suitable enhancement approach. 


\section{Existing Knowledge and Issues with Innovative Annular Flow-boiling}

There is an existing experimental knowledge for steady and pulsatile (steady-in-the-mean with large interfacial standing waves) annular flow-boiling cases reported in [7,9].

\subsection{Earlier results and questions}

\subsubsection{The earlier results}

- With proper inlet quality control, for a chosen total mass-flow rate and heating approach and level, annular flow-boiling is possible over the length of the duct.

- For micro-scale thinness of the film at the heat-flux sensor location in Fig. 1.3, imposition of large-amplitude interfacial waves demonstrated that very large local heat-flux enhancements (200-300 \% for annular flow-boiling and 700-800\% for annular flow condensation) was possible for the low heat-flux FC-72 [7,9] experiments.

\subsubsection{Questions arising from earlier results}

- The earlier experiments involving large-amplitude interfacial waves - with demonstrated and large local heat-flux enhancements of 200-300 \% for annular flow-boiling [7, 9] - did not have a reliable measurement for length-averaged heatflux, yet preliminary estimates suggested an average heat-flux enhancement of no more than 20-30\%. That fact implied that the enhancement flow-physics was likely different for different local film-thickness values over the local (and dynamic measurements capable) heat-flux sensor - and questions arose as to whether there will be greater dividend and opportunities present if: (i) average heat-flux measurements capability was added to the experiment, and (ii) the range of filmthicknesses variations available for the annular flow realization was controlled to be, always, in the desired high enhancement range (say $300-50 \mu \mathrm{m}$ ). 
- The earlier experiments [7,9] involving superposition of large-amplitude interfacial waves also demonstrated very large local heat-flux enhancements of $200-300 \%$ for annular flow-boiling and even larger 700-800\% for annular flow condensation. And yet, everything else being approximately the same, the local enhanced heat transfer coefficient (HTC) for flow-boiling was larger than for flowcondensation (i.e. for similar local heat-flux, local temperature difference was often lower for flow-boiling - ceteris paribus). This raised questions as to possible presence of another mechanism - such as invisible micro-scale nucleation - which made micro-convection effects in flow-condensation different than those for flowboiling.

- The earlier experiments [7,9] were able to implement PID controls of the heaters to approximately fix temperatures at the nine thermocouple locations placed in between the reversed TECs (thermoelectric coolers) heaters described in [9]. It was realized that the nature of heat inputted from the heaters and the 3-D nature of conduction heat transfer resulting from certain exposed parts of the steel plate whose top-surface constituted the boiling-surface - had significant spatial variations in the boiling-surface's wall temperatures (in the flow direction with likely unrecorded peaks at the mid-point of the TEC heaters, where no thermocouples were placed). As a result, the raw temperature profiles $T_{w}(x)$ and the "method of heating" curves $\theta_{\mathrm{w}}(\mathrm{x})$ reported in [9] were less than accurate. The question arose as to how to make the results more accurate by a better measurement/characterization of $\mathrm{T}_{\mathrm{w}}(\mathrm{x})$ and $\theta_{\mathrm{w}}(\mathrm{x})$.

- The earlier experiments [7, 9] introduced pulsations in the incoming vapor flows to create vapor acoustics-enabled large amplitude standing waves on the interface of the highly stabilized thin liquid film (300-200 $\mu \mathrm{m}$ thickness range) experiencing flow-boiling in the annular regime. Although the experiments utilized resonant pulsations at the dominant noise frequency detected in the incoming liquid flow 
(see Fig. 1.3), it was not clear whether the best energy efficient approach was being used to introduce pulsations and to create the large amplitude standing waves on the interface, assuming that such interfacial standing waves were the reason for enhanced heat-flux values observed [9] for both thin film flow-boiling as well as thin film flow-condensation. It was decided that a controlled (both in amplitude and frequency) introduction of pulsations in the incoming liquid with or without the earlier controlled (both in amplitude and frequency) introduction of pulsations in the incoming vapor - with option to keep the two pulsations synchronized - needed to be implemented to explore the best energy efficient approaches for creating the large amplitude standing waves on the interface, assuming that that remains the key issue for enhanced operations (as it was for flow-condensation).

\subsection{New Experiments to Address the Questions Raised in Section 2.1}

For the new experiments, the revised plans have been incorporated in Fig. 2.1 below.

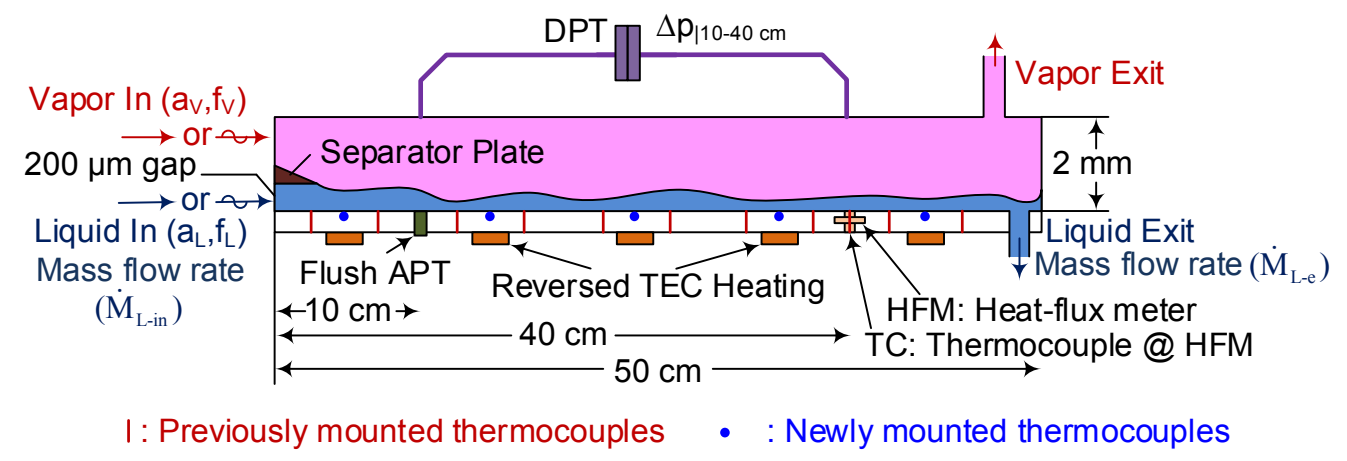

Figure 2.1: A side view schematic of an instrumented test-section which has a $15 \mathrm{~mm}$ width (in direction out of the figure plane). The test-section is for new innovative flow boiling investigations (with FC-72 as the working fluid).

To address the issue of large variations in liquid film thickness over the test-section, as discussed in the first bulleted questions/concerns in section 2.1.2, it was decided to shorten the length of the test-section, from $\mathrm{L}=1 \mathrm{~m}$ to $\mathrm{L}=0.5 \mathrm{~m}$ (as in Fig. 2.1 above). To 
quantitatively and reliably assess the impact on average heat-flux values, and not just the local one at $\mathrm{x}=40 \mathrm{~cm}$ in Fig. 2.1 above, its measurement was included by making arrangements to measure the exiting liquid flow rate (see Fig. 2.1 above) over and above the inlet liquid flow-rate for the test-section.

The second bulleted question/concern in section 2.1.2 raised the issue of assessing the significance of micro-nucleation in annular flow-boiling. As an afterthought, it was realized that in an earlier work [34], local heat-flux values in a heat-fluxed control flowboiling experiment, it was found that experimental values of heat-fluxes were significantly larger (particularly at upstream thicker locations) than those predicted by a onedimensional modeling of flow-boiling that assumed insignificant effects of nucleateboiling on annular thin film flow-boiling. And yet, for many flow realizations involving dry-out over a $1 \mathrm{~m}$ length flow-boiler, it was found that the one-dimensional modeling predictions were in reasonable agreement with measured heat-fluxes near the suppressed nucleation dry-out zones whereas the measured heat-fluxes were significantly higher at thicker upstream locations (where, often, nucleating bubbles became big enough to be visible). It was decided that a more precise set of experimental results, when compared with a more precise set of results obtained from a precise suppressed nucleation modeling and its CFD-based solutions/simulations, can answer the question of significance of micronucleation to heat transfer rates - and that if it is the dominant mechanism, there is no need to expect that micro-convection effects which was observed to be dominant for flowcondensation [9] would also be equally dominant for flow-boiling. Despite the above clarity in hindsight, the existing literature's attempts at decomposing local HTC into nucleate and convective boiling contributions were confusing - and it was not clear whether such results (as reviewed in [13]) applied to this situation (and this is sorted out and discussed in section 4).

The third bulleted question/concern in section 2.1.2 raised the issue of the accuracy of raw temperature profiles $\mathrm{T}_{\mathrm{w}}(\mathrm{x})$ and the "method of heating" curves $\theta_{\mathrm{w}}(\mathrm{x})$, as reported in [9]. It was decided that this is best addressed by doing the difficult hardware modifications needed to add temperature measurements directly on the top of the reversed TECs (these 
new thermocouples are indicated by blue dots underneath the boiling-surface of in Fig. 2.1).

The fourth bulleted question/concern in section 2.1.2 raised the issue of most energy efficient ways of introducing pulsations in the incoming liquid or vapor streams, particularly in the light of the hypothesis that creating large amplitude interfacial waves will remain important for flow-boiling at low (as in the current) and/or high heat-flux (ongoing) flow-boiling experiments. To address this, experimental facility was re-designed by incorporating a liquid line pulsator to allow investigations of enhanced steady-in-themean annular realizations under controlled (both in amplitude and frequency) introduction of pulsations in the incoming liquid with or without the earlier [9] controlled (both in amplitude and frequency) introduction of pulsations in the incoming vapor - with option to keep the two pulsations synchronized. 


\section{Experimental Approach}

This section describes the experimental approach for flow-boiling operations in the innovative operation mode (see Fig. 1.3) - which utilizes vapor re-circulation to maintain steady annular flow regime over the entire boiling-surface of the test-section shown in Fig 3.1 below (width $\mathrm{w}=1.5 \mathrm{~cm}$, height $\mathrm{h}=2 \mathrm{~mm}$, and length $\mathrm{L}=50 \mathrm{~cm}$ ). Moreover, the heat transfer enhancements between a steady case and its associated pulsatile cases (steady-inthe-mean), as achieved by introducing controlled liquid and vapor pulsations in the inlet mass flow rates (see Fig. 3.1), has been studied with the help of a suitably designed set-up. The set-up design is based on modifications of an earlier set-up reported in ([7, 9]). The specific and time consuming modifications from the earlier one - as well as some hardware details - are separately described in Appendix A.

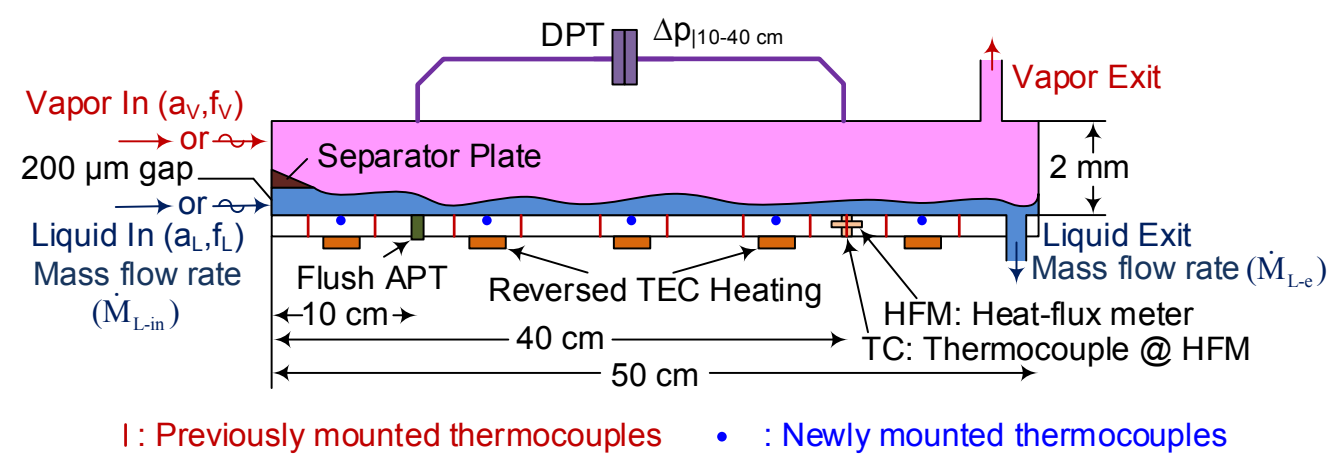

Figure 3.1: A side view schematic of an instrumented test-section which has a $15 \mathrm{~mm}$ width (in direction out of the figure plane). The test-section is for innovative flow-boiling investigations (with FC-72 as the working fluid).

\subsection{Set-up}

The rectangular cross-section horizontal channel test-section in Fig. 3.1 was used. The $2 \mathrm{~mm}$ gap height channel in Fig. 3.1 has sides and the top of that are made of transparent plastic (machined out of transparent polycarbonate plates) covers. With some instrumentation details of the test-section as indicated in Fig. 3.1, the $50 \mathrm{~cm}$ length plastic cover (part of a $1 \mathrm{~m}$ length cover) was mounted on the single horizontal stainless steel plate 
of $50 \mathrm{~cm}$ length (part of a $1 \mathrm{~m}$ length plate), underneath which are 5 thermoelectric modules used as heaters (denoted as TEC, because they are reversed thermoelectric coolers) evenly spaced along the $50 \mathrm{~cm}$ length of the channel. These TECs pump heat into the test-section through the bottom surface of the steel plate (which is $12.7 \mathrm{~mm}$ thick in the vertical direction, $5.08 \mathrm{~cm}$ wide in the horizontal direction, and $1.09 \mathrm{~m}$ long in the flow direction) and 5 individual heat sinks (mounted underneath the TECs) which withdraw heat (occasionally add for PID control) from the water flowing underneath them (see Fig. 3.1). Details of the water flow arrangement are described in [35]. These thermoelectric modules were operated using a computer-controlled variable voltage DC power supply which was PID controlled to maintain set point temperatures on the boiling-surface at specific locations $-\mathrm{x}(\mathrm{cm})$ locations given by $\{\mathrm{x}(\mathrm{cm})\} \equiv\{5,15,25,35,45\}$ - that are directly above the $4 \mathrm{~cm}$ square devices (with flow-direction spread of $4 \mathrm{~cm}$ ) underneath the steel slab maintain desired wall temperature distributions for the boiling flow runs. Thus, it should be noted that for the boiling flow results reported here, the temperature control of the boiling-surface is automated, yielding approximately fixed "methods of heating" as described in section 4 .

For the test-section configuration, a differential pressure transducers, DPT (measuring $\left.\Delta \mathrm{p}_{\mid 10-40}\right)$ shown in Fig. 3.1, were used to record the differential vapor pressure between the $10 \mathrm{~cm}$ and $40 \mathrm{~cm}$ locations along the length of the channel. Besides other absolute pressure transducers (including one at the inlet at $\mathrm{x}=0$ ), a sensitive flush-type absolute pressure transducer at $\mathrm{x}=10 \mathrm{~cm}$ location was used to measure pressure $\mathrm{p}_{10}$. Mounted within the plate shown in Fig. 3.1, a flush heat-flux meter (HFM-40) of the thin-film thermopile type (as part of a removable probe supplied by Vatell Corp.) was first used to measure the timevarying heat-flux and surface temperature over a 5 - $6 \mathrm{~mm}$ diameter surface whose center was $40 \mathrm{~cm}$ downstream from the test-section inlet ( $\mathrm{x}=0$ in Fig. 3.1) and was centered across the channel width. When this dynamic data capable $(2000 \mathrm{~Hz})$ heat-flux meter (HFM-40) broke down, for the remaining data, it was replaced by Vatell's steady heat-flux measuring (low DAQ of $1 \mathrm{~Hz}$ ) new device. Thermocouples mounted in the plate recorded the temperature of the working fluid (FC-72) along the center line of the test-section at 
distances $\mathrm{x}$ given by $\{\mathrm{x}(\mathrm{cm})\} \equiv\{0,5,8.5,11.5,15,18.5,21.5,25,28.5,31.5,35,38.5$, $41.5,45,48.5\}$ locations in Fig. 3.1. The thermocouples measure within $1 \mathrm{~mm}$ radius and their tips are axially located within $\pm 0.5 \mathrm{~mm}$ of the boiling-surface.

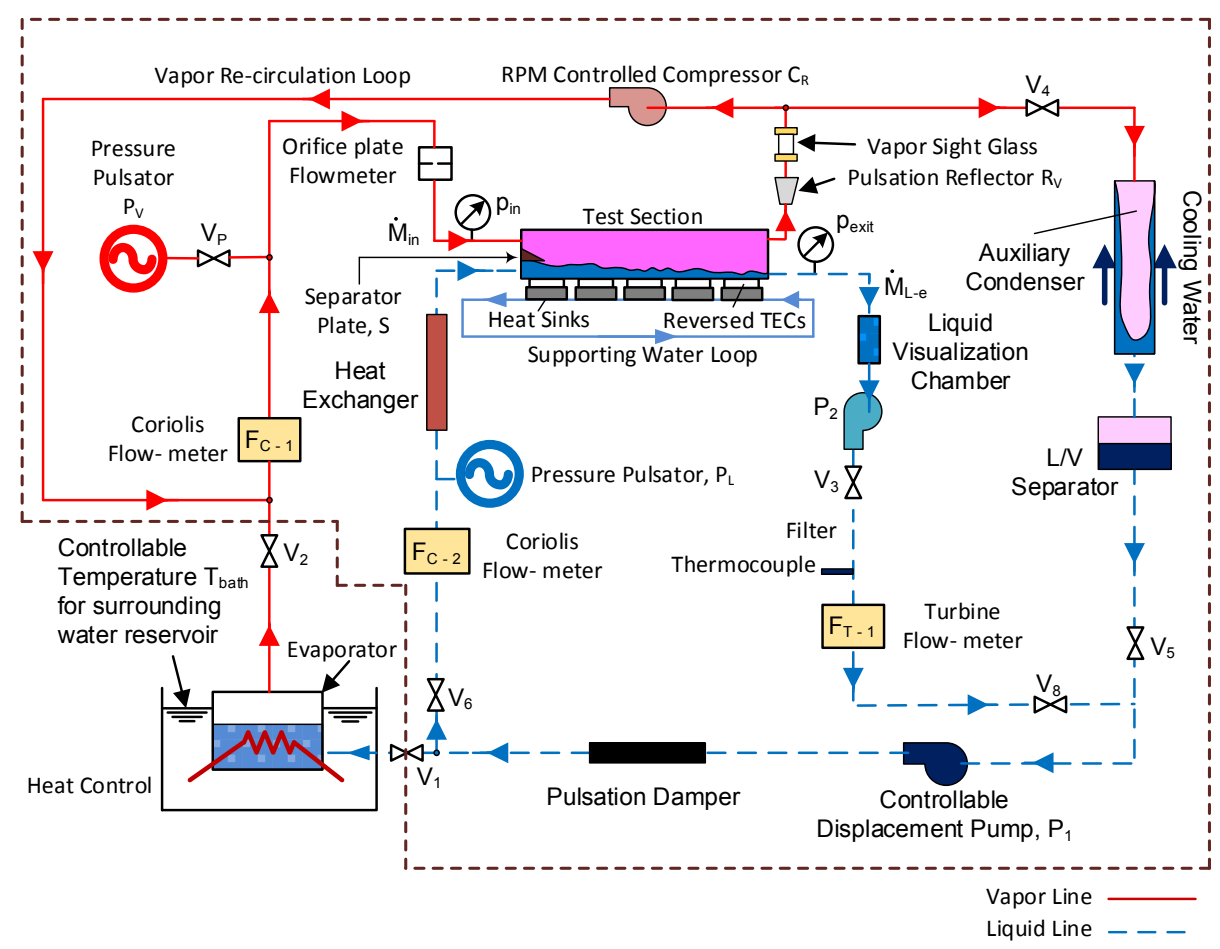

Figure 3.2: A schematic of the experimental flow-loop.

The test-section in Fig. 3.1 is mounted within the flow loop shown in Fig. 3.2. The flow loop provides for the re-circulating vapor flow as well as the incoming liquid flow that would experience flow-boiling. Computer-controlled variable-speed peristaltic pumps $\mathrm{P}_{1}$ and $\mathrm{P}_{2}$ are used to pump the liquid. The recirculation loop is driven by a semi-hermetically sealed, rotary-vane type compressor $\mathrm{C}_{\mathrm{R}}$, which is driven by a variable-speed external DC motor using magnetic coupling through the wall of the heated (thermostat controlled) compressor housing. The speed of the motor, which may be manually or computer controlled, is used to adjust the recirculating vapor flow supplied by the compressor. The heat sinks underneath the TECs in Fig. 3.1 are connected to a water loop of thermostatically or PID controlled temperatures. The flow rate of this water loop (described in [7]) was 
manually controlled through the use of bypass and throttling valves. A liquid pressure pulsator $\mathrm{P}_{\mathrm{L}}$, whose frequency can be manually adjusted by a motor speed knob was use to introduced liquid flow rate pulsations. Although pulsation energy could also be controlled for this device, that control could not be used above a certain amplitude level (therefore, a fixed amplitude was used for experiments involving/needing liquid flow rate pulsations). A vapor pressure pulsator $\mathrm{P}_{\mathrm{V}}$, consisting of a variable speed DC powered diaphragm compressor (with the valves removed between its suction and discharge chambers), was used to introduce pulsations to the vapor supplied to the test-section. The speed of this pulsator was manually set through its motor controller to set the frequency of the imposed vapor pulsations, and the throttling valve $V_{P}$ was manually adjusted to control the amplitude of the imposed vapor pulsations. In the vapor line exiting the test-section, a pulsation reflector $\mathrm{R}_{\mathrm{V}}$ (consisting of a diffuser impinging on a flat plate with a circular pattern of small holes) was used to assist in reflecting acoustic energy - associated with vapor pressure/flow rate pulsations - back into the test-section.

The pool-boiler (or evaporator in Fig. 3.2) was needed to start the flow-loop and arrange for the steady or steady-in-the-mean flow realizations indicated in Fig. 3.1. The temperature of the water reservoir surrounding the pool-boiler (or evaporator in Fig. 3.2) needed to be fixed to achieve saturation pressures in that reservoir which also helps in guiding the system pressure to desired levels. The internal ring-type heater of the poolboiler was computer controlled through pulse-width modulation (PWM). During start-up or transient operations, the pool-boiler was used to evaporate the liquid in it or feed the liquid in it through valve $V_{1}$. It was also used to assist in fluid inventory control of the loop. A vertical counter-flow heat exchanger (of stainless steel welded construction, labeled Auxiliary Condenser in Fig. 3.2, with refrigerant flowing downward through a 6.8 $\mathrm{mm}$ I.D. tube in the center and cooling water flowing upward in the annulus) was used to condense the working fluid boiled in the test-section. The cooling water used by the auxiliary condenser was part of a closed loop with the shell side of a shell-and-tube type heat exchanger (stainless steel), a centrifugal pump, and an elevated water tank. The water 
flow through the tube side of the heat exchanger was provided from a separate chilled water loop [7].

All data was logged and recorded using National Instruments hardware and a desktop computer as described in $[35,36]$. The computerized flow-loop controls and management of data during experiments were mostly implemented through LabVIEW 2014 SP1 (32 bit) but some were implemented/recorded separately (manually or through standalone devices such as compressor housing heaters controlled by thermostats). Additional details of the experimental system, instrumentation, and instrumentation accuracies and resulting uncertainties in measured or calculated data reported here are described in section 4 .

\subsection{Preparations for Starting the Flow-loop}

First of all, before any experiment can be investigated, a leak test needs to be done (typically done with compressed air at $180 \mathrm{kPa}$ ). Since this is a research set-up with many kinds of instruments inserted in the flow-loop, maintaining the system at $100 \%$ leak free is close to impossible. Nevertheless, for reliable results and repeatability, keeping the leak rate at an acceptable minimum is essential. Typically, the overall leak rate (with all of the lines in the experimental set-up connecting all its sub-parts with all the valves open) is maintained at a rate that is lower than $0.1 \mathrm{kPa} / \mathrm{hr}$. For reference, when the system is isolated in sections by closing appropriate valves, the leak rate for each section will be different and will depend on its volume and number of surface fittings in it. Most of the sub-sections leak rates were kept lower than $0.2 \mathrm{kPa} / \mathrm{hr}$. At the test-section area, however, the volume being very small volume and it having many measuring instruments' fittings exposed to the outside atmosphere, the leak rates were greatest compared to the rest of the system. The leak rate at the test-section itself is normally kept at or below $0.4-1 \mathrm{kPa} / \mathrm{hr}$. In addition, there are some sub-sections such as: the pool-boiler, the compressor housing, and the auxiliary condenser that are quite robust and almost leak-free (see Fig 3.2). With such subsection leak rates ensured, the system leak rate was lower than $0.1 \mathrm{kPa} / \mathrm{hr}$. 
To be able to run an experiment, there are some additional preparations that, preferably, need to be done a day earlier - before the run. This is to reduce the work load on the run day. These are listed next. (i) Charging the batteries of the heat-flux amplifier and camera (ii) Water level of the Koolant chiller reservoir need to be checked and filled with distilled water, if necessary. (iii) The water reservoir in the auxiliary condenser cooling loop needs to be checked and filled, if necessary. (iv) The sump-pump water bucket, used in the bathtemperature control flow-loop for the pool-boiler, needs to be filled. (v) The system in Fig. 3.2 needs to be filled with the right amount of liquid FC-72 such that it has enough FC-72 liquid inventory during experimental runs lasting about 24 hours, and then some more needs to be added to account for additional losses that will occur during vacuum and pressure purge processes for the loop. Even though, during the run, a suitable amount of the liquid can be added or removed from the system - this is to be avoided because, potentially, this may cause non-condensable air to get into the system necessitating some pressure purges soon afterward. Therefore, filling FC-72 liquid into the system - from underneath (say through valve $V_{1}$ in Fig. 3.2) - by the right amount could be challenging since, during vacuum purge, some amount of FC-72 will be lost from the system. From past experience, a good practice was adding an extra $200 \mathrm{ml}$ into the pool-boiler - after the liquid FC-72 has reached the level corresponding to the upper float switch located within the pool-boiler, and then after isolating the pool-boiler, more FC-72 liquid is added until liquid level reached the bottom of the vertical auxiliary condenser shown in Fig. 3.2 followed by an additional extra $200 \mathrm{~mL}$ amount of FC-72 added to the condenser. In

addition, 5-10 mL of liquid FC-72 needed to be squirted - with a syringe - into the compressor housing, this is mainly to allow FC-72 vapor to push other gases (air) out of the housing because FC-72 is heavier.

\subsection{Procedures}

It is important to note that, even when no vapor or liquid pulsations are imposed to achieve steady annular realizations in Fig. 3.1, there are some turbulence and compressor vane induced pressure fluctuations in the vapor, vibrations of the boiling-surface (from various 
equipment in the flow loop and other sources), and liquid flow surges arising from the rollers of the peristaltic pumps. Nevertheless, these issues and associated pressure fluctuations (whose signatures are present in dynamic measurements) did not significantly shift (until, as discussed later, when vapor or liquid flow pulsations were deliberately imposed) the time-averaged dynamic heat-flux mean values at $40 \mathrm{~cm}$.

For steady-in-the-mean pulsatile realizations, once the flow in the test-section has been established, liquid or vapor flow pulsations are imposed at various amplitude levels and frequencies to investigate their effects on heat-flux at the $40 \mathrm{~cm}$ location, on the average heat-flux, and on the liquid-vapor interface morphology - a qualitative visual one - within the test-section. It has been experimentally verified that when vapor and liquid pulsations were removed, one approximately recovered the results from no imposed fluctuation cases.

An actual test set-up of the schematic in Fig. 3.2 above is also show below in Fig. 3.3.

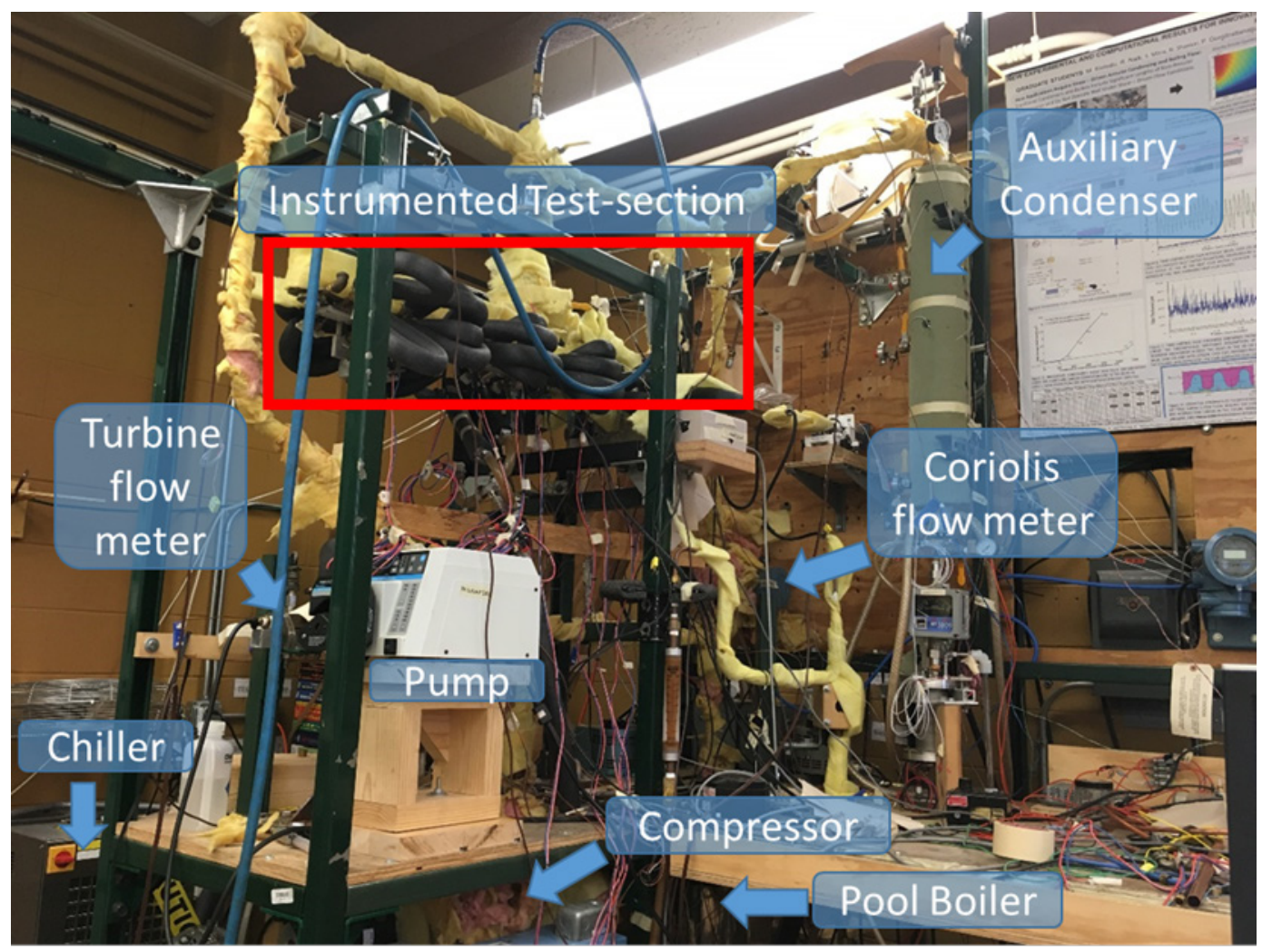

Figure 3.3: A photograph of the experimental test set-up. 


\subsubsection{Start-up of the experiment}

- All experimental runs start with a vacuum purge process. The vacuum purge process starts by opening all of the valves in Figure 3.2 - except valve $V_{1}$ (which is shut to stop communication between the filled up pool-boiler and liquid up to the Auxiliary Condenser) and the valve which connects the vacuum pump to the system at $\mathrm{V}_{4}$ (this is a through a 3-way valve arrangement for $\mathrm{V}_{4}$, not shown in Fig. 3.2). Next the vacuum pump is turned on. The exhaust end of the vacuum pump is connected to a glass bottle surrounded by ice, this is to collect FC-72 vapor from the air-plus-vapor exhaust of the vacuum pump. The process lasts about 3 hours to assure that all of the non-condensable are evacuated out. After that, the system is isolated from the vacuum pump. The system is under very low vacuum pressures for about 2-3 hours. This purges it of non-condensable gases/air until only a sufficiently low and repeatable concentration amount remains within the predominantly liquid and vapor FC-72 within the system. After the vacuum purge is completed, the system is separated/closed-off from the line containing the vacuum pump.

- The electric heater in the water reservoir surrounding the pool-boiler (not shown) is activated. Its independent PID temperature controller (implemented in earlier experimental investigations) is set to a temperature corresponding to the saturation pressure of FC-72 desired within the poolboiler.

After the vacuum purge, and before warming up the pool-boiler, the valve $\mathrm{V}_{2}$ is shut to isolate the pool-boiler from the rest of the system. The poolboiler has its own PID control. For the bath surrounding the pool-boiler, there is a circulating pump for pumping water out from the bottom of the stainless-steel case and putting it back, at a fixed temperature, on the top of the bath - this is mainly for keeping the bath temperature uniform (this nearly stagnant large uniform temperature water bath keeps the FC-72 
vessel inside the pool-boiler at the same temperature, which becomes the pool-boiler's saturation temperature). The PID control for bath temperature has two sources: one for high temperature and another for low temperature. The high temperature source is from a heater in the water bath flow-loop which will activate when the water bath temperature is lower than a set point. The cool temperature source is from another loop cooled by a radiator and fans - which will operate when the bath temperature is higher than the set point. This process of warming up the FC-72 liquid up to a desire set point temperature may take up to 45-60 minutes. The saturation temperature set here at the pool-boiler should be such that the corresponding saturation pressure is about $15 \mathrm{kPa}$ or so higher than the test-section inlet pressure. This is because of the pressure drop, at a representative vapor flow rate, that occurs across the Coriolis flow meter.

- After the above described pool-boiler warming up process, FC-72 vapor is let out of the system through valve $\mathrm{V}_{2}$, and this begins warming up of the rest of the system. Rope heaters wrapped around vapor lines (tubes) are turned on to keep saturated vapor coming out of the pool-boiler at about 510 degrees superheat.

- At the test-section, heating elements using reversed thermoelectric coolers (TECs) are turned on for a PID surface temperature control of temperatures directly above the five TECs. This "method of heating" at low heat-fluxes $\left(0.1-1 \mathrm{~W} / \mathrm{cm}^{2}\right)$ avoids inadvertent overheating of boiling-surface and keeps dry-outs stable (unlike the dry-out instabilities expected at critical heat-fluxes at heat-flux controlled methods of heating).

- The internal electric heater within the pool-boiler is next set at a heating level consistent with the mass flow rate desired at the inlet of the testsection.

- The vapor flowing the test-section goes to the auxiliary condenser, the liquid from there will be pumped back into the pool-boiler. As soon as liquid 
is seen flowing from the auxiliary condenser to the $\mathrm{L} / \mathrm{V}$ separator, valve $\mathrm{V}_{1}$ is opened, and pump $\mathrm{P}_{1}$ is started at a mass flow rate consistent with the vapor mass flow rate from Coriolis flow meter $\mathrm{F}_{\mathrm{C}-1}$.

- Once the flow has stabilized, as indicated by steady or steady-in-the mean flow rate through Coriolis flow meter $\mathrm{F}_{\mathrm{C}-1}$ and steady or steady-in-the mean pressure $p_{\text {in }}$ at the test-section inlet, valve $\mathrm{V}_{6}$ is partially opened, and the flow rate through pump $\mathrm{P}_{1}$ is increased to the sum of the boiling rate in the pool-boiler and the desired liquid mass flow rate into the test-section. Valves $V_{1}$ and $V_{6}$ are adjusted to achieve the desired mass flow splitting between the pool-boiler and test-section inlet.

- Once the test-section pressures and flow rates have again stabilized at the desired levels, compressor $C_{R}$ is started at the desired speed.

- Once the vapor sight glass is clear and the vapor flow through Coriolis meter $\mathrm{F}_{\mathrm{C}-1}$ has again stabilized, the internal heater of the pool-boiler is turned off, valve $V_{2}$ is closed, valve $V_{6}$ is fully opened, and the flow through pump $P_{1}$ is reduced to the desired liquid inlet mass flow rate for the test-section.

- The compressor speed is then increased until the desired re-circulating flow rate is again achieved through flow meter $\mathrm{F}_{\mathrm{C}-1}$.

- When liquid starts building up at the test-section exit, pump $\mathrm{P}_{2}$ is started and adjusted to the rate required to maintain the desired liquid level at the exit of the test-section, as verified visually through the clear test-section channel and liquid visualization chamber of Fig. 3.2. Measurement of hydro-static pressure at the bottom of the liquid visualization chamber may be used to implement computer-based feedback control of pump $\mathrm{P}_{2}$ to maintain the desired liquid level.

- After the flow has been running for a while, some trapped air - mainly in the compressor housing and in the liquid line below the test-section - may 
appear. This trapped air will typically flow to the top of the auxiliary condenser, where additional new pressure purging is done to remove the air.

- When the flow-loop pressures, liquid and vapor flow rates into and out of the test-section, and test-section pressures have become steady or steadyin-the-mean at their desired rates, the pressure pulsators $\mathrm{P}_{\mathrm{V}}$ and $\mathrm{P}_{\mathrm{L}}$ may be started and adjusted to their desired frequency.

\subsubsection{Non-pulsatile Steady Annular Flow-boiling}

- After the above start-up process is completed, the test-section in the system will be experiencing a steady annular flow realization with one inlet pressure provided the recirculating vapor flow rate is within a certain range for a given inlet liquid flow rate. Note that the effective operating subsystem is now, for this operation, the one within the dashed brown enclosure in Fig 3.2 (or, in other words, the sub-system of interest excludes the poolboiler). There are variables for this sub-system's operation that can be varied. These are sub-system's pressure at the inlet of the test-section, inlet liquid mass flow rate, inlet vapor flow rate, and the "level" as well as "method of heating" (as described in section 4). The inlet pressure can be changed with the help of the pool-boiler - whose PID control during start up (along with other controls such as the ones for the liquid and vapor inlet flow rates) determine the test-section's eventual total mass flow rate as well as the inlet pressure.

\subsubsection{Steady-in-the-mean Pulsatile flows Resulting from Imposed Pulsations}

- The new experimental test set-up has ability to impose pulsations into the liquid and vapor flows entering the test-section in Fig. 3.1. This is accomplished by the liquid pulsator $\mathrm{P}_{\mathrm{L}}$ and the vapor pulsator $\mathrm{P}_{\mathrm{V}}$ shown in Fig. 3.2. Pulsations from each of these pulsators have two aspects that can be controlled - these are their amplitudes and frequencies (it suffices here to think of the dominant frequency and the associated amplitude in the 
dynamic pressure signals of the two incoming single-phase - liquid and vapor - streams). The amplitude of vapor pulsations can be changed by manually adjusting the ball valve $V_{P}$ in Fig. 3.2 (this is between the vapor pulsator line and the main vapor line) and the vapor pulsator frequency can be computer controlled by adjusting the motor speed of the pulsator. For the liquid pulsations both amplitude and frequency have to be controlled manually (knob turning).

- Pulsatile cases are realized here after the test-section has reached a specific steady state of interest. To be able to assess the effects of pulsations on flowboiling, different combinations of amplitudes and frequencies have been investigated. First, a desired and approximately equal frequencies for each of the two pulsators are selected. Frequency of the liquid pulsator has to be set before vapor pulsator - this is done by manually adjusting the pulsator's motor speed knob and then looking at the dominant pressure pulsation frequency by acquiring a dynamic liquid line pressure signal with high data acquisition rate $(2,000 \mathrm{~Hz})$, preliminary verification is done by just counting the number of peaks in one second. This process is repeated until the desired frequency for the liquid pulsator is achieved. Then the frequency of the vapor pulsator is set, by an approach similar to the one associated with the liquid pulsations. After the frequencies of both pulsators were set, amplitude of the liquid pulsator was set to a minimum allowable value - this is because of certain limitations (high amplitudes cause cavitation in the liquid line and structural vibrations) that were observed. Starting from a specific steady case, first "liquid only" pulsations" effects are assessed for a given frequency and minimum amplitude setting for the liquid pulsator. After steady-in-the-mean realization is achieved, the associated data for the case are recorded. The second pulsatile realization is typically obtained for the same frequency but by employing "vapor only" pulsations using vapor pulsator at its maximum amplitude setting. The third case involves, "liquid 
and vapor" pulsations at the same dominant frequency - with the liquid pulsator at its fixed allowable amplitude setting and vapor pulsator at a small amplitude (small opening of valve $V_{P}$ in Fig. 3.2). Subsequent "liquid and vapor" pulsatile cases were realized by gradually increasing the vapor pulsator amplitude (until valve $V_{P}$ in Fig. 3.2 reached its fully open configuration). After this, different sets of equal frequencies for the liquid and vapor pulsators were investigated. Note that, each experimental steadyin-the-mean realization was recorded for about 30-40 minutes and during each such duration -5 seconds of dynamic data were collected at $2000 \mathrm{~Hz}$, about 3-5 times per steady-in-the-mean realization. 


\section{Experimental Results and Discussions for Steady and Enhanced Annular Flow-boiling}

As discussed in section 3, the experimental hardware and approach were modified to obtain experimental results for the following purposes. (i) Data for steady annular flow-boiling towards development of more accurate approaches (relative to existing knowledge and approaches) for developing HTC and pressure-drop correlations that are specific to annular flow-regimes and a well-defined parameter-range. This needs to be done in a way that one is able to make use of (or take into account) existing data that are larger in scope (inclusive of non-annular regimes and larger parameter space) and are available in the literature (see [13]. (ii) Data for steady-in-the-mean enhanced annular flow-boiling in a way that one can learn from enhancement results obtained from different approaches that introduce inlet mass flow-rate pulsations in the arrangement shown in Fig. 4.1 - specifically, pulsations in the liquid, vapor, or both the phases.

The heating is over length " $\mathrm{L}=50 \mathrm{~cm}$ " in Fig 4.1. The heating "levels" are characterized by the average temperature difference $\Delta \mathrm{T} \equiv\left|\bar{T}_{\mathrm{w}}-\mathrm{T}_{\mathrm{sat}}\left(\mathrm{p}_{0}\right)\right|$ between the saturation temperature $\mathrm{T}_{\text {sat }}\left(\mathrm{p}_{0}\right)$ and the axially averaged mean wall temperature $\overline{\mathrm{T}}_{\mathrm{w}}$ (alternatively, for heat-flux controlled "method of heating, "the axially averaged mean wall heat-flux, $\overline{\mathrm{q}_{\mathrm{w}}^{\prime \prime}} \equiv \frac{1}{\mathrm{~L}} \int_{0}^{\mathrm{L}} \mathrm{q}_{\mathrm{w}}^{\prime \prime}(\mathrm{x}) \cdot \mathrm{dx}$, could be used to define the level of heating). Furthermore, a specific non-uniform "method of heating" is defined as a specific function $\theta_{\mathrm{w}}(\mathrm{x})$ - or, equivalently, a specific function $\Psi_{\mathrm{q}}(\mathrm{x})$ for heat-flux controlled method of heating - through the relations:

$$
\Delta \mathrm{T}(\mathrm{x}) \equiv\left|\mathrm{T}_{\mathrm{w}}(\mathrm{x})-\mathrm{T}_{\mathrm{sat}}\left(\mathrm{p}_{0}\right)\right| \equiv \Delta \mathrm{T} \cdot \theta_{\mathrm{w}}(\mathrm{x})
$$

and

$$
\mathrm{q}_{\mathrm{w}}^{\prime \prime}(\mathrm{x})=\overline{\mathrm{q}}_{\mathrm{w}}^{\prime \prime} \cdot \Psi_{\mathrm{q}}(\mathrm{x})
$$


The local HTC $h_{x}$ is defined as

$$
\mathrm{q}_{\mathrm{w}}^{\prime \prime}(\mathrm{x})=\mathrm{h}_{\mathrm{x}} \cdot \Delta \mathrm{T}(\mathrm{x})
$$

For non-uniform temperature-controlled heating used here, approximate and specific $\theta_{\mathrm{w}}(\mathrm{x}) \neq 1$ over $0<0<\mathrm{x}<\mathrm{L}$ are defined and used here for correlating the reported data.

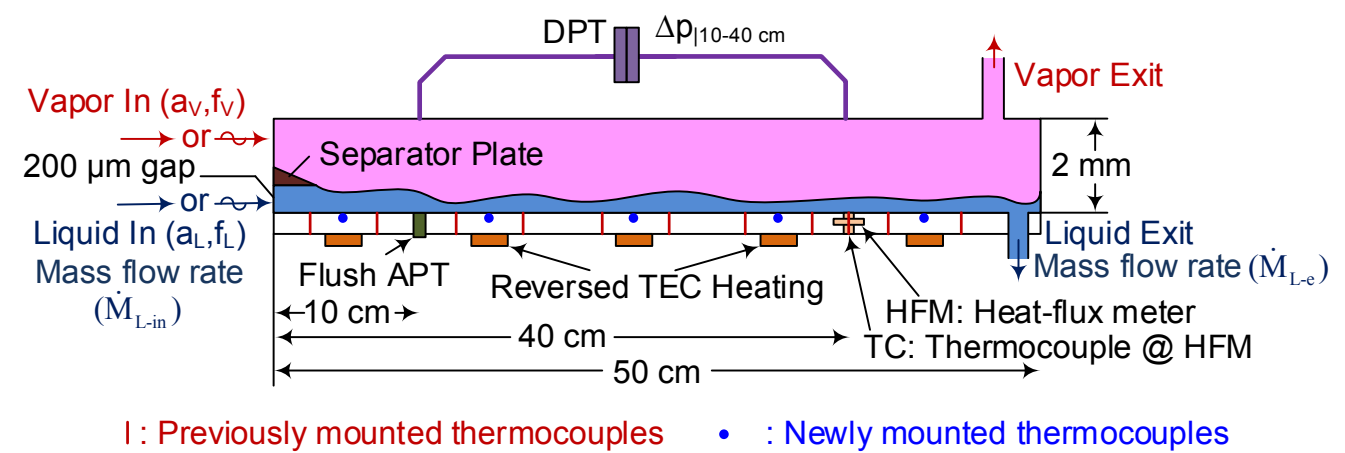

Figure 4.1: A side view schematic of an instrumented test-section which has a $15 \mathrm{~mm}$ width (in direction out of the figure plane). The test-section is for innovative flow boiling investigations (with FC-72 as the working fluid).

The basic features of data collected and reported in this section are described next.

\section{Data Processing and Errors}

The experimental runs are characterized by case numbers in Tables $4.1-4.6$. Each steady or steady-in-the-mean case represents a unique set of experimental conditions which were held steady for a period of 30 - 45 minutes. The entire duration (or a significant subset) for each run case were selected for averaging of the relevant flow variables acquired at the low DAQ rate $(\sim 1.0 \mathrm{~Hz})$. Due to programming limitations, during 5 second gaps in the time history of the low DAQ acquisition of flow variable data, the dynamic data was acquired at $2000 \mathrm{~Hz}$ for some key and feasible measurements of: differential pressure transducer data for $\Delta \mathrm{p}_{\mid 10-40}$, some of the absolute pressure transducers (specifically $\mathrm{p}_{10}$ ), and dynamic heat-flux sensor data (before the sensor broke down and was replaced by a heat-flux sensor that could only provide low DAQ steady measurements). For the reported dynamic data, 
the Fast Fourier Transform (FFT) results were obtained by looking at a sample record length (of $5 \mathrm{~s}$ durations each) and truncating it for periodicity (to avoid leakage). It was found that considerations of the average dynamic signal, by considering several $5 \mathrm{~s}$ duration record lengths and averaging of their records, were not necessary for identifying the reported amplitudes and frequencies (e.g. $a_{p 40}$ for the $\mathrm{p}_{40}$ data reported in Table 4.6 of this section).

Also, the uncertainties reported in the column headers of Tables 4.1-4.2 (and analogous ones in Tables 4.3-4.6) for time-averaged values of the flow variables only apply to their mean values; instantaneous values of data taken at the low DAQ rate may have uncertainty outside of that range. Uncertainties are reported as absolute (a number without a \% symbol), relative (a number followed by a \% symbol), or mixed (both a plain numerical value and a percentage - or its reporting in an equivalent $\%$ relative error form). Absolute uncertainties have the same units as the variable to which they are applied, and relative uncertainty values are applied as a percentage of the reported data values. To determine the uncertainty associated with any measurement with a mixed uncertainty (e.g. $\mathrm{p}_{0}$ with an absolute uncertainty of $\pm 0.5 \mathrm{kPa}$ and in house calibration uncertainty of $2 \%$ ), multiply the percent uncertainty (after division by 100) to the reported data value of interest; then add to it the absolute uncertainty, and that data value is reported to \pm this sum. Here an equivalent approach is taken for $p_{0}$, where the maximum \% uncertainty associated with \pm $0.5 \mathrm{kPa}$ is added to the calibration uncertainty of $2 \%$. The raw variables in Tables 4.1-4.6 are those variables for which no Gaussian errors are reported. The raw variables' errors reported in Tables 4.1-4.6 are made up of instrumentation and calibration errors. For some variables, associated instruments' (such as Coriolis meters) vendors provide the combined instrumentation and calibration errors. For many other raw variables (such as measurements obtained from: thermocouples, turbine flow meter, absolute and differential pressure transducers, etc.), only the instrument error was specified by the vendors - the calibration errors were obtained from in-house calibration procedures and then added to the instrumentation error. For all other calculated variables reported in Tables 4.1 - 4.6, the maximum relative error and Gaussian error estimates were obtained by standard formula- 
based error propagation schemes (see [37]). The confidence interval on maximum relative error uncertainty values in Tables $4.1-4.6$ is above $95 \%$ whereas, for Gaussian estimates, it is likely between $80-90 \%$. The reported estimates include effects of working temperature on the sensors, property table errors, etc.

\subsection{Steady Results and Discussions}

\subsubsection{Steady Results}

The completed steady annular investigations are for modeling/simulation use of experimental data that is described here - with implementation details (work of the modeling/simulations team) as given in section 5. The data have been acquired from experimental runs (with FC-72 as a working fluid) dealing with innovative flow-boiler operations [9] within the rectangular cross-section test-section of Fig 4.1 (width $\mathrm{w}=1.5$ $\mathrm{cm}$, height $\mathrm{h}=2 \mathrm{~mm}$, and length $\mathrm{L}=50 \mathrm{~cm}$ ). The experimental procedures used has been described in section 3. The test-section inlet, in Fig 4.1, is at $\mathrm{x}=0$ and its exit is at $\mathrm{x}=50$ $\mathrm{cm}$ where $\mathrm{x}$ denotes downstream distance location from the inlet. The bulk mean vapor temperature in Fig. 4.1 is slightly superheated, but the superheat can be neglected and the vapor can be assumed to be at close to saturation temperature $\mathrm{T}_{\text {sat }}\left(\mathrm{p}_{0}\right)$ for FC-72 vapor, where $\mathrm{p}_{0}$ is the inlet pressure. Instrumentations described in section 3 are used to measure the following variables: inlet pressure $\mathrm{p}_{0}$, mean differential pressure $\Delta \mathrm{p}_{\mid 10-40}\left(\equiv \mathrm{p}_{10}-\mathrm{p}_{40}\right)$ between the $\mathrm{x}=10 \mathrm{~cm}$ and $40 \mathrm{~cm}$ locations of the test-section, inlet liquid flow rate $\dot{\mathrm{M}}_{\mathrm{L} \text {-in, }}$, inlet vapor flow rate $\dot{\mathrm{M}}_{\mathrm{V} \text {-in }}$, mean wall temperature $\overline{\mathrm{T}}_{\mathrm{w}} \equiv \frac{1}{\mathrm{~L}} \int_{0}^{\mathrm{L}} \mathrm{T}_{\mathrm{w}}(\mathrm{x}) \cdot \mathrm{dx}$ where $\mathrm{T}_{\mathrm{w}}(\mathrm{x})$ represents steady wall temperature variations with distance $\mathrm{x}$ (which have been measured at $\{\mathrm{x}(\mathrm{cm})\} \equiv\{0,5,8.5,11.5,15,18.5,21.5,25,28.5,31.5,35,38.5,41.5,45,48.5\}$ locations). While the inlet pressure $\mathrm{p}_{0}$ has been measured by an absolute pressure transducer at close to $\mathrm{x}=0$ location in Fig. 4.1, the values reported here are from the more accurate and stable measurements at $\mathrm{x}=10 \mathrm{~cm}$ location. This is because $\mathrm{p}_{0} \cong \mathrm{p}_{10}$ is a good approximation and the location has less flow noise and a higher quality transducer. 
The above described variables' measured values are reported, for sample steady annular runs, in Table 4.1. All runs in this table report data for an approximately fixed "method of heating" $\theta_{w}(x)$, which is defined in Fig 4.2 for $0<x^{\#} \leq x \leq x_{e}<L$. The $T_{w}(x)$ values for different runs in Table 4.1 are given in Table B.1 of Appendix B and the extended $\mathrm{T}_{\mathrm{w}}(\mathrm{x})$ and $\theta_{\mathrm{w}}(\mathrm{x})$ curves are defined, over $0<\mathrm{x} \leq \mathrm{L}$, in Appendix B's Figs. B.1 - B.2.

Table 4.1: Experimental run results of a set of steady run cases whose "method of heating" is defined by the function in Fig. 4.2.

\begin{tabular}{|c|c|c|c|c|c|c|c|c|c|c|c|c|c|c|c|}
\hline Case & po & $\Delta \mathrm{p}_{\mid} 10-40 \mathrm{~cm}$ & $\dot{\mathrm{M}}_{\mathrm{L}-\mathrm{in}}$ & $\dot{\mathrm{M}}_{\mathrm{V}-\text { in }}$ & $\dot{\mathrm{M}}_{\mathrm{L}-\text { out }}$ & $\dot{\mathrm{M}}_{\mathrm{V}-\text { out }}$ & $\mathrm{T}_{\mathrm{sat}}\left(\mathrm{p}_{\mathrm{o}}\right)$ & $\overline{\mathrm{T}}_{\mathrm{W}}$ & $\Delta \mathrm{T}$ & $\dot{\mathrm{M}}_{\text {total }}$ & G & $\mathrm{X}_{\mathrm{in}}$ & $\mathrm{X}_{\text {out }}$ & $q_{x \mid x}=40 \mathrm{~cm}$ & $\overline{\mathrm{q}_{\mathrm{W}}^{\prime \prime}}$ \\
\hline Max relative error & $\pm 2.48 \%$ & $\pm 4 \%$ & $\pm 0.1 \%$ & $\pm 0.35 \%$ & $\pm 3 \%$ & $\pm 3.45 \%$ & $\pm 5.18 \%$ & $\pm 1.66 \%$ & $\pm 6.84 \%$ & $\pm 0.45 \%$ & $\pm 6.45 \%$ & $\pm 0.8 \%$ & $\pm 3.9 \%$ & \begin{tabular}{|c|} 
$\pm 3 \%$ \\
\end{tabular} & $\pm 4.2 \%$ \\
\hline Gaussian error & - & - & - & \begin{tabular}{|l|}
- \\
\end{tabular} & - & $\pm 3.02 \%$ & - & - & $\pm 5.43 \%$ & $\pm 0.36 \%$ & $\pm 6.02 \%$ & $\pm 0.57 \%$ & $\pm 3.48 \%$ & - & $\pm 3.17 \%$ \\
\hline Unit & {$[\mathrm{kPa}]$} & {$[\mathrm{Pa}]$} & {$[\mathrm{g} / \mathrm{s}]$} & {$[\mathrm{g} / \mathrm{s}]$} & {$[\mathrm{g} / \mathrm{s}]$} & {$[\mathrm{g} / \mathrm{s}]$} & {$\left[{ }^{\circ} \mathrm{C}\right]$} & {$\left[{ }^{\circ} \mathrm{C}\right]$} & {$\left[{ }^{\circ} \mathrm{C}\right]$} & {$[\mathrm{g} / \mathrm{s}]$} & {$\left[\mathrm{kg} / \mathrm{s} / \mathrm{m}^{2}\right]$} & - & - & {$\left[\mathrm{W} / \mathrm{cm}^{2}\right]$} & {$\left[\mathrm{W} / \mathrm{cm}^{2}\right]$} \\
\hline 1 & 110.04 & 47.56 & 0.245 & 0.390 & 0.052 & 0.583 & 59.40 & 60.90 & 1.50 & 0.635 & \begin{tabular}{|l|}
21.175 \\
\end{tabular} & 0.614 & 0.918 & 0.136 & 0.216 \\
\hline 2 & 109.94 & 53.58 & 0.266 & 0.389 & 0.098 & 0.556 & 59.38 & 60.94 & 1.56 & 0.655 & 21.826 & 0.594 & 0.850 & 0.124 & 0.187 \\
\hline 3 & 109.97 & 71.73 & 0.291 & 0.388 & 0.103 & 0.577 & 59.38 & 60.88 & 1.49 & 0.680 & 22.659 & 0.571 & 0.849 & 0.175 & 0.211 \\
\hline 4 & 109.70 & 80.94 & 0.326 & 0.387 & 0.132 & 0.580 & 59.31 & 60.86 & 1.55 & 0.712 & 23.747 & 0.543 & 0.814 & 0.195 & 0.216 \\
\hline 5 & 110.03 & 91.52 & 0.327 & 0.427 & 0.138 & 0.616 & 59.40 & 60.94 & 1.54 & 0.754 & 25.123 & 0.566 & 0.817 & 0.172 & 0.211 \\
\hline 6 & 109.37 & 96.03 & 0.328 & 0.445 & 0.108 & 0.665 & 59.22 & 60.84 & 1.62 & 0.773 & 25.760 & 0.576 & 0.861 & 0.186 & 0.246 \\
\hline 7 & 108.71 & 129.16 & 0.578 & 0.439 & 0.403 & 0.613 & 59.04 & 60.74 & 1.70 & 1.017 & 33.884 & 0.432 & 0.603 & 0.121 & 0.195 \\
\hline 8 & 108.83 & 279.86 & 0.582 & 0.826 & 0.300 & 1.108 & 59.07 & 60.70 & 1.63 & 1.408 & 46.929 & 0.587 & 0.787 & 0.177 & 0.315 \\
\hline 9 & 108.77 & 416.00 & 0.578 & 1.078 & 0.122 & 1.534 & 59.06 & 60.59 & 1.54 & 1.656 & 55.204 & 0.651 & 0.926 & 0.241 & 0.510 \\
\hline 10 & 108.29 & 508.63 & 0.842 & 1.076 & 0.429 & 1.488 & 58.93 & 60.51 & 1.58 & 1.917 & 63.905 & 0.561 & 0.776 & 0.223 & 0.461 \\
\hline 11 & 107.45 & 1545.06 & 1.238 & 1.950 & 0.532 & 2.657 & 58.69 & 60.35 & 1.66 & 3.189 & 106.283 & 0.612 & 0.833 & 0.316 & 0.790 \\
\hline
\end{tabular}

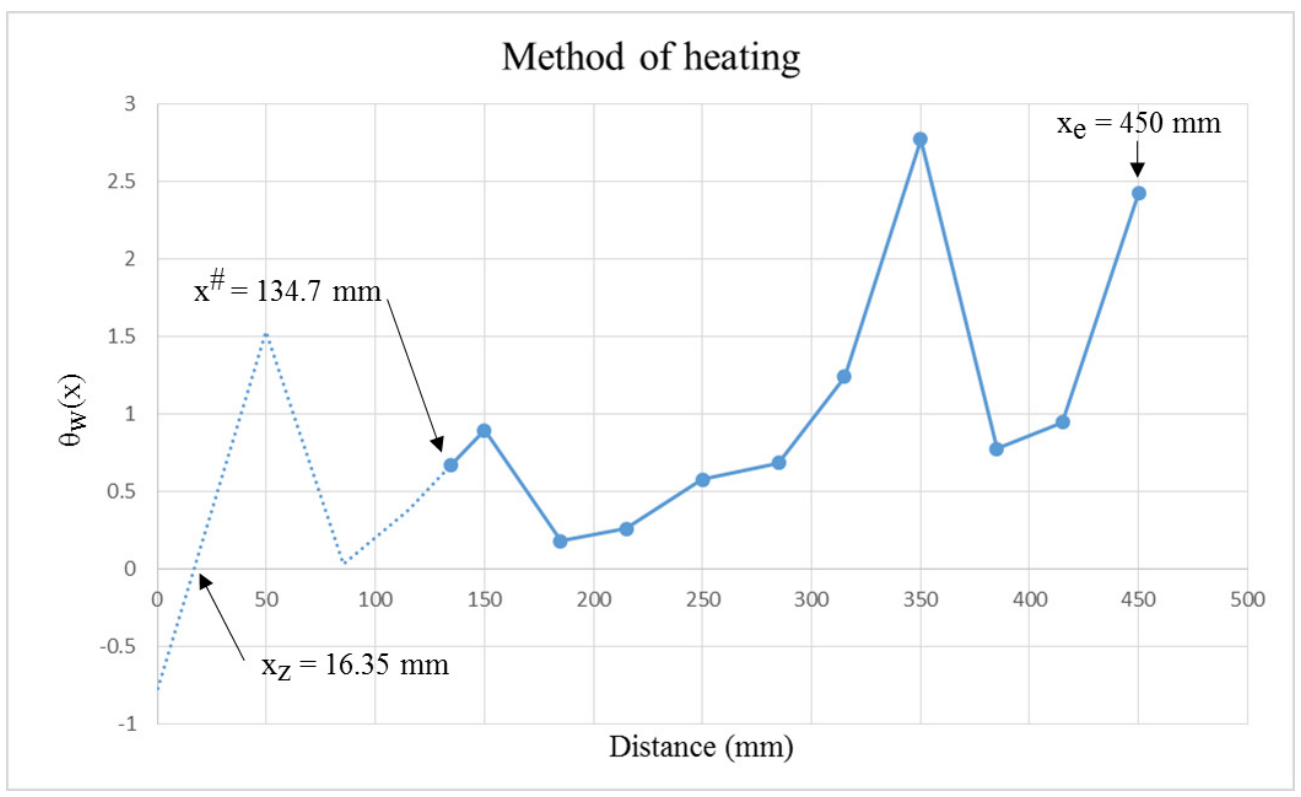


Figure 4.2: The above representative non-dimensionlized temperature profile, over $0<\mathrm{x}^{\#} \leq \mathrm{x} \leq \mathrm{x}_{\mathrm{e}}<\mathrm{L}$, specifies the "method of heating" for all the experimental runs in Table 4.1.

The non-uniform heating method related spatial oscillations in $\theta_{\mathrm{w}}(\mathrm{x})$, around $\theta_{\mathrm{w}}(\mathrm{x})=1$ over $\mathrm{x}^{\#} \leq \mathrm{x} \leq \mathrm{x}_{\mathrm{e}}$ in Fig. 4.2, result from a combination of factors related to the use of the reversed (coolers to heaters) thermoelectric heaters. These heaters, shown in Fig. 4.1, control set point temperatures on the boiling-surface at specific locations $-\mathrm{x}(\mathrm{cm})$ locations given by $\{\mathrm{x}(\mathrm{cm})\} \equiv\{5,15,25,35,45\}$ - that are directly above the $4 \mathrm{~cm}$ square devices (with flow-direction spread of $4 \mathrm{~cm}$ ) underneath the steel slab. The top-surface of the steel slab contains the test-section area that forms a $1.5 \mathrm{~cm}$ x $50 \mathrm{~cm}$ boiling-surface $\left(\mathrm{A}_{\mathrm{bs}}=75\right.$ $\mathrm{cm}^{2}$ ) in Fig 4.1. The steel slab itself is $12.7 \mathrm{~mm}$ thick in the vertical direction, $5.08 \mathrm{~cm}$ wide in the horizontal direction, and $1.09 \mathrm{~m}$ long in the flow direction. Most air exposed surfaces of the slab are wrapped with insulating materials to contain the convective loss of heat to ambient air. Furthermore, the vertical exposed edges of this slab also use some strip heaters (and then wrapped with insulating materials) to minimize convective loss of heat to ambient air. The three dimensional nature of heat-flux vectors within the steel slab that are responsible for heat loss from underneath the boiling-surface, coupled with the above explained set-point temperatures at specified locations, yield the lengthwise nonuniformity in temperatures indicated by the spatial oscillations, around $\theta_{\mathrm{w}}(\mathrm{x})=1$, as indicated in Fig. 4.2.

In addition to the measured variables' values reported in Table 4.1, some associated processed/calculated values of results corresponding to the runs in Table 4.1 are also shown in Table 4.2. The calculated variables in Table 4.1 are: saturation temperature $\mathrm{T}_{\text {sat }}\left(\mathrm{p}_{0}\right)$; average temperature difference $\Delta \mathrm{T}$; total mass flow rate $\dot{\mathrm{M}}_{\text {total }}=\dot{\mathrm{M}}_{\mathrm{L}}(\mathrm{x})+\dot{\mathrm{M}}_{\mathrm{v}}(\mathrm{x})$, where $\dot{\mathrm{M}}_{\mathrm{L}}(\mathrm{x})$ and $\dot{\mathrm{M}}_{\mathrm{v}}(\mathrm{x})$ respectively denote the liquid and vapor mass flow rates at any distance $\mathrm{x}$ from the inlet in Fig. 4.1 (with $\dot{\mathrm{M}}_{\mathrm{L}-\text { in }} \equiv \dot{\mathrm{M}}_{\mathrm{L}}(\mathrm{x}=0), \dot{\mathrm{M}}_{\mathrm{V} \text {-in }} \equiv \dot{\mathrm{M}}_{\mathrm{V}}(\mathrm{x}=0), \dot{\mathrm{M}}_{\mathrm{L}-\text { out }} \equiv$ $\dot{\mathrm{M}}_{\mathrm{L}}(\mathrm{x}=\mathrm{L})$, and $\dot{\mathrm{M}}_{\mathrm{V}-\text { out }} \equiv \dot{\mathrm{M}}_{\mathrm{V}}(\mathrm{x}=\mathrm{L})$ ); mass-flux $\mathrm{G} \equiv \dot{\mathrm{M}}_{\text {total }} / \mathrm{A}_{\mathrm{cs}}$, where cross-sectional area $\mathrm{A}_{\mathrm{cs}}=0.3 \mathrm{~cm}^{2}$; quality $\mathrm{X}(\mathrm{x})\left(\equiv \dot{\mathrm{M}}_{\mathrm{V}}(\mathrm{x}) / \dot{\mathrm{M}}_{\mathrm{in}}\right)$ at any distance $\mathrm{x}$ becomes inlet quality 
$\mathrm{X}_{\text {in }} \equiv \dot{\mathrm{M}}_{\mathrm{V}-\mathrm{in}} / \dot{\mathrm{M}}_{\text {total }}$ at $\mathrm{x}=0$ and outlet quality $\mathrm{X}_{\text {out }} \equiv \dot{\mathrm{M}}_{\mathrm{V} \text {-out }} / \dot{\mathrm{M}}_{\text {total }}$ at $\mathrm{x}=1$; approximate total heat $\mathrm{q}_{\text {total }} \cong \dot{\mathrm{M}}_{\text {total }} *\left(\mathrm{X}_{\text {out }}-\mathrm{X}_{\mathrm{in}}\right) * \mathrm{~h}_{\mathrm{fg}}$ supplied from the boilingsurface to the flow, where $\mathrm{h}_{\mathrm{fg}}$ is the heat of vaporization $(\mathrm{J} / \mathrm{kg})$ of $\mathrm{FC}-72$ at temperature $\mathrm{T}_{\text {sat }}\left(\mathrm{p}_{0}\right)$; and average heat-flux $\overline{\mathrm{q}_{\mathrm{w}}^{\prime \prime}} \equiv \mathrm{q}_{\text {total }} / \mathrm{A}_{\mathrm{bs}}$, where the boiling surface area $\mathrm{A}_{\mathrm{bs}}=75$ $\mathrm{cm}^{2}$.

Generally, be it liquid or vapor mass flow rates or their phase-specific thermodynamic/transport properties, a subscript " $L$ " denotes the liquid phase and a subscript "V" denotes the vapor phase. Both phases are modeled as incompressible (i.e. vapor Mach numbers are low). The properties (density $\rho$, viscosity $\mu$, specific heat $C_{p}$, and thermal conductivity k) are denoted with subscript "I". The properties are to take their representative constant values for each phase ( $\mathrm{I}=$ "L" or "V").

Some of the calculated variables in Table 4.2 are: average HTC $\overline{\mathrm{h}} \equiv \overline{\mathrm{q}_{\mathrm{w}}^{\prime \prime}} / \Delta \mathrm{T}$, local HTC $\left.\mathrm{h}_{\mathrm{x} \mid \mathrm{x}=40 \mathrm{~cm}} \equiv\left[\mathrm{q}_{\mathrm{w}}(\mathrm{x}) / \Delta \mathrm{T}(\mathrm{x})\right]\right|_{\mathrm{x}=40 \mathrm{~cm}}$ where $\Delta \mathrm{T}(\mathrm{x})$ and $\mathrm{q}_{\mathrm{w}}(\mathrm{x})$ are defined in Eqs. (4.1)(4.2), Nusselt Number $\mathrm{Nu}_{\mathrm{x} \mid \mathrm{x}=40 \mathrm{~cm}}, \mathrm{Re}_{\mathrm{L}-\mathrm{in}}, \mathrm{Re}_{\mathrm{V} \text {-in, }}, \mathrm{Re}_{\text {total }}$, Ja, and the remaining calculated variables in Table 4.2 are defined later on in this section.

Table 4.2: Calculated parameters computed for the corresponding case-specific values in Table 4.1.

\begin{tabular}{|c|c|c|c|c|c|c|c|c|c|c|c|c|c|}
\hline Case & $\overline{\mathrm{h}}$ & $\mathrm{h}_{\mathrm{x} \mid \mathrm{x}}=40 \mathrm{~cm}$ & $\mathrm{Nu}_{\mathrm{x}} \mid \mathrm{x}=40 \mathrm{~cm}$ & $X_{\text {in }}$ & $\mathrm{Re}_{\mathrm{L}-\mathrm{in}}$ & $\mathrm{Re}_{\mathrm{V}-\mathrm{in}}$ & $\mathrm{Re}_{\text {Total }}$ & $\mathrm{Ja}$ & $\operatorname{Pr}_{L}$ & $\rho_{\mathrm{V}} / \rho_{\mathrm{L}}$ & $\mu_{\mathrm{V}} / \mu_{\mathrm{L}}$ & $\%$ nb - KM & $\% \mu \mathrm{nb}-\mathrm{CFD}$ \\
\hline Max relative error & $\pm 11.04 \%$ & $\pm 11.04 \%$ & $\pm 20.25 \%$ & $\pm 0.8 \%$ & $\pm 16.46 \%$ & $\pm 16.46 \%$ & $\pm 15.66 \%$ & $\pm 8.84 \%$ & $\pm 3 \%$ & $\pm 2 \%$ & $\pm 2 \%$ & - & - \\
\hline Gaussian error & $\pm 8.02 \%$ & $\pm 8.02 \%$ & $\pm 13.79 \%$ & $\pm 0.57 \%$ & $\pm 10.52 \%$ & $\pm 10.52 \%$ & $\pm 10.49 \%$ & $\pm 5.62 \%$ & $\pm 1.73 \%$ & $\pm 1.41 \%$ & $\pm 1.41 \%$ & - & - \\
\hline 1 & 1439.57 & 842.11 & 57.34 & 0.614 & 65.33 & 4150.93 & 6758.96 & 0.0197 & 9.39 & 0.0091 & 0.02505 & 15.02 & 71.64 \\
\hline 2 & 1196.80 & 1072.58 & 73.03 & 0.594 & 70.85 & 4137.72 & 6967.13 & 0.0206 & 9.39 & 0.0090 & 0.02504 & 15.59 & 80.80 \\
\hline 3 & 1412.58 & 1264.11 & 86.08 & 0.571 & 77.66 & 4132.00 & 7232.78 & 0.0196 & 9.39 & 0.0090 & 0.02504 & 15.51 & 85.13 \\
\hline 4 & 1389.95 & 1378.00 & 93.82 & 0.543 & 86.70 & 4116.43 & 7581.24 & 0.0204 & 9.40 & 0.0090 & 0.02502 & 16.24 & 87.51 \\
\hline 5 & 1370.50 & 1208.48 & 82.29 & 0.566 & 87.14 & 4540.40 & 8019.16 & 0.0203 & 9.39 & 0.0091 & 0.02505 & 15.97 & 84.80 \\
\hline 6 & 1513.82 & 1278.78 & 87.04 & 0.576 & 87.21 & 4736.85 & 8225.58 & 0.0214 & 9.40 & 0.0090 & 0.02500 & 16.27 & 84.07 \\
\hline 7 & 1151.15 & 818.87 & 55.72 & 0.432 & 153.51 & \begin{tabular}{|l|}
4670.49 \\
\end{tabular} & \begin{tabular}{|l|}
10823.68 \\
\end{tabular} & 0.0223 & 9.41 & \begin{tabular}{l|}
0.0089 \\
\end{tabular} & 0.02495 & 18.62 & 86.72 \\
\hline 8 & 1937.43 & 1273.33 & 86.64 & 0.587 & 154.53 & 8797.68 & 14989.42 & 0.0214 & 9.41 & \begin{tabular}{l|l|}
0.0090 \\
\end{tabular} & 0.02496 & 15.89 & 85.84 \\
\hline 9 & 3314.93 & 2047.23 & 139.30 & 0.651 & 153.68 & 11474.63 & 17633.36 & 0.0202 & 9.41 & 0.0089 & 0.02495 & 14.18 & TBC \\
\hline 10 & 2909.53 & 1853.53 & 126.08 & 0.561 & 223.32 & 11454.90 & 20417.93 & 0.0208 & 9.42 & \begin{tabular}{l|l}
0.0089 \\
\end{tabular} & \begin{tabular}{|l|}
0.02492 \\
\end{tabular} & 15.71 & TBC \\
\hline 11 & 4774.78 & 2536.04 & 172.42 & 0.612 & 327.89 & 20780.01 & 33974.18 & 0.0217 & 9.43 & 0.0088 & 0.02485 & 14.61 & TBC \\
\hline
\end{tabular}


Similar to the results in Table 4.1, additional measured values for steady annular runs are reported in Table 4.3 for a different approximately fixed "method of heating" $\theta_{\mathrm{w}}(\mathrm{x}) \equiv$ $\left(\left.\theta_{\mathrm{w}}(\mathrm{x})\right|^{2 \text { nd }}\right)$ defined in Fig 4.3 , for $0<\mathrm{x}^{\#} \leq \mathrm{x} \leq \mathrm{x}_{\mathrm{e}}<\mathrm{L}$. The $\mathrm{T}_{\mathrm{w}}(\mathrm{x})$ values for different runs in Table 4.3 are given in Table B.2 of Appendix B whereas the extended $\mathrm{T}_{\mathrm{w}}(\mathrm{x})$ and $\theta_{\mathrm{w}}(\mathrm{x})$ curves are defined, for $0<\mathrm{x} \leq \mathrm{L}$, in Appendix B's Figs. B.3-B.4. In addition to the measured variables' values reported in Table 4.3, some associated processed/calculated values of results corresponding to the runs are also shown in Table 4.4.

Table 4.3: Experimental run results of steady run cases which different from Table 4.1.

\begin{tabular}{|c|c|c|c|c|c|c|c|c|c|c|c|c|c|c|}
\hline Case & $\mathrm{p}_{\mathrm{o}}$ & $\dot{\mathrm{M}}_{\mathrm{L}-\mathrm{in}}$ & $\dot{\mathrm{M}}_{\mathrm{V} \text {-in }}$ & $\dot{\mathrm{M}}_{\mathrm{L}-\text { out }}$ & $\dot{\mathrm{M}}_{\mathrm{V}-\text { out }}$ & $\overline{\mathrm{T}}_{\mathrm{W}}$ & $\mathrm{T}_{\mathrm{sat}}\left(\mathrm{p}_{\mathrm{o}}\right)$ & $\Delta \mathrm{T}$ & $\dot{\mathrm{M}}_{\text {total }}$ & $\mathrm{G}$ & $X_{\text {in }}$ & $\mathrm{X}_{\text {out }}$ & $\mathrm{q}_{\mathrm{x} \mid \mathrm{x}=40 \mathrm{~cm}}^{\prime \prime}$ & $\overline{\mathrm{q}_{\mathrm{W}}^{\prime \prime}}$ \\
\hline Max relative error & $\pm 2.47 \%$ & $\pm 0.1 \%$ & $\pm 0.35 \%$ & $\pm 3 \%$ & $\pm 3.45 \%$ & $\pm 1.6 \%$ & $\pm 5.13 \%$ & $\pm 6.74 \%$ & $\pm 0.45 \%$ & $\pm 6.45 \%$ & $\pm 0.8 \%$ & $\pm 3.9 \%$ & $\pm 3 \%$ & $\pm 4.2 \%$ \\
\hline Gaussian error & - & - & - & - & $\pm 3.02 \%$ & - & - & $\pm 5.38 \%$ & $\pm 0.36 \%$ & $\pm 6.02 \%$ & $\pm 0.57 \%$ & $\pm 3.48 \%$ & - & $\pm 3.17 \%$ \\
\hline Unit & {$[\mathrm{kPa}]$} & {$[\mathrm{g} / \mathrm{s}]$} & {$[\mathrm{g} / \mathrm{s}]$} & {$[\mathrm{g} / \mathrm{s}]$} & {$[\mathrm{g} / \mathrm{s}]$} & {$\left[{ }^{\circ} \mathrm{C}\right]$} & {$\left[{ }^{\circ} \mathrm{C}\right]$} & {$\left[{ }^{\circ} \mathrm{C}\right]$} & {$[\mathrm{g} / \mathrm{s}]$} & {$\left[\mathrm{kg} / \mathrm{s} / \mathrm{m}^{2}\right]$} & - & - & {$\left[\mathrm{W} / \mathrm{cm}^{2}\right]$} & {$\left[\mathrm{W} / \mathrm{cm}^{2}\right]$} \\
\hline 1 & 106.54 & 1.050 & 0.222 & 0.383 & 0.890 & 62.38 & 58.44 & 3.93 & 1.272 & 42.412 & 0.175 & 0.699 & 0.099 & 0.751 \\
\hline 2 & 107.54 & 1.055 & 0.468 & 0.373 & 1.149 & 62.46 & 58.72 & 3.74 & 1.522 & 50.742 & 0.307 & 0.755 & 0.134 & 0.766 \\
\hline 3 & 107.63 & 1.053 & 0.622 & 0.307 & 1.368 & 62.43 & 58.74 & 3.68 & 1.675 & 55.839 & 0.371 & 0.817 & 0.172 & 0.838 \\
\hline 4 & 107.25 & 1.050 & 0.779 & 0.277 & 1.552 & 62.32 & 58.64 & 3.68 & 1.829 & 60.961 & 0.426 & 0.849 & 0.240 & 0.869 \\
\hline 5 & 112.19 & 1.046 & 1.280 & 0.000 & 2.326 & 63.65 & 59.98 & 3.67 & 2.326 & 77.529 & 0.550 & 1.000 & 0.251 & 1.169 \\
\hline 6 & 109.33 & 1.595 & 0.403 & 0.891 & 1.108 & 63.02 & 59.21 & 3.81 & 1.999 & 66.626 & 0.202 & 0.554 & 0.090 & 0.791 \\
\hline 7 & 112.95 & 1.600 & 0.836 & 0.712 & 1.724 & 64.07 & 60.18 & 3.89 & 2.436 & 81.197 & 0.343 & 0.708 & 0.165 & 0.992 \\
\hline 8 & 114.94 & 1.600 & 1.105 & 0.603 & 2.103 & 64.48 & 60.71 & 3.77 & 2.705 & 90.172 & 0.408 & 0.777 & 0.184 & 1.112 \\
\hline 9 & 118.69 & 1.613 & 1.237 & 0.503 & 2.347 & 65.62 & 61.68 & 3.94 & 2.851 & 95.020 & 0.434 & 0.823 & 0.199 & 1.233 \\
\hline 10 & 123.05 & 1.618 & 1.722 & 0.347 & 2.993 & 66.54 & 62.77 & 3.76 & 3.340 & 111.341 & 0.516 & 0.896 & 0.284 & 1.405 \\
\hline
\end{tabular}

Table 4.4: Calculated parameters based on values from Table 4.3.

\begin{tabular}{|c|c|c|c|c|c|c|c|c|c|c|c|c|c|}
\hline Case & $\overline{\mathrm{h}}$ & $\mathrm{h}_{\mathrm{x} \mid \mathrm{x}}=40 \mathrm{~cm}$ & $\mathrm{Nu}_{\mathrm{x} \mid \mathrm{X}}=40 \mathrm{~cm}$ & $X_{\text {in }}$ & $\mathrm{Re}_{\mathrm{L}-\text { in }}$ & $\mathrm{Re}_{\mathrm{V}-\text { in }}$ & Re $_{\text {Total }}$ & $\mathrm{Ja}$ & $\operatorname{Pr}_{L}$ & $\rho_{\mathrm{V}} / \rho_{\mathrm{L}}$ & $\mu_{\mathrm{V}} / \mu_{\mathrm{L}}$ & $\% \mathrm{nb}-\mathrm{KM}$ & $\% \mu \mathrm{nb}-\mathrm{CFD}$ \\
\hline Max relative error & $\pm 10.94 \%$ & $\pm 10.94 \%$ & $\pm 12.94 \%$ & $\pm 0.8 \%$ & $\pm 9.25 \%$ & $\pm 9.25 \%$ & $\pm 8.45 \%$ & $\pm 8.74 \%$ & $\pm 3 \%$ & $\pm 2 \%$ & $\pm 2 \%$ & - & - \\
\hline Gaussian error & $\pm 7.94 \%$ & $\pm 7.94 \%$ & $\pm 11.03 \%$ & $\pm 0.57 \%$ & $\pm 6.65 \%$ & $\pm 6.65 \%$ & $\pm 6.6 \%$ & $\pm 5.56 \%$ & $\pm 1.73 \%$ & $\pm 1.41 \%$ & $\pm 1.41 \%$ & - & - \\
\hline 1 & 1908.96 & 327.32 & 22.24 & 0.175 & 277.39 & 2370.53 & 13564.38 & 0.052 & 9.44 & 0.0088 & 0.0248 & 36.48 & 65.63 \\
\hline 2 & 2049.02 & 468.44 & 31.85 & 0.307 & 279.33 & 4982.04 & 16219.08 & 0.049 & 9.43 & 0.0088 & 0.0249 & 32.88 & 70.25 \\
\hline 3 & 2275.05 & 619.61 & 42.13 & 0.371 & 278.98 & 6627.78 & 17847.66 & 0.048 & 9.43 & 0.0089 & 0.0249 & 31.06 & TBC \\
\hline 4 & 2358.16 & 889.94 & 60.50 & 0.426 & 277.88 & 8299.74 & 19488.65 & 0.048 & 9.43 & 0.0088 & 0.0248 & 29.57 & TBC \\
\hline 5 & 3122.18 & 1054.22 & 71.88 & 0.550 & 280.36 & 13597.97 & 24717.33 & 0.048 & 9.36 & 0.0092 & 0.0252 & 26.48 & TBC \\
\hline 6 & 2075.93 & 302.70 & 20.60 & 0.202 & 424.44 & 4294.04 & 21274.91 & 0.050 & 9.40 & 0.0090 & 0.0250 & 36.72 & $\mathrm{TBC}$ \\
\hline 7 & 2551.07 & 614.59 & 41.92 & 0.343 & 429.50 & 8880.05 & 25876.34 & 0.051 & 9.35 & 0.0093 & 0.0253 & 33.6 & TBC \\
\hline 8 & 2950.08 & 739.49 & 50.50 & 0.408 & 431.67 & 11723.96 & 28705.64 & 0.050 & 9.32 & 0.0094 & 0.0254 & 31.28 & TBC \\
\hline 9 & 3126.51 & 801.71 & 54.87 & 0.434 & 438.99 & 13105.50 & 30189.29 & 0.053 & 9.27 & 0.0098 & 0.0257 & 31.77 & TBC \\
\hline 10 & 3734.36 & 1179.74 & 80.95 & 0.516 & 444.82 & 18196.67 & 35295.81 & 0.050 & 9.22 & 0.0101 & 0.0260 & 28.73 & TBC \\
\hline
\end{tabular}




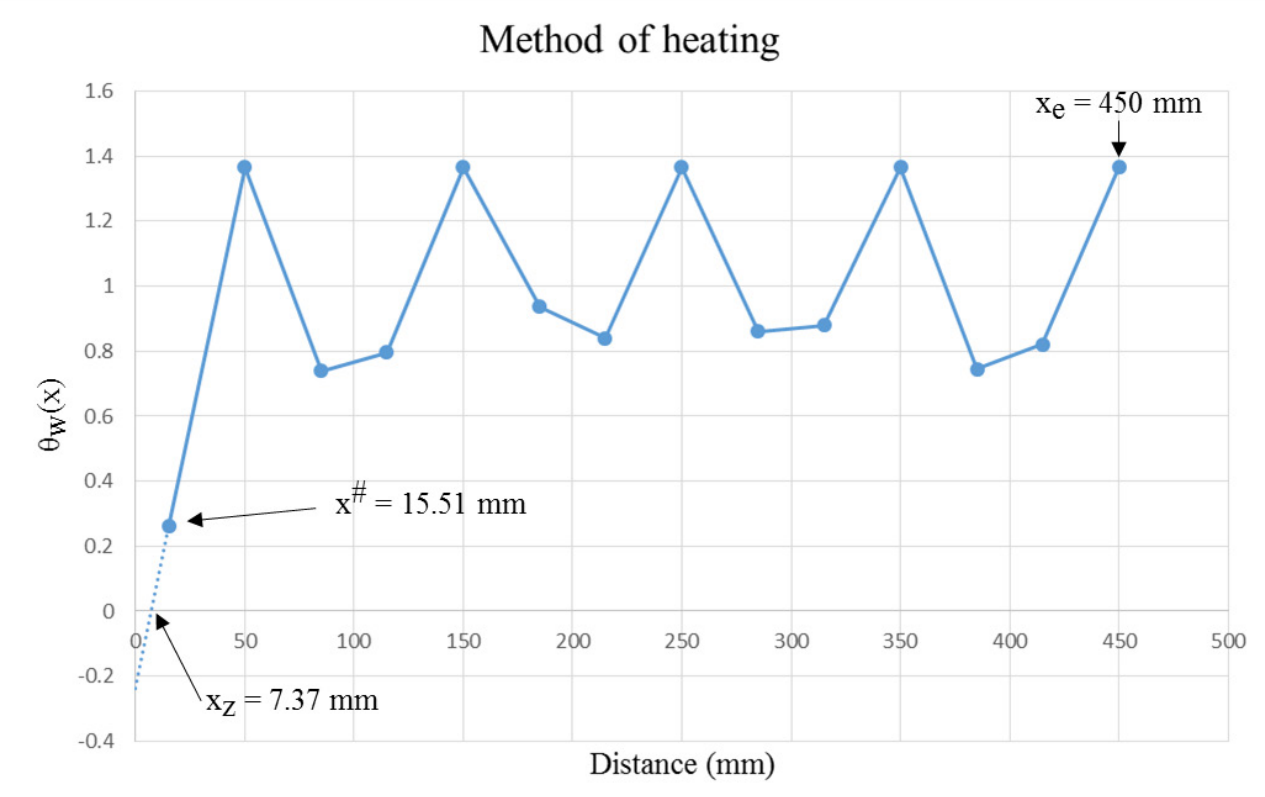

Figure 4.3: This non-dimensionalized temperature profile specifies the "method of heating" for the runs in Table 4.3.

\subsubsection{Discussions of Steady Results}

The above basic results (in Tables 4.1 and 4.3) explore steady annular flow-boiling for two different prescriptions of non-uniform wall temperature "methods of heating" - as specified by functions $\theta_{\mathrm{w}}(\mathrm{x})$ in Figs. 4.2 and 4.3. The non-dimensional local HTC $\mathrm{h}_{\mathrm{x}}$ values $\mathrm{Nu}_{\mathrm{x}}$ are defined as

$$
\mathrm{Nu}_{\mathrm{x}} \equiv \mathrm{h}_{\mathrm{x}} \cdot \frac{\mathrm{D}_{\mathrm{h}}}{\mathrm{k}_{\mathrm{L}}}, \mathrm{D}_{\mathrm{h}} \equiv 4 \mathrm{~A}_{\mathrm{cs}} / \mathrm{P}
$$

Using the cross-sectional area $\mathrm{A}_{\mathrm{cs}}$ and perimeter $\mathrm{P}$ for the rectangular cross-section testsection (width $\mathrm{w}=15 \mathrm{~mm}$ and height $\mathrm{h}=2 \mathrm{~mm})$, the hydraulic diameter $\mathrm{D}_{\mathrm{h}} \equiv 2 \mathrm{wh} /(\mathrm{w}+$ h) $=3.53 \mathrm{~mm}$ is used for reporting the processed experimental results in Table 4.2. Average constant thermal conductivity for the liquid flow is denoted as $\mathrm{k}_{\mathrm{L}}$. For comparing or utilizing results from steady annular suppressed nucleation 2-D CFD simulation results (as discussed in section 5), a channel approximation (with $\mathrm{h} / \mathrm{w}=2 / 15=0.13<<1$ ) is used where the corresponding CFD model [14] has $\mathrm{D}_{\mathrm{h}} \cong 2 \mathrm{~h}=4 \mathrm{~mm}$. 
For other processed experimental values of variables in Table 4.2, the following definitions are used:

$$
\mathrm{X}(\mathrm{x}) \equiv \dot{\mathrm{M}}_{\mathrm{V}}(\mathrm{x}) / \dot{\mathrm{M}}_{\mathrm{in}}, \mathrm{Re}_{\text {total }} \equiv \mathrm{GD}_{\mathrm{h}} / \mu_{\mathrm{V}}, \mathrm{Ja} \equiv \mathrm{C}_{\mathrm{pL}} \Delta \mathrm{T} / \mathrm{h}_{\mathrm{fg}}, \mathrm{Pr}_{\mathrm{L}} \equiv \mu_{\mathrm{L}} \mathrm{C}_{\mathrm{pL}} / \mathrm{k}_{\mathrm{L}}
$$

For laminar/turbulent nature of the flow assessments, one often uses "local" values of liquid and vapor Reynolds numbers $\left(\operatorname{Re}_{\mathrm{L}}(\mathrm{x})\right.$ and $\operatorname{Re}_{\mathrm{V}}(\mathrm{x})$ respectively) defined as

$$
\operatorname{Re}_{\mathrm{L}} \equiv \frac{\mathrm{G} \cdot(1-\mathrm{X}(\mathrm{x})) \cdot \mathrm{D}_{\mathrm{h}}}{\mu_{\mathrm{L}}} \text {, and } \operatorname{Re}_{\mathrm{V}} \equiv \frac{\mathrm{G} \cdot \mathrm{X}(\mathrm{x}) \cdot \mathrm{D}_{\mathrm{h}}}{\mu_{\mathrm{v}}}
$$

For separated annular flows considered here, $\operatorname{Re}_{\mathrm{L}}\left(\right.$ or $\left.\mathrm{Re}_{\mathrm{V}}\right)<2000$ continue to approximately indicate laminar nature of the flow in that phase. Similarly, $\operatorname{Re}_{\mathrm{L}}\left(\right.$ or $\left.\operatorname{Re}_{\mathrm{V}}\right) \gg$ 2000 continue to approximately indicate turbulent nature of the flow.

As discussed in [13], any impact of $\theta_{\mathrm{w}}(\mathrm{x})$ is adequately taken into account by its use in computing the variations of quality $\mathrm{X}(\mathrm{x})$ with distance $\mathrm{x}$. As far as $\theta_{\mathrm{w}}(\mathrm{x}) \neq 1$ conditions' impact on non-dimensional local $\mathrm{HTC} \mathrm{h}_{\mathrm{x}}$ values - given as $\mathrm{Nu}_{\mathrm{x}}$ correlations - is concerned, most engineering correlations [13] do not take its effects into account because they consider it to be insignificant. This is largely due to the fact that most experiments do not employ conditions where $\theta_{\mathrm{w}}(\mathrm{x}) \neq 1$ variations are strong in the sense that, for $0<\mathrm{x}<\mathrm{L}$, the distance function $\left\|\theta_{\mathrm{w}}(\mathrm{x})-1\right\| \quad$ is small, i.e. $\left\|\theta_{\mathrm{w}}(\mathrm{x})-1\right\| \equiv\left\{1 /\left(\mathrm{x}_{\mathrm{e}}-\mathrm{x}^{\#}\right)\right\}$. $\int_{\mathrm{x}^{\#}}^{\mathrm{x}_{\mathrm{e}}}\left[\left\{\theta_{\mathrm{w}}(\mathrm{x})-1\right\}^{2}+\left\{\theta_{\mathrm{w}}^{\prime}(\mathrm{x})\right\}^{2}\right] \cdot \mathrm{dx} \ll 1$. For example, in Figs. 4.1 and 4.3, $\left\|\theta_{\mathrm{w}}(\mathrm{x})-1\right\|$ values are respectively 0.018 and 0.004 . Besides ignoring the impact of $\theta_{\mathrm{w}}(\mathrm{x}) \neq 1$ on $\mathrm{Nu}_{\mathrm{x}}$ correlations, there is another reason. This has to do with the fact that in developing $\mathrm{Nu}_{\mathrm{x}}$ correlations for local HTC as $\mathrm{h}_{\mathrm{x}} \equiv \mathrm{q}_{\mathrm{w}}^{\prime \prime}(\mathrm{x}) / \Delta \mathrm{T}(\mathrm{x})$, often $\mathrm{h}_{\mathrm{x}}$ is evaluated under $\Delta \mathrm{T}(\mathrm{x}) \equiv$ $\Delta \mathrm{T} . \theta_{\mathrm{w}}(\mathrm{x}) \cong \Delta \mathrm{T}$ approximation. As a result, the impact on quality $\mathrm{X}(\mathrm{x})$ variations do not arise if the correct non-dimensional equations for $\mathrm{dX} / \mathrm{dx}$ - if it correctly takes into account $\theta_{\mathrm{w}}(\mathrm{x})$ effects as given in [13] - are used.

Looking at the processed variables data in Table 4.2, it is clear that the range of nondimensional parameters for this set of steady annular experiments cover: 
$0.432 \leq \mathrm{X}_{\text {in }} \leq 0.651 ; 63.29 \leq \operatorname{Re}_{\mathrm{L}-\text { in }} \leq 327.89 ; 4022.11 \leq \operatorname{Re}_{\mathrm{V} \text {-in }} \leq 20780.01$

$6643.32 \leq \mathrm{Re}_{\text {total }} \leq 33974.2 ; \quad 0.0196 \leq \mathrm{Ja} \leq 0.0296 ; 9.39 \leq \operatorname{Pr}_{\mathrm{L}} \leq 9.47$

$0.0086 \leq \rho_{\mathrm{V}} / \rho_{\mathrm{L}} \leq 0.0091 ; 0.02465 \leq \mu_{\mathrm{V}} / \mu_{\mathrm{L}} \leq 0.02505$.

Similarly, looking at the processed variables data in Table 4.4, it is clear that the range of non-dimensional parameters for this second set of steady annular experiments cover:

$0.175 \leq \mathrm{X}_{\text {in }} \leq 0.550 ; 277.3916 \leq \mathrm{Re}_{\mathrm{L}-\text { in }} \leq 444.8155 ; 2370.53 \leq \mathrm{Re}_{\mathrm{V} \text {-in }} \leq 18196.67$

$13564.38 \leq \mathrm{Re}_{\text {total }} \leq 35295.81 ; 0.048 \leq \mathrm{Ja} \leq 0.053 ; 9.22 \leq \operatorname{Pr}_{\mathrm{L}} \leq 9.44$

$0.0088 \leq \rho_{\mathrm{V}} / \rho_{\mathrm{L}} \leq 0.0101 ; 0.0248 \leq \mu_{\mathrm{V}} / \mu_{\mathrm{L}} \leq 0.0260$

The purpose of obtaining the above described experimental results are threefold. They are needed to: (i) help assess the relative importance of micro-scale nucleate boiling in the reported experimentally measured values of local heat-flux or local HTC $h_{x}$ (as reported here and in [34]) - this is to be achieved through a suitable synthesis with CFD based modeling capabilities of our team (see section 5), (ii) help the modeling group in our team (see section 5) to obtain and propose methodologies for more accurate flow-regime (annular, in this case) and parameter-space specific HTC correlations, and (iii) help develop better understanding and methodologies for experimental results - when experiments switch from steady annular realizations to corresponding steady-in-the-mean pulsatile annular flows with enhanced heat transfer.

The first two contexts are briefly discussed here - while related works of others [13, 14] in our group are summarized in section 5 . The third context of enhanced steady-in-the-mean annular flows are discussed separately in section 4.2.

\subsubsection{Role of micro-nucleation}

For an assessment of the relative importance of micro-scale nucleate boiling in experimentally measured local heat-flux or local HTC values, data were obtained in the 
parameter-space specified by Eq. (4.7). This is because, for this parameter space and $\left\|\theta_{\mathrm{w}}(\mathrm{x})-1\right\|=0.018<1$, the $\mathrm{Nu}_{\mathrm{x}}$ correlations obtained in [14] are valid. The results in [14] correspond to a hypothetical flow realization (with $\mathrm{X}(\mathrm{x})$, film-thickness versus distance, etc. variations obtained from CFD are different from the actual) under suppressed nucleation assumptions that have been obtained from a nearly exact and feasible CFD simulation approach. The results from this approach can be used to obtain the hypothetical "convective boiling only" contribution to local HTC, denoted $\mathrm{h}_{\mathrm{x} \mid \mathrm{cb}}$, at any $\mathrm{x}$ location in Fig. 4.1 provided one uses experimentally measured values of the inlet and wall temperature conditions in the nucleation-absent CFD [14] runs associated with the actual experimental runs of Table 4.1. Recall that the actual experimentally measured local HTC $\mathrm{h}_{\mathrm{x}-40 \text { |Expt-st }}$ values in Table 4.1 are obtained from the relationship: $\mathrm{q}_{\mathrm{w}-40 \mathrm{~cm} \mid \mathrm{Expt}}^{\prime \prime} \equiv$ $\left.\mathrm{h}_{\mathrm{x}-40 \mid \text { Expt-st }} \cdot\left(\mathrm{T}_{\mathrm{w}}(\mathrm{x})-\mathrm{T}_{\mathrm{sat}}\left(\mathrm{p}_{\mathrm{in}}\right)\right)\right|_{\mathrm{x}=40 \mathrm{~cm}}$. As proposed in $([13],[14])$ that the only feasible (at least in the near future) way to estimate local HTC contributions, denoted $\mathrm{h}_{\mathrm{x} \mid \mu \mathrm{nb}}$, from micro-scale nucleate boiling is to use the decomposition $\mathrm{q}_{\mathrm{w}-40 \mathrm{~cm} \mid \mathrm{Expt}} \equiv$ $\mathrm{q}_{\mathrm{w}-40 \mathrm{~cm} \mid \text { Hypoth-CFD }}^{\prime \prime}+\mathrm{q}_{\mathrm{w}-40 \mathrm{~cm} \mid \mu \mathrm{nb}}$, which translates into $\mathrm{h}_{\mathrm{x} \mid \text { Expt-st }} \equiv \mathrm{h}_{\mathrm{x} \mid \mu \mathrm{nb}}+\mathrm{h}_{\mathrm{x} \mid \mathrm{cb}}$. This approach has been used in Tables 4.2 and 4.4 for the measurement location of $x=40 \mathrm{~cm}$. Table 4.2 shows that " $\% \mu n b-C F D \equiv \mathrm{h}_{\mathrm{x} \mid \mu \mathrm{nb}} / \mathrm{h}_{\mathrm{x} \mid \text { Expt-st }} * 100$ " is dominant, for the filled rows, and are in the $80-90 \%$ range. The filled rows in Table 4.2 reporting "\% $\%$ nb-CFD" correspond to runs for which the thin liquid film flow is laminar and vapor flow is laminar near the interface - these being the only cases for which the necessary CFD procedures [14] are currently available. The unfilled rows with "TBC (to be computed)" entries under “\% $\mu$ nb-CFD" column-header in Tables 4.2 and 4.4 make the case for further maturation of the proposed decomposition procedure by developing and making available CFD-based effective estimates of convective HTC contributions - for flow-boiling simulations (under the hypothetical absence of nucleate boiling) that can be trusted to give good estimates for annular regimes for these unassessed runs, which involve significantly turbulent vapor (unlike the approach in [14]) and laminar liquid flows. 
The local (at $x=40 \mathrm{~cm}$ ) and average heat-flux measurements of $\mathrm{q}_{\mathrm{w}-40 \mathrm{~cm}}^{\prime \prime}$ and $\overline{\mathrm{q}_{\mathrm{w}}^{\prime \prime}}$, respectively in Table 4.1 tell a story consistent with the results in an earlier heat-flux controlled annular flow-boiling experiment [34]. For the temperature-controlled boiling experiments, average heat-flux (over the $50 \mathrm{~cm}$ length of the channel) is much higher than the measured local heat-flux. Furthermore, for the heat-flux controlled annular flowboiling experiment [34], the local experimentally measured heat-flux (or HTC $h_{x}$ ) values at upstream locations near the inlet are much higher than estimates obtained from suppressed nucleation modeling/computational estimates (obtained from a 1-D version used in [34]). Still an order of magnitude agreement between experimentally obtained $\mathrm{q}_{\mathrm{w}}^{\prime \prime}(\mathrm{x})$ and suppressed nucleation theory [34] is obtained for certain run conditions' downstream locations where the liquid film is sufficiently thin (because of the locations' proximity to stable dry-out conditions) and suppressed micro-nucleation conditions are actually achieved. Both current and earlier experimental results establish that micronucleation heat-transfer is more significant at upstream thicker liquid locations (they were visible for some cases, particularly in [34]) where a larger range of bubble departure diameters (and associated frequencies) are available and these contributions gradually diminish over the length of the channel. Clearly, for $50-300 \mu \mathrm{m}$ thick liquid films of interest here, micro-nucleation is a more significant carrier of heat than thin-film convection (without nucleation) mechanisms. It should be noted that the available poolboiling related experimental data and their analyses [13] for nucleation site densities, bubble departure diameter, bubble departure frequency, etc. should only be used as guides and are only approximately valid for the micro-scale nucleate boiling of interest here. This is because, for micro-/nano-scale bubbles, the bubble-ebullition cycles are affected by many other parameters that are not fully understood at this time [13].

This decomposition should not be confused with popularly available decompositions, as in [38], where ad hoc decompositions use the "nucleate boiling" term of the HTC correlation to relate to (or model) upstream larger diameter "nucleate boiling" regimes in traditional flow-boiling (i.e., all liquid flow at the inlet), while relating the remaining term to "convection" dominant flow-regimes (which include annular flows of interest here). This 
is the reason why Kim and Mudawar correlations [38] yield (also see [13] for a proper description of assessments for this correlation), in Table 4.1, a very different " $\% \mathrm{nb}-\mathrm{KM}$ " $(=8-40 \%)$ for the heat carried by the so-called "nucleate boiling" terms.

\subsubsection{Role of experiments in obtaining more flow-regime and parameter-space based HTC correlations}

Looking at the two sets of data in Tables 4.1 and 4.3 along with the parameter spaces given in Eqs. (4.7) and (4.8), it is understood that one can obtain $\mathrm{Nu}_{\mathrm{x}}$ correlations - ignoring $\theta_{\mathrm{w}}(\mathrm{x})$ effects on $\mathrm{Nu}_{\mathrm{x}}$ correlations - while accounting for its effects when obtaining quality $\mathrm{X}(\mathrm{x})$ variations with $\mathrm{x}$ [13]. The combined parameter space (for Eqs. (4.7) and (4.8)) under consideration is:

$0.175 \leq \mathrm{X}_{\text {in }} \leq 0.651 ; 63.29 \leq \operatorname{Re}_{\mathrm{L}-\text { in }} \leq 444.8155 ; 2370.53 \leq \mathrm{Re}_{\mathrm{V} \text {-in }} \leq 20780.01$

$6643.32 \leq \operatorname{Re}_{\text {Total }} \leq 35295.81 ; 0.0196 \leq \mathrm{Ja} \leq 0.053 ; 9.22 \leq \operatorname{Pr}_{\mathrm{L}} \leq 9.47$

$0.0086 \leq \rho_{\mathrm{V}} / \rho_{\mathrm{L}} \leq 0.0101 ; 0.02465 \leq \mu_{\mathrm{V}} / \mu_{\mathrm{L}} \leq 0.0260$

These experiments offer flow-regime (annular) and parameter-space (Eq. (4.9)) specific values of $\left.\mathrm{Nu}_{\mathrm{x}}\right|_{\mathrm{x}}=40 \mathrm{~cm}$ and $\overline{\mathrm{q}_{\mathrm{w}}^{\prime \prime}}$ (which, see section 5, corresponds to known values of $\int_{\hat{\mathrm{x}}=0}^{\hat{x}=\mathrm{L} / \mathrm{D}_{\mathrm{h}}} \mathrm{Nu}_{\mathrm{x}} \cdot \theta_{\mathrm{w}}(\hat{x}) \cdot \mathrm{d} \hat{\mathrm{x}}$, where $\left.\hat{\mathrm{x}} \equiv \mathrm{x} / \mathrm{D}_{\mathrm{h}}\right)$. While these data, by themselves, are not sufficient for proposing accurate $\mathrm{Nu}_{\mathrm{x}}$ correlations, they can be judiciously combined with many other flow-boiling data that already exist (and are considered in the correlation given in [38]) - and cover this flow-regime and parameter-space in Eq. (4.9) through considerations of numerous other experiments in millimeter scale hydraulic diameter channels and tubes. That is, the idea is to retain the form of such "order of magnitude" correlations ([38]) while seeking agreement with the reasonably specific and accurate steady annular flow-boiling data for the parameter space given in Eq. (4.9). This approach, see section 5, effectively expands the data presented in Tables 4.1 and 4.3 and yields a reliable correlation that caters to a different need. 
The approach described in section 5 is quite important. It allows for future and other annular-regime data with known/specified parameter-space (as will be the case when we augment/replace the above data in Tables 4.1 and 4.3 with the moderate to high heat-flux "water as a working fluid" data obtained from our group's new ongoing experiments [39]) that can be used to propose other useful correlations covering a parameter space different than the one given in Eq. (4.9).

\subsection{Pulsatile Enhanced Annular Flow Results and Discussions}

Previously proposed "low heat-flux $\left(0.1-1 \mathrm{~W} / \mathrm{cm}^{2}\right)$ " innovative annular flow-boiling operations [9], a sub-case of operations indicated in Fig. 4.4, employed pulsatile vapor flows (of different amplitudes and frequencies, with FC-72 as working fluid) at the inlet with an unavoidable "low-level" pulsations that was always present in the liquid flow-rate. This "low-level" liquid pulsations were at approximately $3 \mathrm{~Hz}$ and came from a peristaltic liquid pump located upstream of the liquid inlet. This earlier study involved a $1 \mathrm{~m}$ length test-section as opposed to $50 \mathrm{~cm}$ long test-section in the current study. However the testsection gap height of $2 \mathrm{~mm}$ and width of $15 \mathrm{~mm}$ in this current study was the same as in the earlier study [9]. The earlier reported results [9], for a representative flow condition and heating approach, indicated the following: (i) a dominant presence of the $3 \mathrm{~Hz}$ frequency (present at "low amplitude" in the liquid flow) and its harmonics (even when no vapor pulsations were imposed) in the dynamic heat-flux and local pressure measurements (as indicated by the Fast Fourier Transform, FFT, of the measurements at the $40 \mathrm{~cm}$ location), (ii) a significant enhancement, by 200-300\%, of the local heat-flux (at the $40 \mathrm{~cm}$ measurement location) was observed when vapor pulsations of sufficient amplitude were imposed at the same $3 \mathrm{~Hz}$ frequency that intrinsically existed with the liquid flow at the inlet, and (iii) there were no good estimates available for average heat-flux values (though it was estimated to be in the low $20-40 \%$ range), it could not be directly estimated because the earlier flow-loop needed a flow-meter for measuring the liquid mass flow-rate exiting the test-section) with regard to the overall heat-flow rate enhancements that were being achieved over the length of the test-section. 
The above described enhanced annular flows [9] were experiencing temperature controlled heating that utilized reversed (from cooler to heater) thermoelectric heaters described in section 3 - thereby maintaining nearly the same "method of heating" (i.e., $\theta_{\mathrm{w}}(\mathrm{x})$ ) for the enhanced steady-in-the-mean realization as in the regular steady realization. Furthermore, in the context of the definitions given in Eqs. (4.1) - (4.3), it is observed that while the local heat-flux at the $40 \mathrm{~cm}$ measurement location increased by $200-300 \%$ for some runs, the characteristic temperature-difference $\Delta \mathrm{T}$ increased only a little (see Fig. 16 in [9]). This is because of thermoelectric heaters' control efforts to hold $\Delta \mathrm{T}$ approximately constant. This meant that the local HTC $h_{x}$ in Eq. (4.3) showed significant increases - indicating flow-physics improvements due to enhanced superposed pulsations at $3 \mathrm{~Hz}$ that also resulted in visually observed formation of large amplitude interfacial standing waves.

At the time of interpreting the above results [9], there was a greater focus on paralleling the interpretation of the results with those of pulsatile annular flow-condensation (which showed even greater $600-800 \%$ enhancements over steady realizations, though at comparable mass-flux and local quality, the magnitude of $\Delta \mathrm{T} \equiv\left|\overline{\mathrm{T}}_{\mathrm{w}}-\mathrm{T}_{\mathrm{sat}}\left(\mathrm{p}_{0}\right)\right|$ was higher). But, as discussed earlier in this section's steady annular flow considerations and in [13], we have since established that micro-nucleation plays a dominant/significant role (as shown later on here, often $80-90 \%$ of the heat is being carried by this mechanism) for steady annular flow-boiling - whereas no similar mechanism exist for thin film annular flow-condensation. Therefore, while the micro-convection related hypotheses for pulsatile annular thin film flow-condensation - as discussed in [9] and improved in [13] - has merit, it is a relatively small factor for enhanced annular "low" heat-flux flow-boiling being studied here.

In the above context, some of the main questions for the new pulsatile annular flow-boiling experiments are listed next. (i) What happens if the underlying liquid pulsation of $3 \mathrm{~Hz}$ coming from the liquid pump is muffled and results are obtained - for steady cases as well as pulsatile cases? For pulsatile cases (see Fig. 4.4), liquid alone pulsations, vapor alone pulsations, and impositions of pulsations in both the liquid and the vapor flows (using the liquid and vapor pulsators shown in the flow-loop Fig. 3.2) should be experimented with 
at different mutually resonant frequencies, but at separately prescribed levels of amplitudes, that satisfy $f_{P L} \cong f_{P V}$. Here $f_{P L}$ and $f_{P V}$ respectively represent the dominant frequencies (introduced by their pulsators) in the incoming liquid and vapor flows (see Fig. 4.4 below). (ii) What is the relationship of observed local heat-flux enhancements to: micro-scale nucleation, ability of the interfacial standing waves' "troughs" to be close enough to the boiling-surface ([13]) so it can favorably alter the bubble-nucleation associated heat rates, and micro-convection associated enhancements (as in flow condensation) that came from large amplitude wavy liquid film flows? (iii) What is the relationship of local heat-flux enhancements to enhancements in the length-averaged heatflux values?

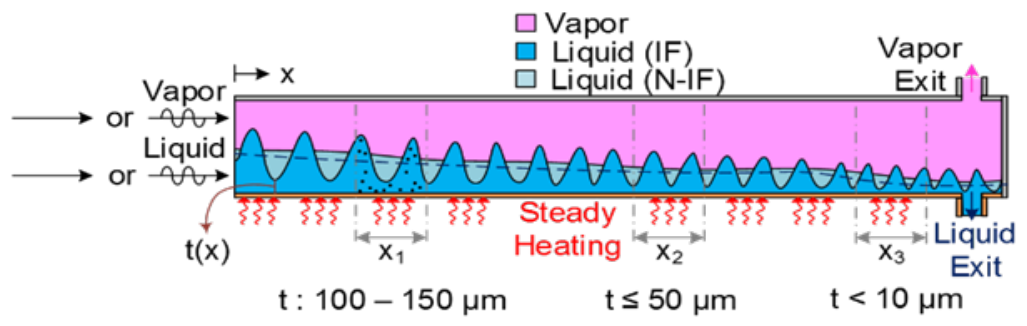

Figure 4.4: A schematic diagram of the test-section showing a flow realization with large amplitude standing waves on the liquid-vapor interface. The test-section is closed in the vapor flow direction for acoustics enabled formation of interfacial standing waves. The zones $\mathrm{x}_{1}, \mathrm{x}_{2}$ and $\mathrm{x}_{3}$ are zones of decreasing film thicknesses, respectively. Bubbles have been represented as "black dots" in zone $\mathrm{x}_{1}$ but are present in the liquid film throughout the test-section, except in the region of suppressed nucleation (zone $\mathrm{x}_{3}$ ). The liquid film thickness, shown as $\mathrm{t}(\mathrm{x})$, varies along the length of the channel, and is measured from the heating surface to the trough of the interfacial wave.

\subsubsection{Pulsatile Steady-in-the-Mean Annular Flow Results}

To answer the above questions, representative earlier experimental results [9] are shown in Fig. 4.5a-c below. The result in Fig. $4.5 \mathrm{~d}$ shows a steady and pulsatile case's dynamic heatflux results, in real time, at the $40 \mathrm{~cm}$ location, as obtained from the new $50 \mathrm{~cm}$ long testsection facility described in section 3 . During the steady and associated pulsatile (for which 
$\mathrm{f}_{\mathrm{PL}} \cong \mathrm{f}_{\mathrm{PV}}=5 \mathrm{~Hz}$ ) experiments, the pressure-transducer for measuring $\Delta \mathrm{p}_{\mid 10-40}$ was not functional but the remaining variables' time-averaged values were obtained and they are as shown in Table 4.5 - with the corresponding approximately fixed "method of heating" $\theta_{\mathrm{w}}(\mathrm{x})$ shown as in Fig. 4.6. For the real time heat-flux data in Fig. 4.5d, the corresponding real time-data for the absolute pressure at $\mathrm{x}=10 \mathrm{~cm}$ location (plotted as “ $\mathrm{p}_{10}(\mathrm{t}) \equiv \mathrm{p}_{\mathrm{x}=10 \mathrm{~cm}}(\mathrm{t})-\overline{\mathrm{p}}_{\mathrm{x}=10 \mathrm{~cm}}$ ”), $\quad \dot{\mathrm{M}}_{\mathrm{L}-\text { in }}(\mathrm{t})$, and $\dot{\mathrm{M}}_{\mathrm{V} \text {-in }}(\mathrm{t})$ are shown in Fig. 4.7a-c respectively. As far as Coriolis meter readings in Figs. 4.5b-c are concerned, only their time-averaged values can be trusted (as these meters lack dynamic data measurements capabilities for frequencies above $2 \mathrm{~Hz}$ ). The magnitudes of the Fast Fourier Transforms (FFTs) of the time varying $\mathrm{p}_{10}(\mathrm{t})$ and heat-flux $\mathrm{q}_{\mathrm{w}-40 \mathrm{~cm}}(\mathrm{t})$ data - for the steady case - are respectively shown in Figs. 4.8 and 4.9. The magnitude of the FFT of heat-flux $\mathrm{q}_{\mathrm{w}-40 \mathrm{~cm}}(\mathrm{t})$ data - for the pulsatile case (with $\mathrm{fPL}_{\mathrm{PL}} \cong \mathrm{f}_{\mathrm{PV}}=5 \mathrm{~Hz}$ ) - is shown in Fig. 4.10.

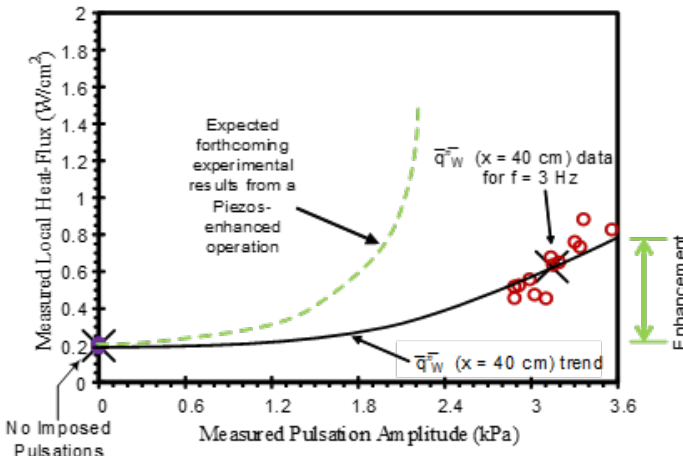

(a)

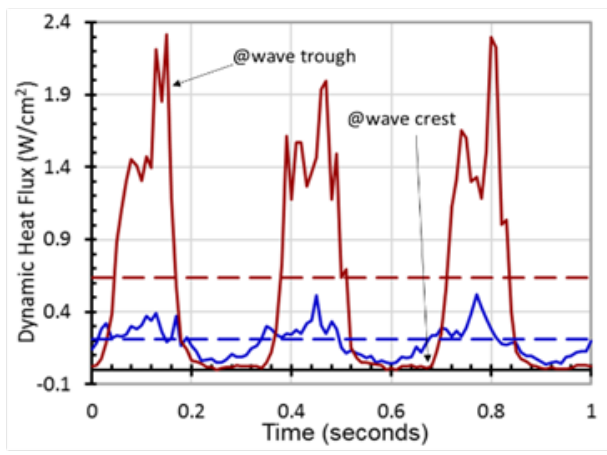

(c)

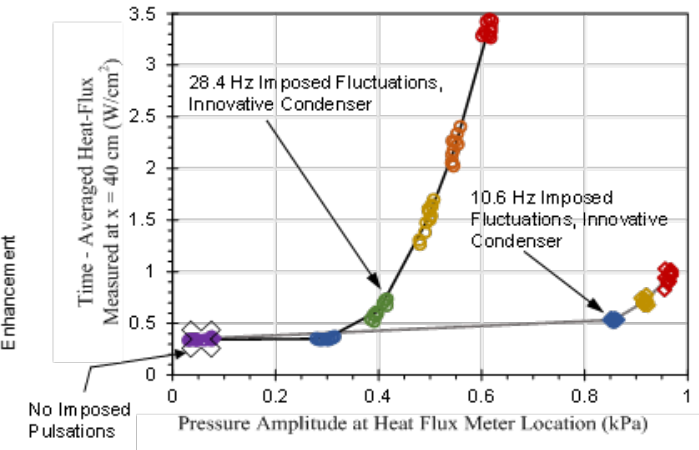

(b)

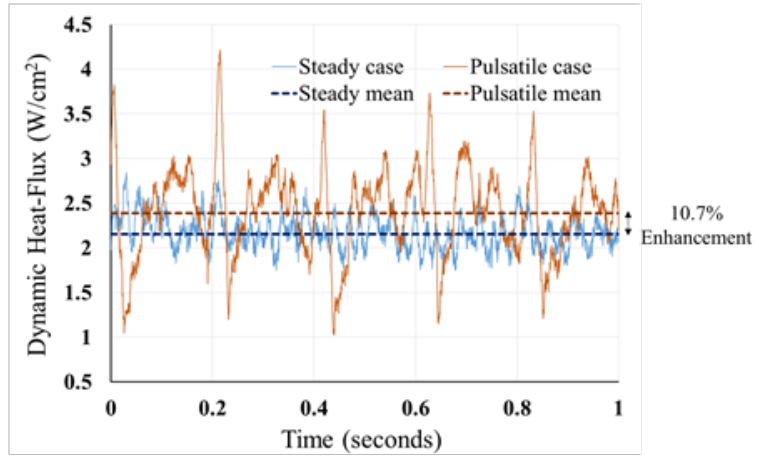

(d) 
Figure 4.5: (a) The experimentally obtained time-averaged heat-flux values for flowboiling of FC-72 exhibit primary dependence on amplitude of inlet pressure fluctuations. The black curve for $\mathrm{f}_{\mathrm{P}} \approx 3 \mathrm{~Hz}$ represents experimental values (for $\Delta \mathrm{T} \approx 10{ }^{\circ} \mathrm{C}$ ) and the indicated dashed-curve is an expected result from a new enhancement approach. (b) Timeaveraged heat-flux values for flow-condensation of FC-72 are experimentally obtained [9] (with $\Delta \mathrm{T} \approx 20^{\circ} \mathrm{C}$ at mass-fluxes and fluid as in (a)) and their primary dependence on amplitude of local (at the Heat-flux Sensor location of $\mathrm{x}=40 \mathrm{~cm}$ ) pressure fluctuations are shown above for two frequencies - with the $28.4 \mathrm{~Hz}$ frequency likely being closer to the acoustics-enabled dominant frequency for interfacial standing waves. (c) Time-varying heat-flux measurements with and without imposed inlet vapor pulsations, measured by a flush-type dynamic heat-flux sensor at the $40 \mathrm{~cm}$ heat-flux meter location. The experimental arrangement is similar to the innovative arrangement in Fig. 2a (but with dryout and therefore without the recirculating liquid) [9]. (d) Dynamic and computed timeaveraged heat-flux values are shown for steady non-pulsatile and pulsatile cases in Table 4.5. These are obtained for the new flow-boiling experiments with $\mathrm{f}_{\mathrm{PL}} \cong \mathrm{f}_{\mathrm{PV}}=5 \mathrm{~Hz}$ and $\mathrm{x}$ $=40 \mathrm{~cm}$ location corresponds to the thicker $\mathrm{x}_{1}$ locations in Fig. 4.4 [Reproduction of Fig. $4.5 \mathrm{~b}-\mathrm{c}$ was granted from Elsevier publishing, see Appendix C].

Table 4.5: Experimental runs associated with Fig. $4.5 \mathrm{~d}$ are characterized by this Table (these are results when the original dynamic heat-flux sensor was available, not broken).

\begin{tabular}{|c|c|c|c|c|c|c|c|c|c|c|c|c|c|c|}
\hline Case & $\mathrm{p}_{\mathrm{o}}$ & $\dot{\mathrm{M}}_{\mathrm{L}-\text { in }}$ & $\dot{\mathrm{M}}_{\mathrm{V}-\text { in }}$ & $\dot{\mathrm{M}}_{\mathrm{L}-\text { out }}$ & $\dot{\mathrm{M}}_{\mathrm{V}-\text { out }}$ & $\mathrm{T}_{\mathrm{sat}}\left(\mathrm{p}_{\mathrm{O}}\right)$ & $\overline{\mathrm{T}}_{\mathrm{W}}$ & $\Delta \mathrm{T}$ & $\dot{\mathrm{M}}_{\text {total }}$ & $\mathrm{G}$ & $\mathrm{X}_{\mathrm{in}}$ & $\mathrm{X}_{\mathrm{out}}$ & $\mathrm{q}_{\mathrm{x} \mid \mathrm{x}=40 \mathrm{~cm}}^{\prime \prime}$ & $\overline{\mathrm{q}}_{\mathrm{W}}$ \\
\hline Max relative error & $\pm 2.45 \%$ & $\pm 0.1 \%$ & $\pm 0.35 \%$ & $\pm 3 \%$ & $\pm 3.45 \%$ & $\pm 5.05 \%$ & $\pm 1.64 \%$ & $\pm 6.69 \%$ & $\pm 0.45 \%$ & $\pm 6.45 \%$ & $\pm 0.8 \%$ & $\pm 3.9 \%$ & $\pm 3 \%$ & $\pm 4.2 \%$ \\
\hline Gaussian error & - & - & - & - & $\pm 3.02 \%$ & - & - & $\pm 5.31 \%$ & $\pm 0.36 \%$ & $\pm 6.02 \%$ & $\pm 0.57 \%$ & $\pm 3.48 \%$ & - & $\pm 3.17 \%$ \\
\hline Unit & {$[\mathrm{kPa}]$} & {$[\mathrm{g} / \mathrm{s}]$} & {$[\mathrm{g} / \mathrm{s}]$} & {$[\mathrm{g} / \mathrm{s}]$} & {$[\mathrm{g} / \mathrm{s}]$} & {$\left[{ }^{\circ} \mathrm{C}\right]$} & {$\left[{ }^{\circ} \mathrm{C}\right]$} & {$\left[{ }^{\circ} \mathrm{C}\right]$} & {$[\mathrm{g} / \mathrm{s}]$} & {$\left[\mathrm{kg} / \mathrm{s} / \mathrm{m}^{2}\right]$} & - & - & {$\left[\mathrm{W} / \mathrm{cm}^{2}\right]$} & {$\left[\mathrm{W} / \mathrm{cm}^{2}\right]$} \\
\hline Steady & 121.03 & 1.734 & 1.225 & 0.498 & 2.461 & 62.27 & 65.73 & 3.46 & 2.959 & 98.630 & 0.414 & 0.832 & 2.159 & 1.365 \\
\hline Pulsatile & 122.74 & 1.731 & 1.230 & 0.318 & 2.643 & 62.69 & 66.11 & 3.42 & 2.961 & 98.694 & 0.415 & 0.893 & 2.231 & 1.559 \\
\hline
\end{tabular}




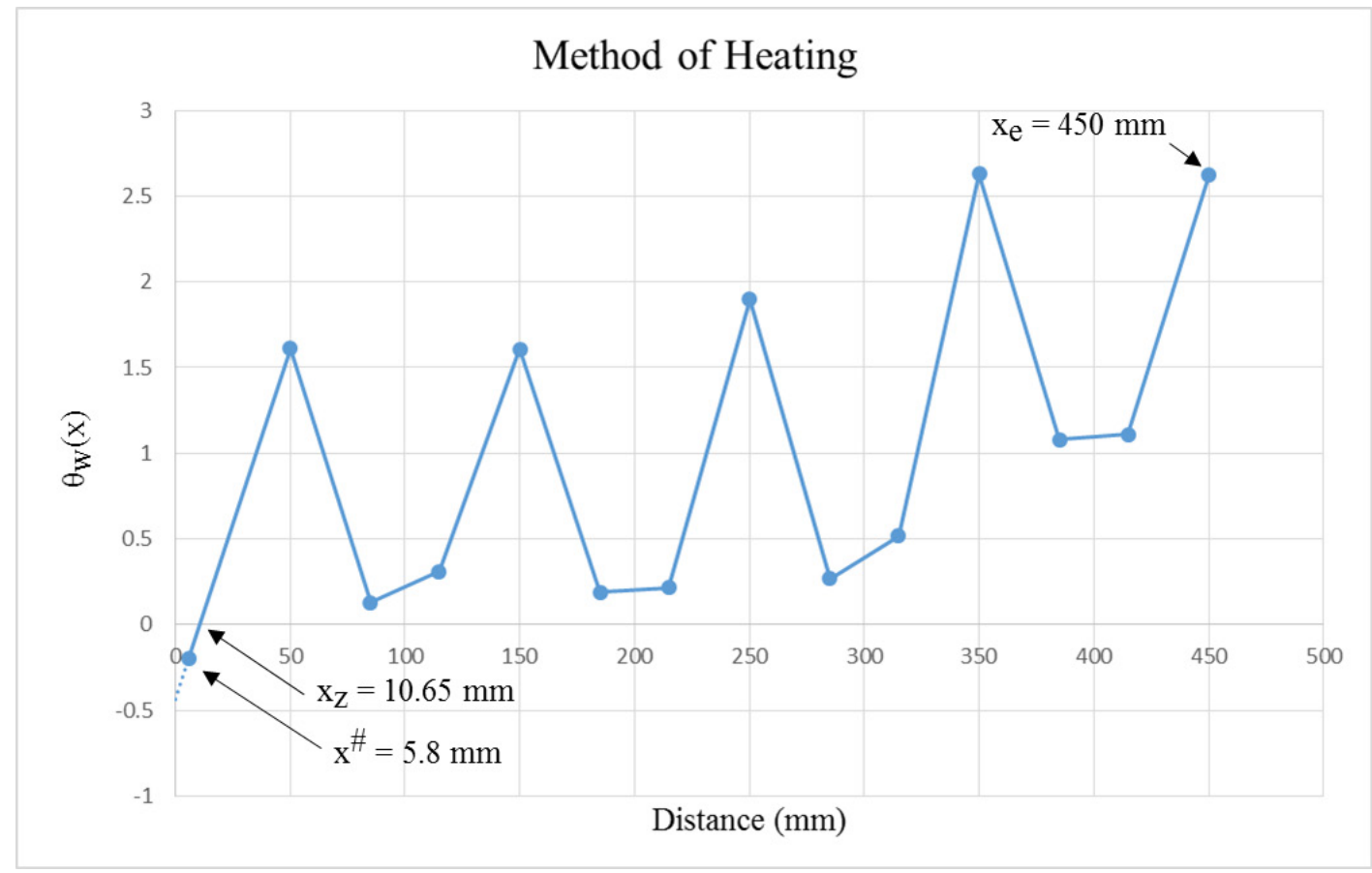

Figure 4.6: Heating method (Non-dimensionalized wall temperature profile) of cases in Table 4.5. There is a slight sub-cooling over $\mathrm{x}<\mathrm{x}_{\mathrm{z}}=10.65 \mathrm{~mm}$.

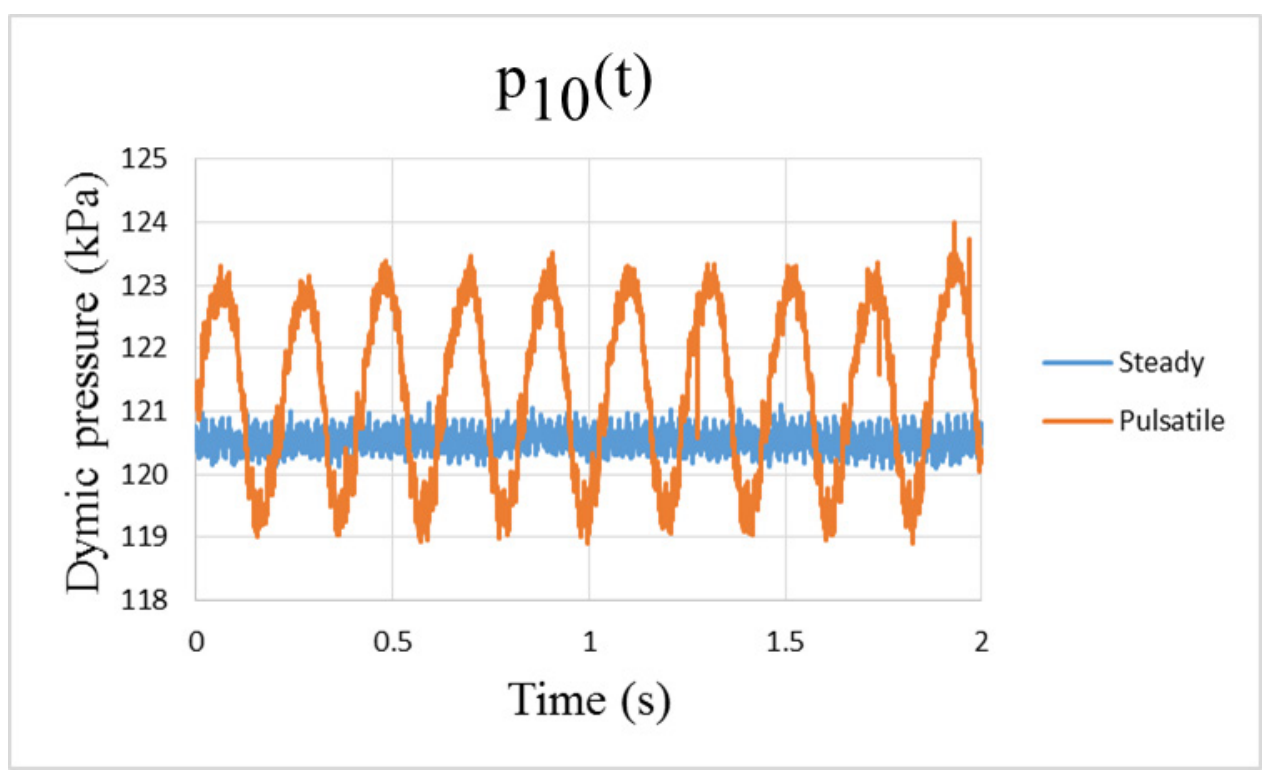

(a) 


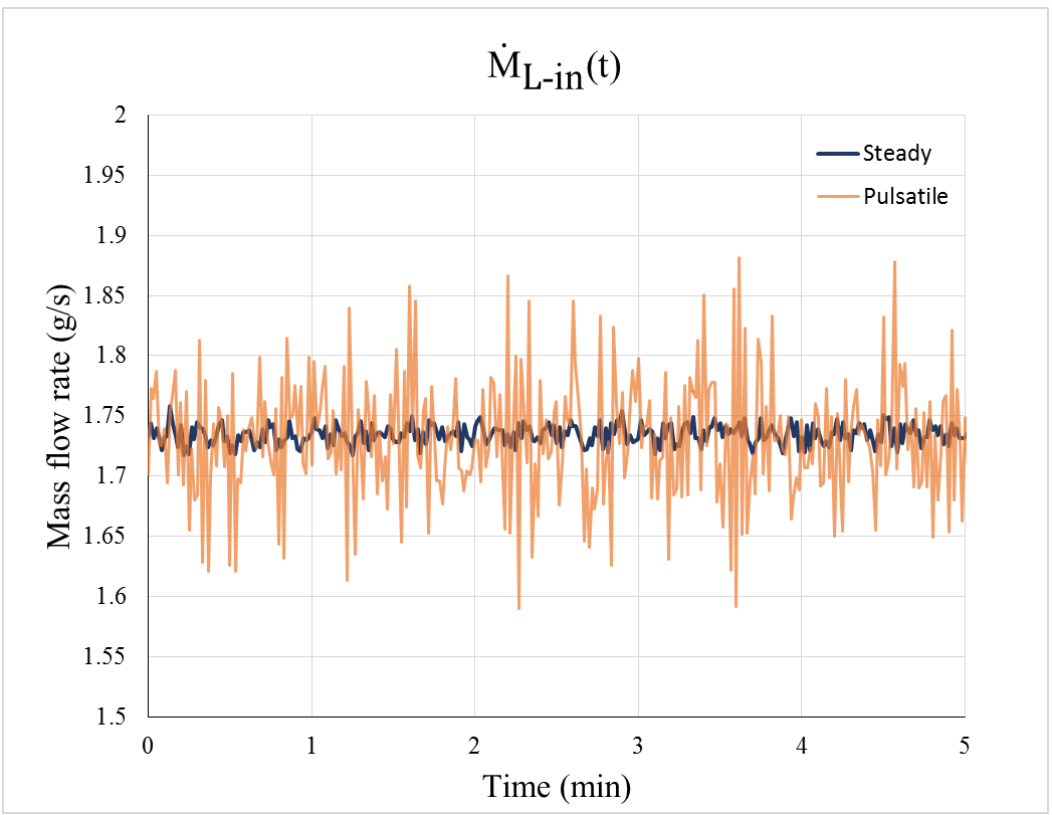

(b)

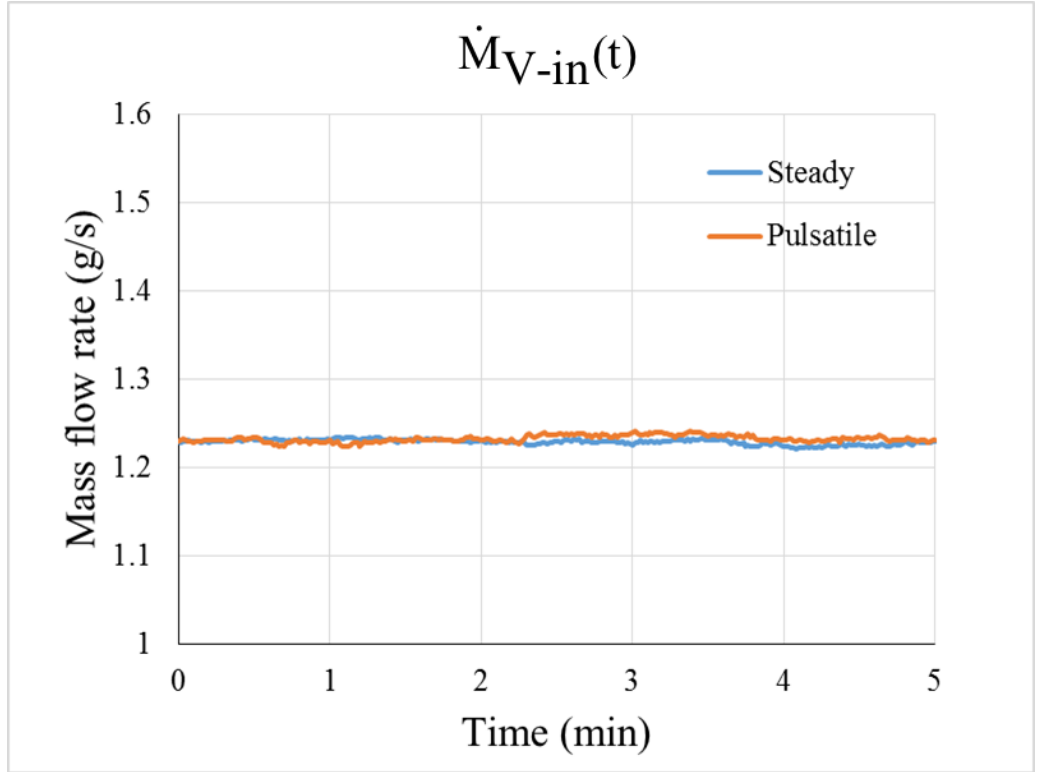

(c)

Figure 4.7: For steady and steady-in-the-mean (pulsatile) cases reported in Table 4.5, (a) Sample real time dynamic data record for $\mathrm{p}_{10}(\mathrm{t})$, (b) Low DAQ $\dot{\mathrm{M}}_{\mathrm{L}-\text { in }}(\mathrm{t})$ data of inlet liquid mass flow rate, and (c) Low DAQ $\dot{\mathrm{M}}_{\mathrm{V} \text {-in }}(\mathrm{t})$ data of inlet vapor mass flow rate. 


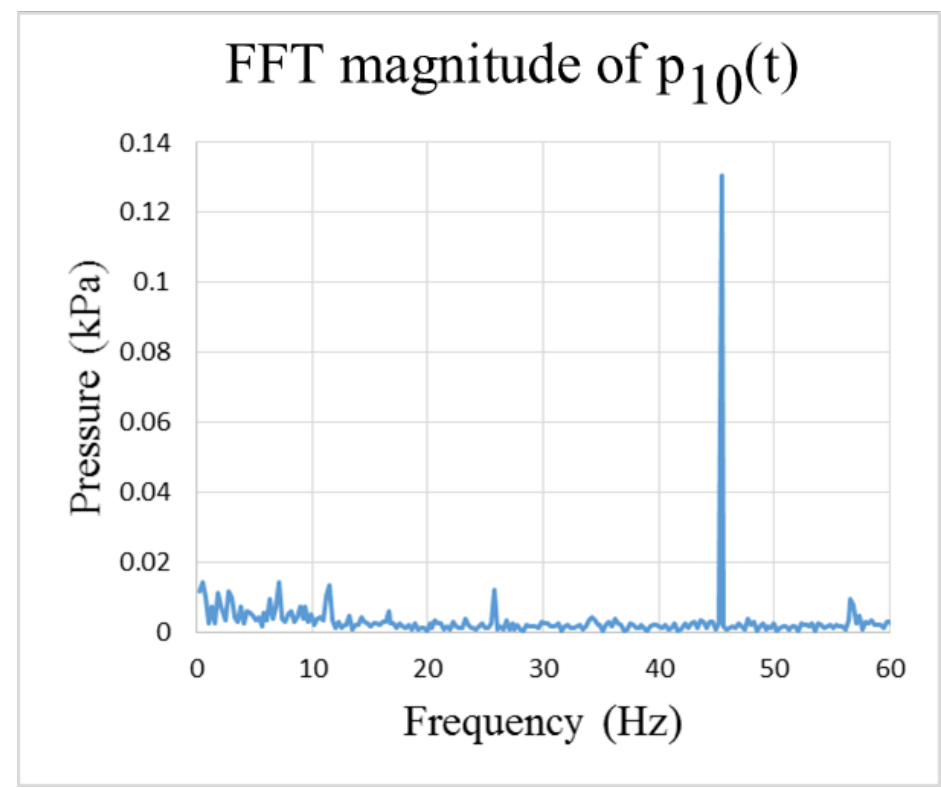

Figure 4.8: The above shows the FFT of $\mathrm{p}_{10}(\mathrm{t})$ associated with the steady case in Table 4.5. This and other FFTs confirm a dominant noise frequency of $45 \mathrm{~Hz}$.

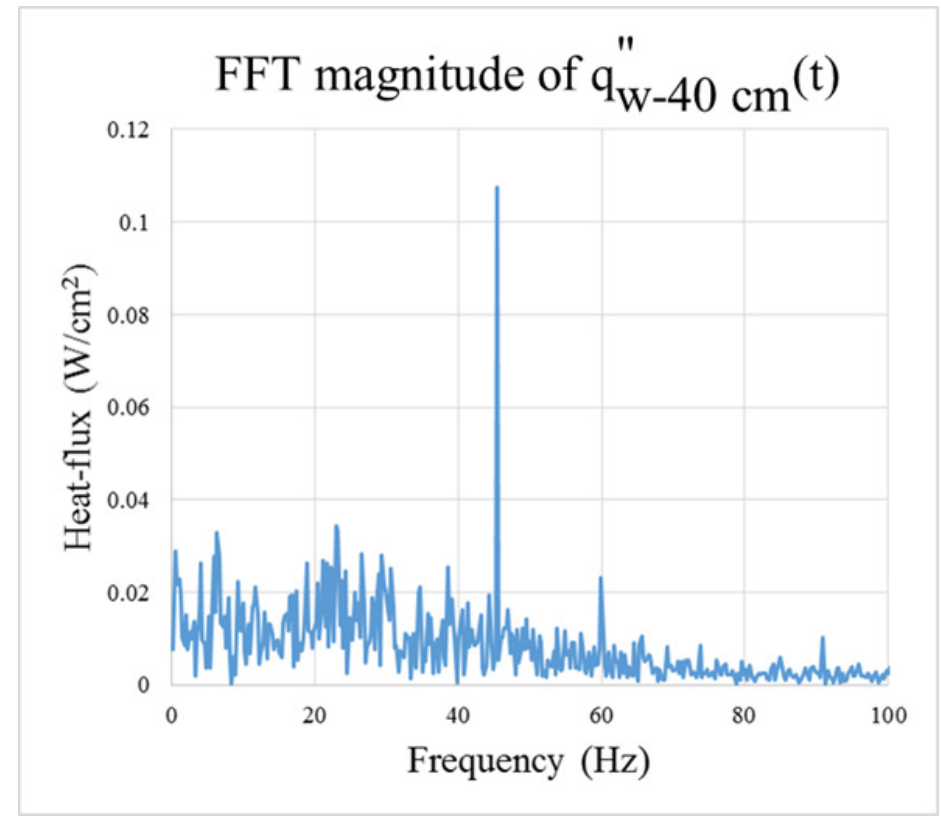

Figure 4.9: The above shows the FFT of $\mathrm{q}_{\mathrm{w}-40 \mathrm{~cm}}(\mathrm{t})$ associated with the steady case in Table 4.5. This and other FFTs confirm a dominant noise frequency of $45 \mathrm{~Hz}$. 


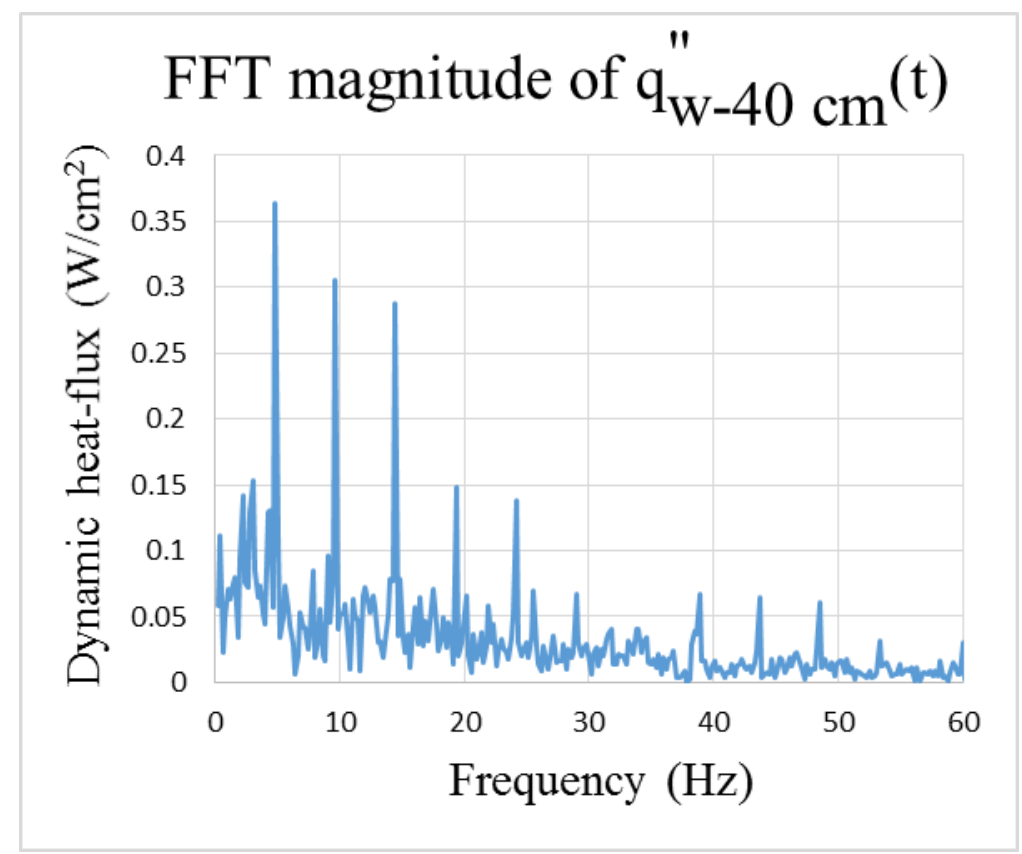

Figure 4.10: The figure above shows the FFT of $\mathrm{q}_{\mathrm{w}-40 \mathrm{~cm}}^{\prime \prime}(\mathrm{t})$ associated with the pulsatile case in Table 4.5. The externally imposed pulsations frequency $\mathrm{f}_{\mathrm{PL}} \cong \mathrm{f}_{\mathrm{PV}} \cong 5 \mathrm{~Hz}$ clearly dominate the bubble nucleation frequency over the heat-flux sensor at $40 \mathrm{~cm}$ location. However, $5 \mathrm{~Hz}$ is not in sync with the $45 \mathrm{~Hz}$ in Fig. 4.8, hence the dominant subharmonics at $10,15,20$, etc. Hz.

It is clear from the FFT of the steady case in Figs. 4.8-4.9 that the dominant frequencies (though negligible) in $\mathrm{p}_{10}(\mathrm{t})$ and $\mathrm{q}_{\mathrm{w}-40 \mathrm{~cm}}(\mathrm{t})$ correlate with one another and are $\mathrm{f} \cong 45$ and $46 \mathrm{~Hz}$ respectively. In principle, such dominant frequencies may be associated either with the "naturally" dominant mico-scale nucleate-boiling's bubble departure frequencies (and associated bubble-departure diameters) in a negligible-noise steady realization, denoted

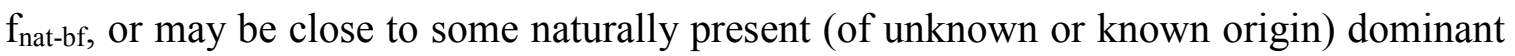
noise frequency $\mathrm{f}_{\text {nat-dom-noise }}$ present in the liquid flow rate that forces the bubble departure frequencies to be synchronized with it. The second conjectured possibility, related to sensitivity of dominant bubble-departure frequency to be such that it will get synchronized with inadvertent pulsation frequency (or frequencies) present in the liquid flow rate, is also supported by the earlier FFT of steady time varying $\mathrm{q}_{\mathrm{w}-40 \mathrm{~cm}}(\mathrm{t})$ data in Fig. $4.5 \mathrm{c}$, which showed (see [9]) significant influence/presence of dominant bubble-departure frequencies 
that came from the small amplitude peristaltic pump frequency $\mathrm{f}_{\text {nat-dom-noise }}$ of $3 \mathrm{~Hz}$, which was also present in the steady liquid flow realization. This conclusion is important because dominance of micro-scale nucleate boiling has been already established in Table 4.2 and elsewhere [34]. However the reported dynamic flow measurements are able to reveal how sensitive the statistical variations associated with bubble departure diameters and frequencies are to random flow conditions. Therefore, in Figs. $4.8-4.9$, there exists a natural dominant noise frequency in the steady realization $\mathrm{p}_{10}(\mathrm{t})$ data, denoted $\mathrm{f}_{\text {nat-dom-noise }}$ $\approx 45 \mathrm{~Hz}$ (as well as in other upstream pressure transducer data whose FFT is not reported here), but for the pulsatile imposition of $f_{P L} \cong f_{P V}=5 \mathrm{~Hz}$, the externally imposed frequency of greater energy dominates bubble-departure frequencies in Fig. 4.10.

The other important result in Table 4.5 is that, relative to the steady case, the local and average heat-fluxes $\left(\mathrm{q}_{\mathrm{w}-40 \mathrm{~cm}}^{\prime \prime}\right.$ and $\overline{\mathrm{q}_{\mathrm{w}}^{\prime \prime}}$ respectively) for the pulsatile steady-in-the-mean cases, respectively showed enhancement levels of only $10.7 \%$ and $14.2 \%$. These cases involved liquid and vapor pulsators (mid-level) operating at $f_{P L} \cong f_{P V}=5 \mathrm{~Hz}$. Even with increasing vapor pulsation amplitudes for this case (not reported/discussed here), local heat-flux enhancement levels were nowhere near $200-400 \%$ observed for the cases in Fig. 4.5a and Fig. 4.5c. As verified later on by additional data, it is conjectured that this anomaly in local heat-flux enhancement levels is largely due to whether local film thickness at the heat-flux measurements locations are thick or thin enough - relative to the amplitude of interfacial standing-waves (see Fig. 4.4) - to allow the "wave troughs" to come close enough (within tens of micrometers) to the wetting boiling-surface so the waves can also, besides micro-convection related enhancements of $15-30 \%$, beneficially impact the bubble ebullition mechanisms associated with the micro-scale sized nucleating bubbles.

After the results in Fig. 4.5d and Figs. 4.7-4.10 and Table 4.5 were obtained (around October 2016), the original (and expensive) dynamic heat-flux sensor failed (broke down). Subsequent results were obtained, after replacing the dynamic heat-flux sensor, by a low DAQ heat-flux sensor only good for measuring steady values and, also, after making the 
differential pressure-transducer (measuring $\Delta \mathrm{p}_{\mid 10-40}$ ) measurements functional and reliable.

More systematic experimental study of the steady-in-the-mean enhanced annular flowboiling

This set of experimental runs investigate enhancement levels and energy efficiencies that are associated with different approaches for introducing pulsations (i.e. different amplitudes and frequencies for pulsations introduced at the inlet: in the liquid alone, in the vapor alone, or in both the liquid and the vapor flows) towards achieving different steadyin-the-mean enhanced annular flows relative to a "fixed" representative steady annular flow realization. First a representative set of inlet liquid and vapor mass flow rates $\dot{\mathrm{M}}_{\mathrm{L} \text {-in }} \cong$ $1.09 \mathrm{~kg} / \mathrm{s}$ and $\dot{\mathrm{M}}_{\mathrm{V} \text {-in }} \cong 0.84 \mathrm{~kg} / \mathrm{s}$ are approximately held fixed for steady and pulsatile flows in Table 4.6. This is achieved by the control strategies described in section 3 . The inlet pressure is also approximately held fixed. Representative values of these variables are indicated in Table 4.6. Control of reverse thermoelectric heaters ensures, as before, that the "method of heating" $\theta_{\mathrm{w}}(\mathrm{x})$ is being held approximately fixed, as shown in Fig. 4. 11. 


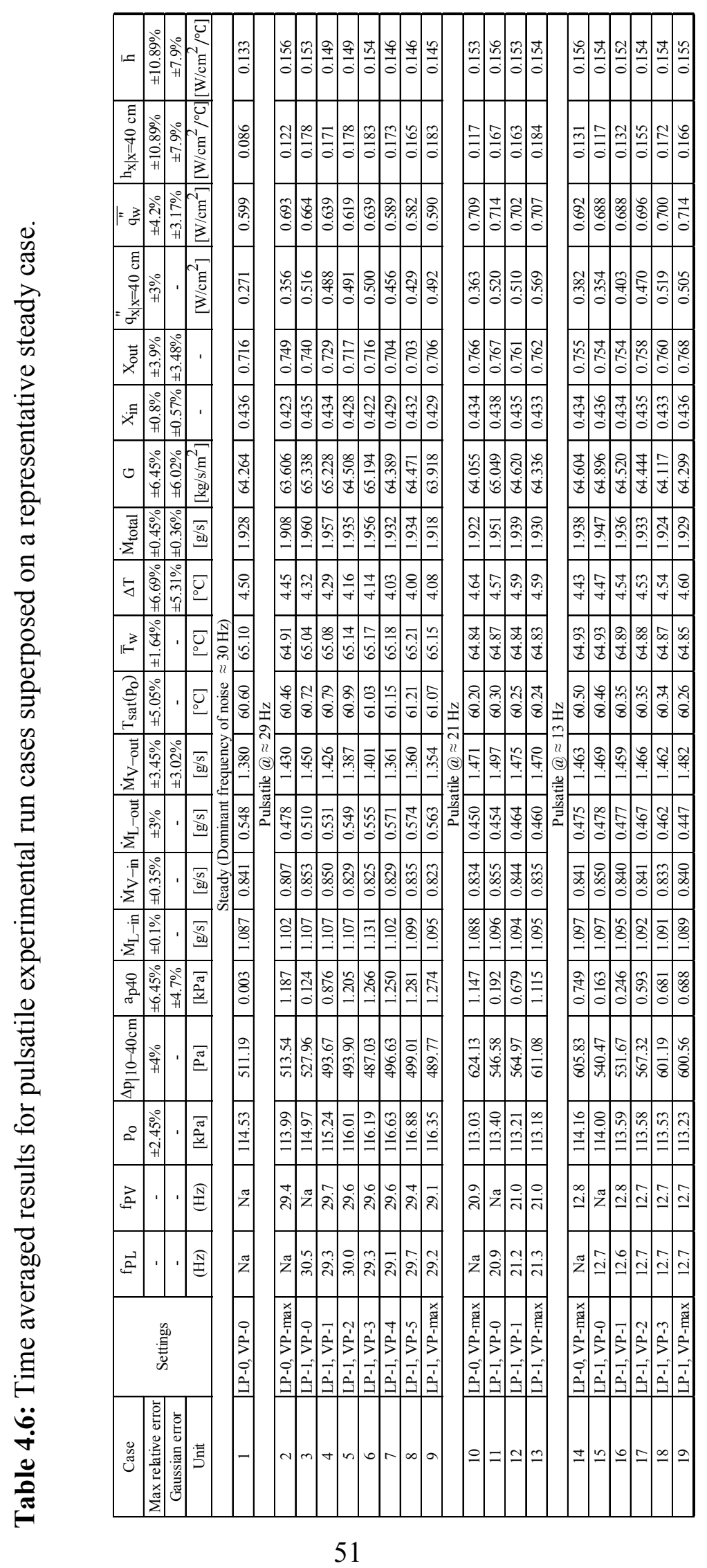




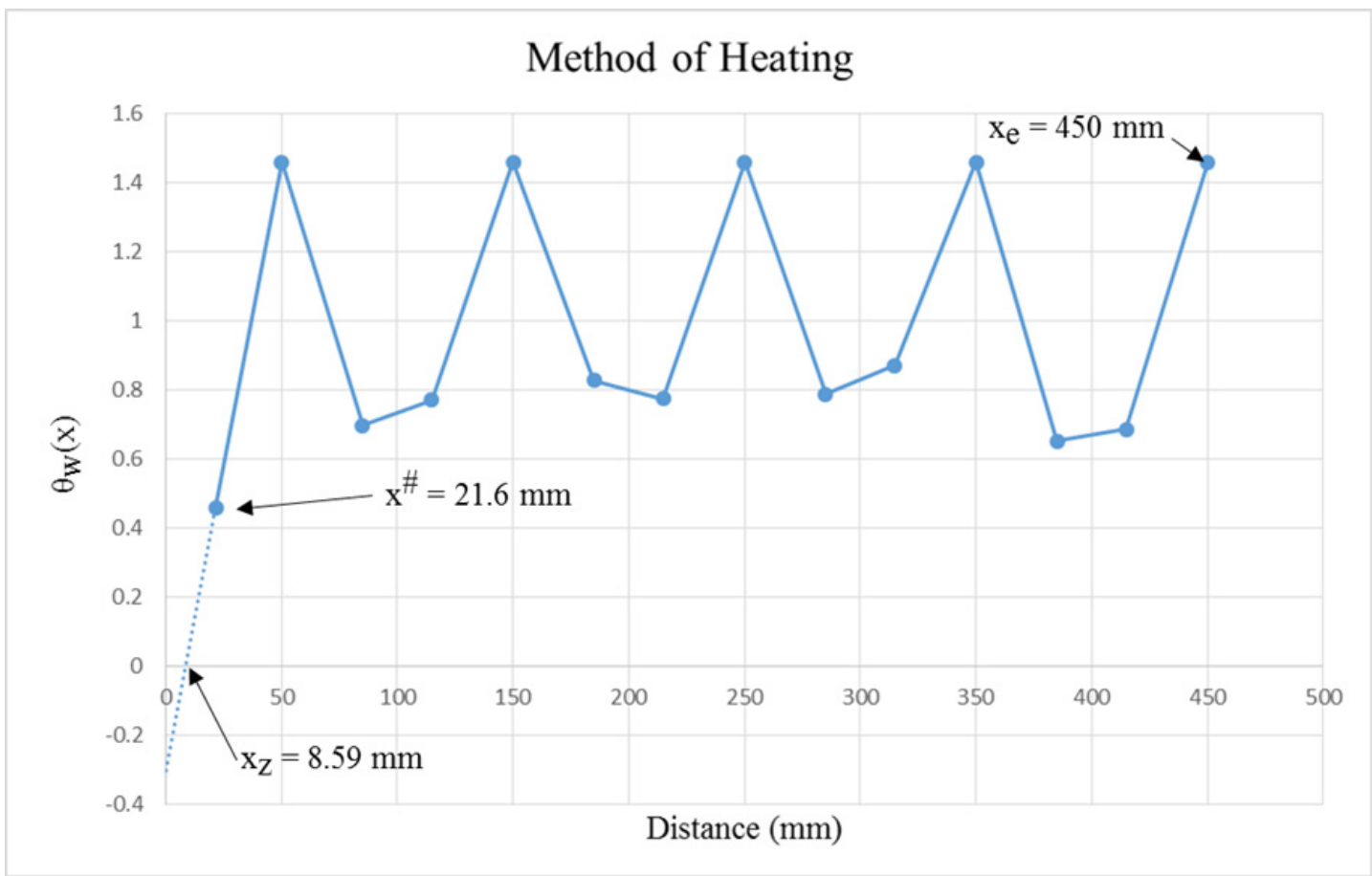

Figure 4.11: Non dimensional wall temperature profile $\theta_{w}(x), 0<x^{\#} \leq x \leq x_{e}<L$, for the two runs in Table 4.6.

The amplitude of liquid pulsations are controlled by the power settings of the liquid pulsator in Fig. 3.2. The amplitude of vapor pulsations is controlled by the vapor pulsator's power settings along with the degree of opening of valve $\mathrm{P}_{\mathrm{V}}$ shown in Fig. 3.2. Experimental runs in Table 4.6 employed the liquid pulsator in only two modes - it was either "off" (denoted as LP-0 in the "Settings" column of Table 4.6) or "on" at a fixed power setting (denoted as LP-1 in the "Settings" column of Table 4.6). With regard to vapor pulsations, in Table 4.6, the vapor pulsator was either "off" (denoted as VP-0) or was "on" with increasing opening levels - up to "fully open" for the ball valve $V_{P}$ in Fig. 3.2 (denoted as VP-1, VP-2, ... up to VP-max). As indicated in Table 4.6, for the steady run shown as case 1 , three different sets of pulsatile data were obtained that corresponded to $\mathrm{fL}_{\mathrm{PL}} \cong 29 \mathrm{~Hz}, \mathrm{f}_{\mathrm{PL}} \cong 23 \mathrm{~Hz}$, and $\mathrm{f}_{\mathrm{PL}} \cong 13 \mathrm{~Hz}$. A quantitative measure of the pulsations' amplitudes were obtained by looking at several time records of the absolute pressure $\mathrm{p}_{40}(\mathrm{t})$ $\equiv \mathrm{p}_{10}(\mathrm{t})-\left\{\mathrm{p}_{10}(\mathrm{t})-\mathrm{p}_{40}(\mathrm{t})\right\}$, obtaining their FFT and using the mean peak amplitude at $\mathrm{f}=$ 
$f_{P L}$, denoted as $a_{p-40}\left(f_{P L}\right)$, as representative of the amplitude of the pulsations relevant to the characterization of heat-flux measurement $\mathrm{q}_{\mathrm{w}-40 \mathrm{~cm}}^{\prime \prime}$.

Table 4.6 also shows the local (at $\mathrm{x}=40 \mathrm{~cm}$ ) and length-averaged steady-in-the-mean heat-

flux values of $\mathrm{q}_{\mathrm{w}-40 \mathrm{~cm}}^{\prime \prime}$ and $\overline{\mathrm{q}_{\mathrm{w}}^{\prime \prime}}$. In addition, the local and length-averaged HTC values of $\mathrm{h}_{\mathrm{x}}$ and $\overline{\mathrm{h}}$ are also reported for steady and enhanced annular realizations.

\subsubsection{Discussions for the Pulsatile Steady-in-the-Mean Annular Flow Results}

The FFT of $\mathrm{p}_{10}(\mathrm{t})$ and $\mathrm{p}_{40}(\mathrm{t})$ data associated with steady (negligible imposed pulsations) case in row-1 of Table 4.6 shows prominent presence of energy at 30, 45, and $60 \mathrm{~Hz}$. Since the dynamic heat-flux sensor was not available, as for the earlier considerations of cases involving $\mathrm{f}_{\text {nat-dom-noise }} \approx 45 \mathrm{~Hz}$ in Figs. $4.8-4.10$, it is conjectured that $\mathrm{fPL}_{\mathrm{PL}} \approx 30 \mathrm{~Hz}$ is associated with $\mathrm{f}_{\text {nat-dom-noise }} \approx 30 \mathrm{~Hz}$ for case 1 in Table 4.6. Additional dynamic pressure measurements' FFT results also support this conclusion.

The first thing to observe in Table 4.6 is that "liquid only pulsation" cases, i.e. cases (LP1, VP-0) in the "Settings" column of Table 4.6, required minimum energy input from the liquid pulsator (with respect to larger energy inputs coming from vapor pulsator in Fig. 3.2) and showed enhancement levels - relative to the steady case 1 - for local heat-flux $\mathrm{q}_{\mathrm{w}-40 \mathrm{~cm}}^{\prime \prime}$ that are, respectively, $123 \%$ for $\mathrm{f}_{\mathrm{PL}} \approx 29 \mathrm{~Hz}, 92.5 \%$ for $\mathrm{f}_{\mathrm{PL}} \approx 21 \mathrm{~Hz}$, and $35 \%$ for $\mathrm{f}_{\mathrm{PL}} \approx 13 \mathrm{~Hz}$. As was the case for high local heat-flux enhancement levels observed in Fig. $4.5 \mathrm{c}$, unlike the one in Fig. $4.5 \mathrm{~d}$, such high enhancements are likely due to the fact that the local film thickness at the heat-flux measurements locations are thin enough (see " $\mathrm{x}_{2}$ " locations in Fig. 4.4) - relative to the amplitude of interfacial standing-waves - to allow the "wave troughs" to come close enough to the wetting boiling-surface so the waves can beneficially impact the bubble ebullition mechanisms associated with the micro-scale sized nucleating bubbles. 
However, for the same (LP-1, VP-0) cases in the "Settings" column of Table 4.6, with the "method of heating" $\theta_{\mathrm{w}}(\mathrm{x})$ as shown in Fig. 4.11, the average heat-flux $\overline{\mathrm{q}_{\mathrm{w}}}$ values showed, respectively, enhancement levels of only $10.6 \%$ for $\mathrm{f}_{\mathrm{PL}} \approx 29 \mathrm{~Hz}, 19 \%$ for $\mathrm{f}_{\mathrm{PL}} \approx 21 \mathrm{~Hz}$, and $14.6 \%$ for $\mathrm{f}_{\mathrm{PL}} \approx 13 \mathrm{~Hz}$. These lower enhancements of average heat-flux, as discussed for the case in Fig. 4.5d, are likely due to the fact that most of the enhanced annular flowboiling regions correspond to higher film thickness " $\mathrm{x}_{1}$ " locations indicated in Fig. 4.4. Furthermore, when the "wave troughs" are far enough from the boiling-surface, it is likely that not only they cannot beneficially impact the micro-scale bubbles' ebullition mechanisms, much of the pulsatile energy at the inlet of the liquid is transferred towards the interface and goes into generating large amplitude interfacial waves and enhanced interfacial shear. This is what happens in thicker liquid pulsatile annular flow-condensation as well, where enhancement levels of $\overline{\mathrm{q}_{\mathrm{W}}^{\prime \prime}}$ are $10-30 \%$, consistent with similar enhanced interfacial shear cases of thicker wavy film flow-boiling.

Another key observation in Table 4.6 is that when liquid flow rate pulsations are fixed at LP-1 level, and vapor pulsations of maximum amplitude are superimposed, i.e. (LP-1, VPmax) cases in Table 4.6, and a lot of extra pulsatile energy is used to supplement liquid pulsations (through interfacial waves associated enhanced interfacial shear energies), the gains in average heat-flux $\overline{\mathrm{q}_{\mathrm{W}}^{\prime \prime}}$ are minimal with increasing pulsation amplitudes $\mathrm{a}_{\mathrm{p} 40}\left(\mathrm{f}_{\mathrm{PL}}\right)$. Some gains are limited to pulsation frequencies being off-resonant with respect to the dominant noise frequency (e.g., imposed $\mathrm{f}_{\mathrm{PL}} \cong \mathrm{f}_{\mathrm{PV}} \cong 13 \mathrm{~Hz}$ being away from $\mathrm{f}_{\text {nat-dom-noise }} \approx$ $30 \mathrm{~Hz}$ ). For these cases, Table 4.6 reports average heat-flux $\overline{\mathrm{q}_{\mathrm{w}}^{\prime \prime}}$ enhancement levels of: $1.6 \%$ for $\mathrm{f}_{\mathrm{PL}} \approx 29 \mathrm{~Hz}, 18.3 \%$ for $\mathrm{f}_{\mathrm{PL}} \approx 21 \mathrm{~Hz}$, and $19 \%$ for $\mathrm{f}_{\mathrm{PL}} \approx 13 \mathrm{~Hz}$. These indicate that the extra micro-convection assisting vapor pulsations do not significantly help in comparison to the liquid only pulsation cases of (LP-1, VP-0) unless imposed pulsation frequencies are significantly off from $\mathrm{f}_{\text {nat-dom-noise }}$ and one is interested in local heat-flux enhancements at thin $\mathrm{x}_{2}$ locations in Fig. 4.4. For such cases, Table 4.6 reports local heatflux $\mathrm{q}_{\mathrm{w}-40 \mathrm{~cm}}$ enhancement levels of $81.4 \%$ for $\mathrm{f}_{\mathrm{PL}} \approx 29 \mathrm{~Hz}, 110 \%$ for $\mathrm{f}_{\mathrm{PL}} \approx 21 \mathrm{~Hz}$, and 85 $\%$ for $\mathrm{f}_{\mathrm{PL}} \approx 13 \mathrm{~Hz}$. These trends cannot be consistently predicted in terms of thickness 
levels under the troughs - which are not known. But the fact that the enhancement levels are large are suggestive of the fact that the heat-flux sensor locations for these measurements correspond to thin " $\mathrm{x}_{2}$ " locations indicated in Fig. 4.4.

Table 4.6 results also suggest that monotonic increase in $\mathrm{q}_{\mathrm{w}-40 \mathrm{~cm}}^{\prime \prime}$ values with pulsation amplitude $\mathrm{a}_{\mathrm{p} 40}\left(\mathrm{f}_{\mathrm{PL}}\right)$, as seen in Fig. $4.5 \mathrm{a}$ with respect to pulsation amplitude $\mathrm{a}_{\mathrm{p} 10}\left(\mathrm{f}_{\mathrm{PL}}\right)$, occur only for "significantly" off-resonant case of $\mathrm{f}_{\mathrm{PL}} \approx 13 \mathrm{~Hz}$ relative to $\mathrm{f}_{\text {nat-dom-noise }} \approx 30 \mathrm{~Hz}$. For this, consider cases 16-19 in Table 4.6. For these cases increase in $\mathrm{q}_{\mathrm{w}-40 \mathrm{~cm}}^{\prime \prime}$ is associated with increase in pulsation amplitude $\mathrm{a}_{\mathrm{p} 40}\left(\mathrm{fPL}_{\mathrm{PL}}\right)$.

All the above results suggest that local heat-flux $\mathrm{q}_{\mathrm{w}-40 \mathrm{~cm}}^{\prime \prime}$ enhancements come from thin enough " $x_{2}$ " locations in Fig. 4.4 - and whether one is close to or off the $\mathrm{f}_{\text {nat-dom-noise }} \approx 30$ $\mathrm{Hz}$ frequency, the most energy efficient strategy for local heat-flux enhancements is liquid only pulsations corresponding to (LP-1, VP-0) cases in the "Settings" column of Table 4.6 - this is perhaps true for an arrangement where liquid pulsators energy could be gradually increased from LP-1 levels. Such an arrangement, however, were not available for the reported experiments due to certain hardware limitations (associated with cavitation and structural vibrations of the flow-loop) associated with increasing liquid pulsator amplitudes in Fig. 3.2.

The fact that " $x_{1}$ " locations in Fig. 4.4 do not allow sufficient local heat-flux enhancements due to pulsations not reaching the boiling-surface (where nucleation occurs) also has to do with the introduced energy of pulsations more easily escaping through interfacial waves on to the vapor flow.

The above understanding and conclusions have helped Dr. Narain and his team to come up with superior ways of controlling micro-scale nucleation that are likely to yield large enhancements for both local $\mathrm{q}_{\mathrm{w}}^{\prime \prime}(\mathrm{x})$ and average $\overline{\mathrm{q}_{\mathrm{w}}^{\prime \prime}}$ levels. 


\section{Experiments Enabled Modeling and Simulations that Yield Heat-Transfer Correlations and Assess Role of Micro-nucleation for Steady Annular Flow-boiling}

This main contributions of this thesis are in section 4. However, this section presents results from Dr. Narain's modeling/simulations group [40] which is enabled by results and discussion in section 4 . The steady annular experimental data reported in section 4 has three uses that are listed below.

(i) It enables scientific estimates of the role and significance of micro-nucleation in the experimentally measured values of heat transfer rates associated with steady annular flow-boiling.

(ii) It enables, in conjunction with other existing experimental data, a more reliable development of local HTC correlation that is specific to flow-regime (annular in this case) and parameter ranges. The approach can be easily generalized to cover other parameter ranges (e.g. those that are being obtained from our ongoing experiments - with water as a working fluid and moderate to high heatflux heating).

(iii) The steady annular HTC correlations in (ii) above are also essential to the development of correlations for the enhanced steady-in-the-mean annular flowboiling (as discussed for pulsatile cases in section 4.2). The local HTC, as experimentally measured, for the enhanced annular flow-boiling when written as $\mathrm{h}_{\mathrm{x} \mid \text { Expt-enhanced }}$ is best correlated as $\mathrm{h}_{\mathrm{x} \mid \text { Expt-enhanced }} \equiv \mathrm{h}_{\mathrm{x} \mid \text { Expt-st }}+$ $\Delta \mathrm{h}_{\mathrm{x} \mid \text { enhanced }}$ where $\mathrm{h}_{\mathrm{x} \mid \text { Expt-st }}$ is obtained from steady annular empirical HTC correlations in (ii) above and $\Delta \mathrm{h}_{\mathrm{x} \mid \text { enhanced }}$ is related to the enhancements observed for the steady-in-the-mean cases (as in section 4.2).

Of the three uses above, the first two are briefly described here for completeness - as it is part of an extended work [40] that is enabled by this thesis. Correlation development for 
$\mathrm{h}_{\mathrm{x} \mid \text { Expt-enhanced }}$ is not undertaken by the modeling/simulations group until a new set of data is obtained by a superior enhancement approach.

\subsection{Role of Micro-nucleation}

Experimental estimates of local (at $\mathrm{x}=40 \mathrm{~cm}$ ) $\mathrm{HTC} \mathrm{h}_{\mathrm{x} \mid \mathrm{x}=40 \mathrm{~cm}}$ are available in Tables 4.2 and 4.4. These tables are respectively associated with runs in Tables 4.1 and 4.3 with "method of heating" specified in Figs. 4.2 and 4.3. The question is how does one estimate the role and significance of micro-nucleation in the heat-transfer process - or, in other words, what percentage of the experimentally measured values of $h_{x \mid x}=40 \mathrm{~cm}$ are affected by micro-nucleation phenomena?

In this section, we limit our considerations to the local $H T C h_{x \mid x}=40 \mathrm{~cm}$ values available in Table 4.2 - and associated with run cases 1-8. This is because these runs correspond to steady annular realizations where the liquid flow is laminar and the vapor flow is sufficiently laminar near the interface though core vapor flows could be turbulent provided one is restricted to the parameter-space specified by Eq. (4.7) (which means, approximately, $\operatorname{Re}_{\mathrm{V} \text {-in }} \leq 20780$ and $\mathrm{Re}_{\mathrm{V} \text {-out }} \leq 31000$ ).

The local (at $\mathrm{x}=40 \mathrm{~cm}$ ) and average heat-flux measurements, $\mathrm{q}_{\mathrm{w}-40 \mathrm{~cm}}$ and $\overline{\mathrm{q}_{\mathrm{w}}^{\prime \prime}}$, respectively, in Table 4.1 tell a consistent story. For these temperature-controlled boiling experiments, average heat-flux (over the $50 \mathrm{~cm}$ length of the channel) is much higher than the measured local heat-flux. This is because micro-nucleation is more significant at upstream locations and it gradually diminishes over the length of the channel. In addition, nucleate boiling mechanisms transfer (significantly) more heat than thin-film convection (without nucleation) mechanisms. This fact has also been experimentally confirmed, with visualization, in an earlier heat-flux controlled flow-boiling experiments [34].

What is unique about this experimental data set in Tables 4.1-4.2 is that - together with results from a rigorous modeling and CFD simulation (to be described) - it allows a feasible "decomposition method" for experimentally measured local heat-flux (at $\mathrm{x}=40 \mathrm{~cm}$ ) 
values, $\mathrm{q}_{\mathrm{w}-40 \mathrm{~cm}}^{\prime \prime} \equiv \mathrm{h}_{\mathrm{x}-40 \mid \text { Expt-st }} \cdot\left(\mathrm{T}_{\mathrm{w}}(\mathrm{x})-\mathrm{T}_{\mathrm{sat}}\left(\mathrm{p}_{\text {in }}\right)\right)$, into convective and micro-scale nucleate boiling parts. This is done by defining the convective contribution to local heatflux to be the one associated with a hypothetical realization under suppressed nucleation assumptions. Figures 5.1 and 5.2 below show, respectively, an actual experimental and a hypothetical suppressed nucleation realization.

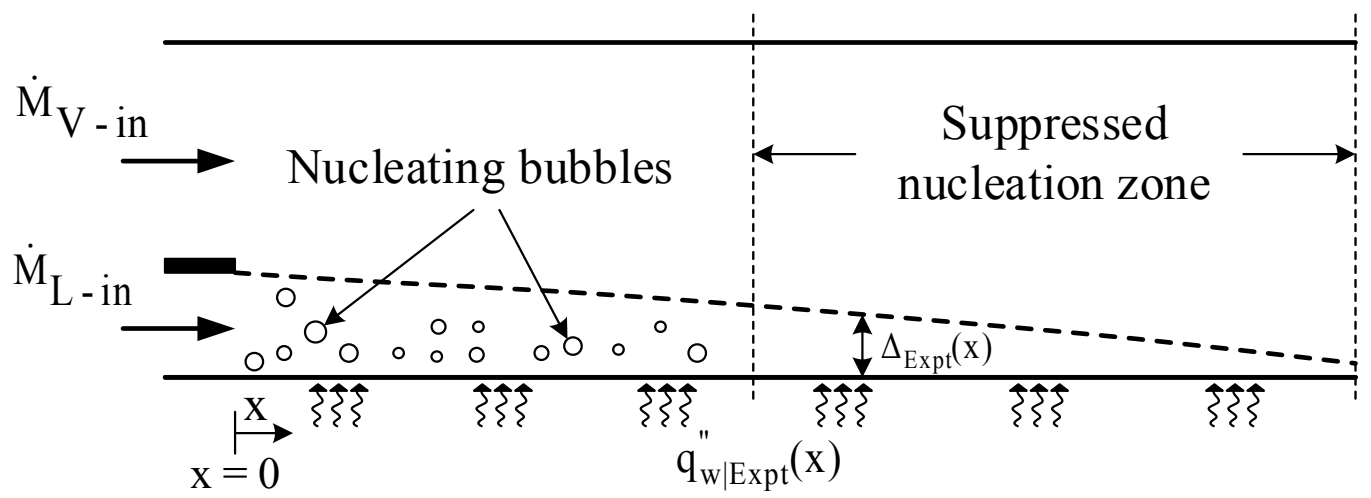

Figure 5.1: An actual experimental realization with known/measured values of $\dot{\mathrm{M}}_{\mathrm{L}-\mathrm{in}}$, $\dot{\mathrm{M}}_{\mathrm{V}-\mathrm{in}}$, wall temperature variation $\mathrm{T}_{\mathrm{w}}(\mathrm{x})$, and some values of $\left.\mathrm{q}_{\mathrm{w}}(\mathrm{x})\right|_{\text {Expt }}$.

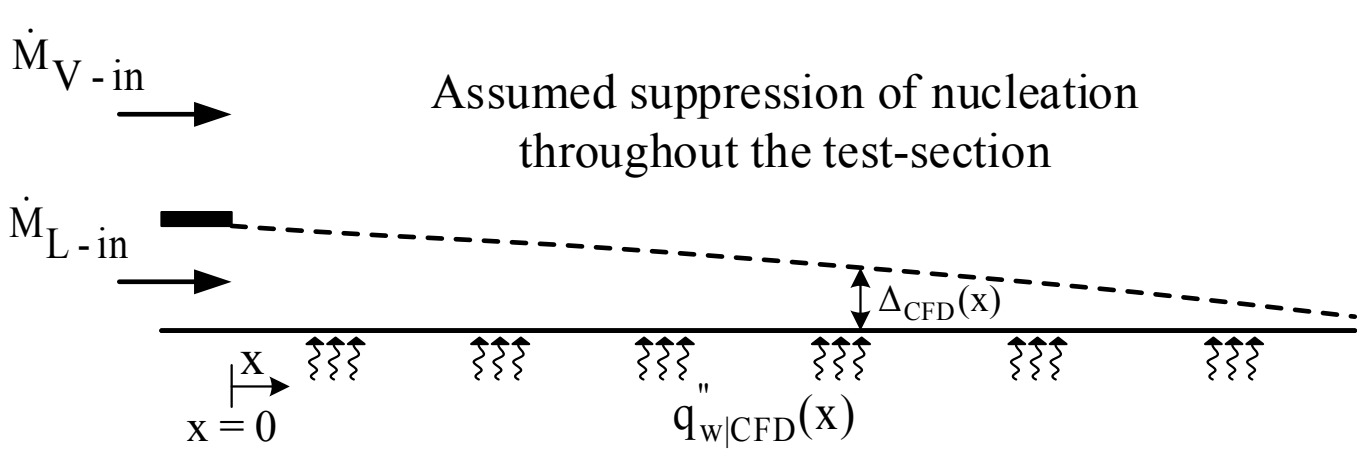

Figure 5.2: A hypothetical flow realization obtained by a rigorous CFD which employs experimental values (as in Fig. 5.1) of $\dot{\mathrm{M}}_{\mathrm{L}-\mathrm{in}}, \dot{\mathrm{M}}_{\mathrm{V}-\mathrm{in}}$, etc. as inlet condition and experimental values of wall temperature variation $\mathrm{T}_{\mathrm{w}}(\mathrm{x})$ as thermal boundary condition. CFD predicts wall heat-flux $q_{w \mid C F D}(x)$, etc. which are typically different (because micronucleation phenomena is not modeled) than corresponding values in Fig. 5.1. 
The CFD-based estimates of convective heat-flux $\mathrm{q}_{\mathrm{w} \mid \mathrm{CFD}}^{\prime \prime}(\mathrm{x}) \equiv \mathrm{h}_{\mathrm{x} \mid \mathrm{cb}-\mathrm{CFD}} \cdot \Delta \mathrm{T}(\mathrm{x})$ and associated local values of convective $\mathrm{HTC} \mathrm{h}_{\mathrm{x} \mid \mathrm{cb}-\mathrm{CFD}}$ are reliable as the only missing physics in the simulations (see [41] and Fig. 5.3 below) are the phenomena of nucleation (rather micro-scale invisible nucleation in experiments involving liquid film thicknesses in the 300 $-50 \mu \mathrm{m}$ range).

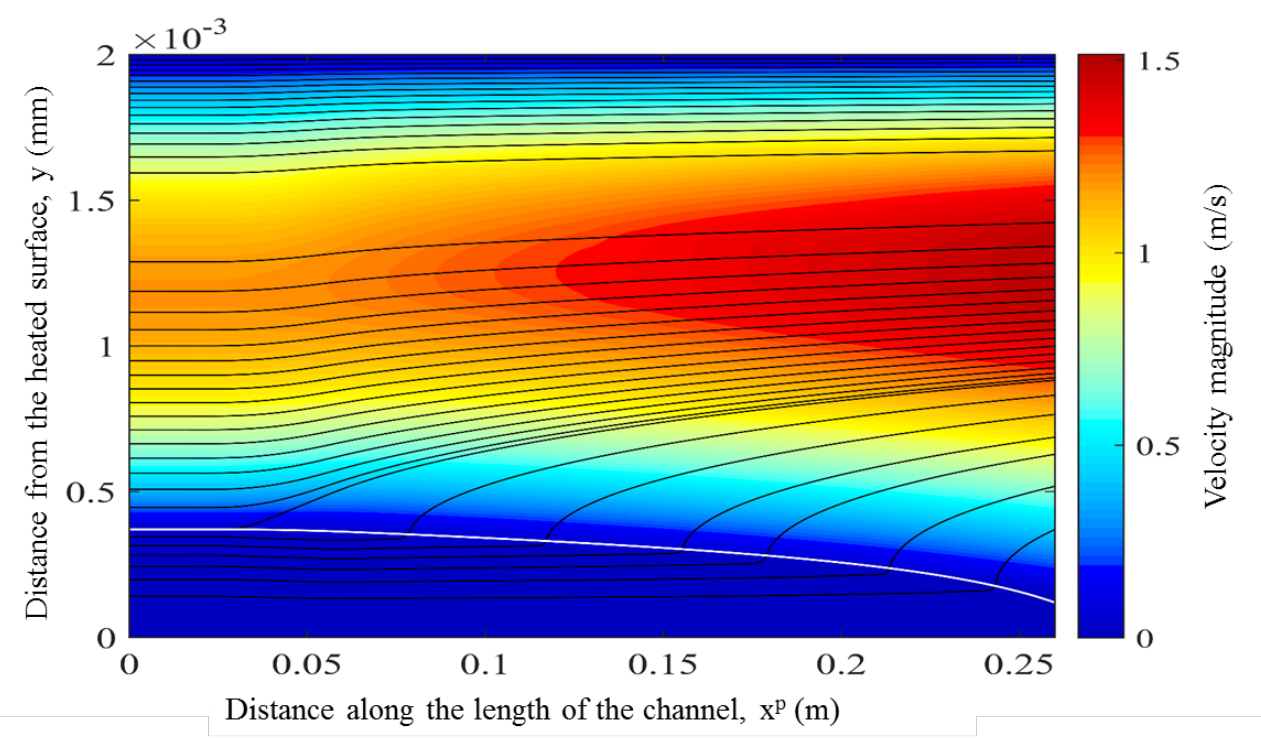

Figure 5.3: A representative and rigorous CFD simulation (that models all flow-physics quite accurately, except for nucleating bubbles) result [41] showing the streamlines for steady annular suppressed nucleation flow-boiling. [Reproduction of the figure was granted from Springer International Publishing, see Appendix C].

It is proposed [40] that the easiest feasible decomposition of the measured values of $\left.\mathrm{q}_{\mathrm{w}}^{\prime \prime}(\mathrm{x})\right|_{\text {Expt }}$ is to acknowledge that the difference between the much larger $\left.\mathrm{q}_{\mathrm{w}}^{\prime \prime}(\mathrm{x})\right|_{\text {Expt }}$ in Fig. 5.1 and the associated $\mathrm{q}_{\mathrm{w} \mid \mathrm{CFD}}(\mathrm{x})$ in Fig. 5.2 is due to micro-nucleation. That is,

$$
\begin{aligned}
\mathrm{q}_{\mathrm{w} \mid \mu \mathrm{nb}}^{\prime \prime}(\mathrm{x}) & \equiv \mathrm{q}_{\mathrm{w} \mid \operatorname{Expt}}^{\prime \prime}(\mathrm{x})-\mathrm{q}_{\mathrm{w} \mid \mathrm{CFD}}^{\prime \prime}(\mathrm{x}) \\
\mathrm{h}_{\mathrm{x} \mid \mu \mathrm{nb}} & \equiv \mathrm{h}_{\mathrm{x} \mid \operatorname{Expt}}-\mathrm{h}_{\mathrm{x} \mid \mathrm{cb}-\mathrm{CFD}}
\end{aligned}
$$


Use of Eq. (5.1) in Table 4.2 yields the calculated results for $\% \mu \mathrm{nb}-\mathrm{CFD} \equiv$ $\mathrm{h}_{\mathrm{x} \mid \mathrm{nnb}} / \mathrm{h}_{\mathrm{x} \mid \text { Expt }} * 100$ at the $\mathrm{x}=40 \mathrm{~cm}$ location. Table 4.2 shows that micro-nucleation heattransfer is dominant, some $80-90 \%$ of the total heat-flux at a representative location is due to this phenomena. The above decomposition defines micro-nucleation HTC differently than the ones which consider convection effects on the nucleating bubbles as part of the convective heat-transfer component. However, the proposed decomposition is both more feasible and more reliable (recall that experiments agree with CFD over suppressed nucleation zones, if they actually exist in a particular realization [34]). Also, the same CFD approach for annular condensation $[11,12]$ agree with known experiments (see [42]).

Though for some cases, CFD is directly used to obtain $h_{x \mid \mu n b}$ through Eq. (5.1), the approach mostly followed here is to obtain $\mathrm{h}_{\mathrm{x} \mid \mathrm{cb}-\mathrm{CFD}}$ in Eq. (5.1) from the CFD-based $\mathrm{Nu}_{\mathrm{x}}$ correlation given in [41]. This is because the parameter space in Eq. (4.7) satisfies the criteria for use of $\mathrm{Nu}_{\mathrm{x}}$ correlation in [41]. This correlation is used here first to calculate the quality $\mathrm{X}(\mathrm{x})$ variations - as per procedure given in [13] - and then to compute $\mathrm{h}_{\mathrm{x} \mid \mathrm{cb}-\mathrm{CFD}}$ values. A sample $\mathrm{X}(\mathrm{x})$ calculation for case 3 in Tables 4.1-4.2 with "method of heating" $\theta_{\mathrm{w}}(\mathrm{x})$ as in Fig. 4.2 is shown in Fig. 5.4. The caption of Fig. 5.4 gives the $\mathrm{X}(\mathrm{x})$ value at $\mathrm{x}$ $=40 \mathrm{~cm}$ which is used in $\mathrm{Nu}_{\mathrm{x}}$ correlation in [41] to obtain $\mathrm{h}_{\mathrm{x} \mid \mathrm{cb}-\mathrm{CFD}}$ and how, together with Table 4.2 and Eq. (5.1), one obtains "\% $\%$ nb-CFD." 


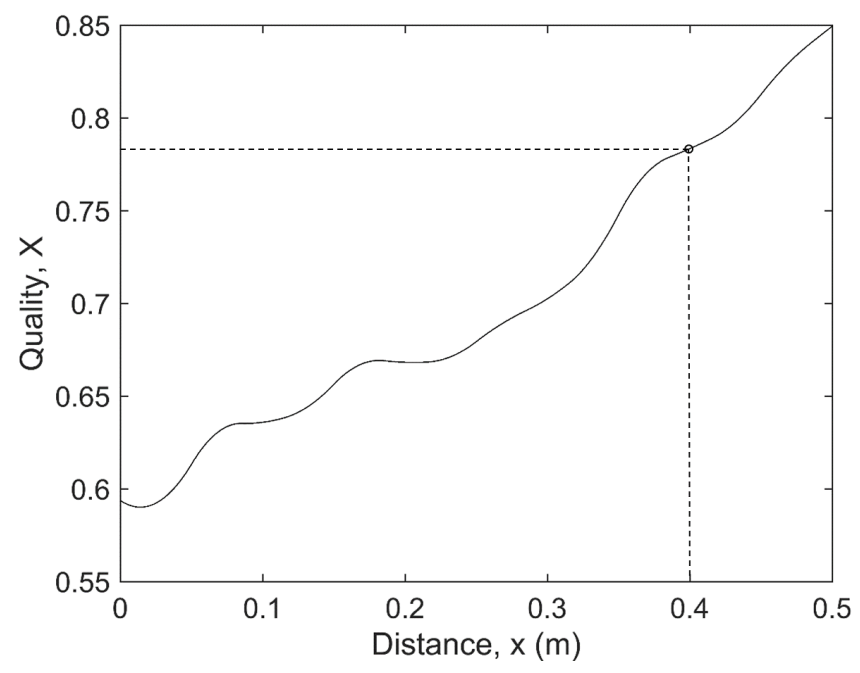

(a)

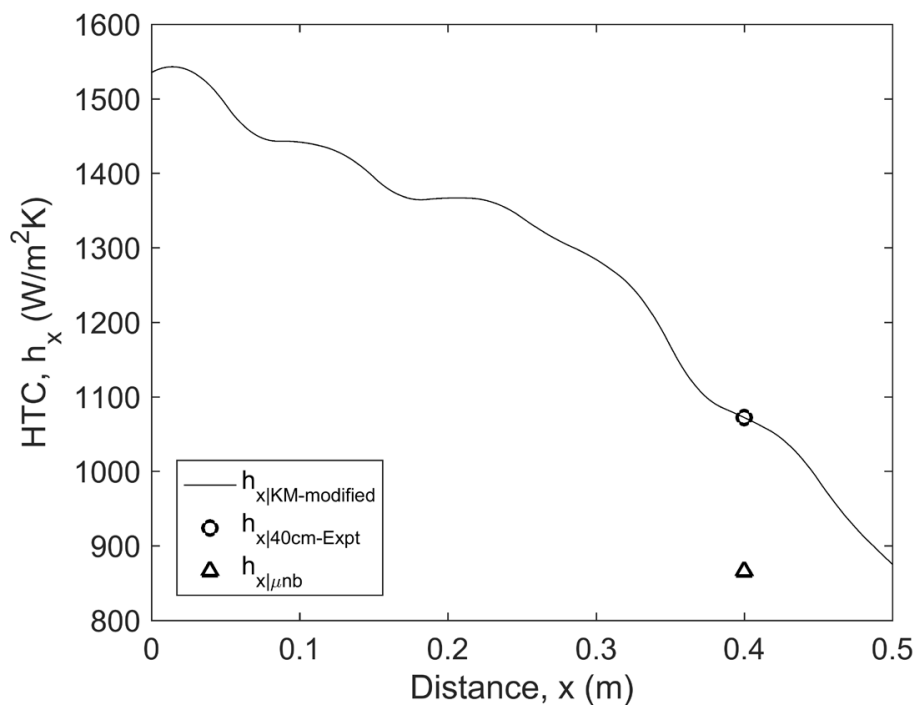

(b)

Figure 5.4: (a) A representative $X(x)$ calculation for case 3 in Tables 4.1-4.2 is shown. Here $X(x=40 \mathrm{~cm})=0.783$ in $\mathrm{Nu}_{\mathrm{x}}$ correlation in [41] yields $\mathrm{h}_{\mathrm{x} \mid \mathrm{cb}-\mathrm{CFD}}=206.1 \mathrm{~W} /\left(\mathrm{m}^{2}-\mathrm{K}\right)$. (b) The figure shows a graphical comparison between $\mathrm{h}_{\mathrm{x} \mid \text { Expt }}=1072.6 \mathrm{~W} /\left(\mathrm{m}^{2}-\mathrm{K}\right)$ in Table 4.2, and $\mathrm{h}_{\mathrm{x} \mid \mu \mathrm{nb}}=866.5 \mathrm{~W} /\left(\mathrm{m}^{2}-\mathrm{K}\right)$ (calculated from Eq. (5.1)). The corresponding $\% \mu \mathrm{nb}-\mathrm{CFD}=80.8 \%$. 
The above described decomposition should not be confused with popularly available decompositions, as in [38], where ad hoc decompositions use the "nucleate boiling" term of the HTC correlation to relate to (or crudely model) upstream larger diameter "nucleate boiling" regimes in traditional flow-boiling (i.e., all liquid flow at the inlet), while relating the remaining term to "convective" dominant flow-regimes (which include annular flows of interest here) as discussed in [13]. This is the reason why Kim and Mudawar [38] correlations yield, in Table 4.2 , only $8-40 \%$ of the heat from their so-called "nucleate boiling" terms. The unfilled rows (with "TBC" entries) in Tables 4.2 and 4.4 make the case for further maturation of the proposed decomposition procedure by developing, as proposed, CFD-based flow-boiling simulations (under the hypothetical absence of nucleate boiling) that can be trusted to give good estimates for significantly turbulent vapor and laminar liquid annular flow-boiling regimes.

\subsection{Parameter-range Specific HTC Correlation for Steady Annular Flow-boiling}

As discussed in section 4.1.2.2, the results in Tables $4.1-4.4$ cover the parameter space in Eq. (4.9) and "methods of heating" in Figs. 4.2-4.3. The results specifically yield values of $\mathrm{h}_{\mathrm{x}-40 \mathrm{~cm}} \equiv \mathrm{q}_{\mathrm{w}-40 \mathrm{~cm}}^{\prime \prime} / \Delta \mathrm{T}(\mathrm{x})$ and $\overline{\mathrm{h}} \equiv \overline{\mathrm{q}_{\mathrm{w}}^{\prime \prime}} / \Delta \mathrm{T}$. These correspond to the known experimental values of $\left.\mathrm{Nu}_{\mathrm{x}}\right|_{\mathrm{x}}=40 \mathrm{~cm}-\mathrm{Expt}$ and $\overline{\mathrm{Nu}}_{\mathrm{L}} \equiv\left(\mathrm{D}_{\mathrm{h}} / \mathrm{L}\right) \cdot \int_{\hat{\mathrm{x}}=0}^{\hat{\mathrm{x}}=\mathrm{L} / \mathrm{D}_{\mathrm{h}}} \mathrm{Nu}_{\mathrm{x}} \cdot \theta_{\mathrm{w}}(\hat{\mathrm{x}}) \cdot \mathrm{d} \hat{\mathrm{x}}$. Thus any reasonably correct new $\mathrm{Nu}_{\mathrm{x}}$ correlation proposal, represented as $\mathrm{Nu}_{\mathrm{x} \text { |prop }}$, satisfying the fundamental physics and non-dimensionalization based structure given in [13] should also satisfy:

$$
\begin{gathered}
\mathrm{Nu}_{\mathrm{x} \mid \text { prop } \mathrm{x}}=40 \mathrm{~cm} \cong \mathrm{Nu}_{\mathrm{x} \mid \mathrm{x}}=40 \mathrm{~cm} \mid \mathrm{Expt}, \text { and } \\
\overline{\mathrm{Nu}}_{\mathrm{L} \mid \text { prop }} \cong \overline{\mathrm{Nu}}_{\mathrm{L} \mid \text { Expt }}
\end{gathered}
$$

It should be recalled from [13] that the fundamental physics and non-dimensionalization based structure for $\mathrm{Nu}_{\mathrm{x} \text { prop }}$ is given as:

$$
\mathrm{Nu}_{\mathrm{x}}=\mathrm{Nu}_{\mathrm{x}}\left(\mathrm{X}, \mathrm{X}_{\mathrm{in}}, \mathrm{Re}_{\text {total }}, \operatorname{Ja}, \mathrm{Pr}_{\mathrm{L}}, \frac{\rho_{\mathrm{V}}}{\rho_{\mathrm{L}}}, \frac{\mu_{\mathrm{V}}}{\mu_{\mathrm{L}}}, \mathrm{We},\left\{\mathrm{S}^{*}\right\}_{\text {non-dim }}\right)
$$


where, the parameters in the argument list of Eq. (5.3) has been defined earlier and in [13]. It is worthwhile to recall that $\left\{\mathrm{S}^{*}\right\}_{\text {non-dim }}$ represents relevant properties and other variables that characterize vapor-liquid-solid interactions at micro/nano-layers found near contactlines over the heated solid-surfaces and particularly those which, in turn, influence macroscopic behavior of nucleating bubbles (see, [19, 20,43] etc.). The list of such variables may include non-dimensional values of: contact-angles, surface-texture profile measures, liquid-vapor-solid interactions that relate to contact-angles and nucleation site density, surface chemistry, time-averaged local values of wall heat-flux (or wall temperature) that affect the growth, departure, and emission frequency of a representative bubble. The transient bubble dynamics (not necessarily the average nucleate boiling heattransfer coefficient $\mathrm{Nu}_{\mathrm{x}}$ ) is also affected by parameters that affect the thermal transients of the externally or internally heated solid, which forms the boiling-surface (these include the solid's density, specific heat, thermal conductivity, and characteristic thickness in the heat flow direction). For now, all correlations are sought for a given fixed set of solid-liquidvapor interactions (including boiling-surface texture) - and hence $\left\{\mathrm{S}^{*}\right\}_{\text {non-dim }}$ dependence in Eq. (5.3) will not be explicitly recognized.

The new proposed correlation is of the form as shown in Eqs. (5.4) - (5.7)

$$
\mathrm{h}_{\mathrm{x} \mid \text { prop }} \equiv \mathrm{h}_{\mathrm{x}}=\mathrm{h}_{\mathrm{x} \mid \mathrm{nb}}+\mathrm{h}_{\mathrm{x} \mid \mathrm{cb}}
$$

where,

$$
\mathrm{h}_{\mathrm{x} \mid \mathrm{nb}} \equiv\left\{[ \alpha ( \mathrm { Bl } \frac { \mathrm { P } _ { \mathrm { H } } } { \mathrm { P } _ { \mathrm { F } } } ) ^ { \gamma } \mathrm { P } _ { \mathrm { R } } ^ { 0 . 3 8 } ] \left(\begin{array}{c}
\left.0.023\left(\operatorname{Re}_{\mathrm{L}}-\mathrm{Re}^{*}\right)^{\beta} \operatorname{Pr}_{\mathrm{L}}^{0.4} \frac{\mathrm{k}_{\mathrm{L}}}{\mathrm{D}_{\mathrm{h}}}\right), \text { for } \mathrm{Re}_{\mathrm{L}}>\mathrm{Re}^{*} \\
0, \text { for } \mathrm{Re}_{\mathrm{L}} \leq \mathrm{Re}^{*}
\end{array}\right.\right.
$$

and

$$
\mathrm{h}_{\mathrm{x} \mid \mathrm{cb}} \equiv\left[5.2\left(\mathrm{Bl} \frac{\mathrm{P}_{\mathrm{H}}}{\mathrm{P}_{\mathrm{F}}}\right)^{0.1 \cdot \gamma+0.01} \mathrm{We}_{\mathrm{L} 0}^{-0.54}+3.5\left(\frac{1}{\widetilde{\mathrm{X}}_{\mathrm{tt}}}\right)^{0.94}\left(\frac{\rho_{\mathrm{V}}}{\rho_{\mathrm{L}}}\right)^{0.25}\right]\left(0.023 \operatorname{Re}_{\mathrm{L}}^{\beta} \operatorname{Pr}_{\mathrm{L}}^{0.4} \frac{\mathrm{k}_{\mathrm{L}}}{\mathrm{D}_{\mathrm{h}}}\right)
$$


The parameters in the above definitions of $h_{x}$ are:

$$
\begin{aligned}
\mathrm{Bl} \equiv \frac{\overline{\mathrm{q}}_{\mathrm{w}}^{\prime \prime}}{\mathrm{G} \cdot \mathrm{h}_{\mathrm{fg}}}, & \mathrm{P}_{\mathrm{R}}=\frac{\mathrm{p}_{\mathrm{o}}}{\mathrm{p}_{\mathrm{cr}}}, \quad \operatorname{Re}_{\mathrm{L}} \equiv \frac{\mathrm{G}(1-\mathrm{X}) \mathrm{D}_{\mathrm{h}}}{\mu_{\mathrm{L}}}, \operatorname{Re}_{\mathrm{L} 0} \equiv \frac{\mathrm{GD}_{\mathrm{h}}}{\mu_{\mathrm{l}}}, \operatorname{Pr}_{\mathrm{L}} \equiv \frac{\mu_{\mathrm{L}} \mathrm{C}_{\mathrm{p}, \mathrm{L}}}{\mathrm{k}_{\mathrm{L}}}, \\
\mathrm{We}_{\mathrm{L} 0} \equiv \frac{\mathrm{G}^{2} \mathrm{D}_{\mathrm{h}}}{\rho_{\mathrm{L}} \sigma}, & \widetilde{\mathrm{X}}_{\mathrm{tt}}=\left(\frac{\mu_{\mathrm{L}}}{\mu_{\mathrm{V}}}\right)^{0.1}\left(\frac{1-\mathrm{X}}{\mathrm{X}}\right)^{0.9}\left(\frac{\rho_{\mathrm{V}}}{\rho_{\mathrm{L}}}\right)^{0.5}
\end{aligned}
$$

where, $\mathrm{P}_{\mathrm{F}}$ is the wetted perimeter (in case a tube/channel is not wetted on all its periphery) and $\mathrm{P}_{\mathrm{H}}$ is the heated perimeter (and includes cases for which a tube/channel is not heated on all its periphery). This is also the perimeter where $q_{w}^{\prime \prime}(x)$ is replaced by $\overline{q_{w}^{\prime \prime}}$.

It can be seen that the proposed correlation has a structure similar to that of HTC correlation proposed by Kim and Mudawar [38]. This is partly because, besides satisfying the first relationship in Eq. (5.2), $\mathrm{h}_{\mathrm{x} \mid \text { prop }}$ (or $\mathrm{Nu}_{\mathrm{x} \mid \text { prop }}$ ) should also agree with experimental values obtained for several values of $\mathrm{x}=\mathrm{x}^{*}$ which are different than $\mathrm{x}=40 \mathrm{~cm}$, as long as $0<\mathrm{x}^{\#} \leq$ $\mathrm{x}^{*} \leq \mathrm{x}_{\mathrm{e}}<\mathrm{L}$. Since, such extensive experimental data is difficult from the current experimental setup, it is suggested that a correlation structure similar to that of the correlation proposed by Kim and Mudawar in [38] be used, since this correlation covers a very large data set which include the parameter space in Eq. (4.9) - i.e. horizontal millimeter-scale ducts with FC-72 as working fluids at comparable mass and heat-fluxes. Furthermore, Kim and Mudawar correlation $\mathrm{Nu}_{\mathrm{x} \mid \mathrm{KM}}$ in [38], despite employing different non-dimensional numbers as compared to the ones in Eq. (5.3), also approximately satisfies the structure in Eq. (5.3) (see Appendix of [40]). Since, the purpose of Kim and Mudawar correlations in [38] is different - which is to provide an "order of magnitude" estimate for flow-boiling covering a much larger set of flow-regimes and fluids (than just the parameter set in Eq. (4.9)) - it is required here that $\mathrm{Nu}_{\mathrm{x} \mid \text { prop }}$ approximately satisfy:

$$
\left.0.1 * \mathrm{Nu}_{\mathrm{x}}\right|_{\mathrm{KM}} \leq\left.\mathrm{Nu}_{\mathrm{x}}\right|_{\text {prop }} \leq\left. 3.0 * \mathrm{Nu}_{\mathrm{x}}\right|_{\mathrm{KM}}
$$

However, the new proposed correlation, while having a structure similar to the one proposed by Kim and Mudawar [38], also has some major differences. The differences are as follows: 
(i) The overall HTC has a "superposition" form instead of the power-law form in the original correlation by Kim and Mudawar - i.e., the nucleate and convective boiling terms are directly added instead of being combined through a powerlaw form (Eq. (5.4)). That is $n=1$ instead of the $n=2$ of [38] in the more general power law form discussed in [13].

(ii) The explicit dependence of nucleate boiling component of HTC $h_{x \mid n b}$ on quality, as given in the correlation by Kim and Mudawar [38], has been discarded since there is an implicit dependence through liquid Reynolds number $\operatorname{Re}_{\mathrm{L}}$ (defined in Eq. (5.7)).

(iii) A new term $\mathrm{Re}^{*}$ has been introduced in the correlation to model the known possibility of suppression of nucleation if the liquid film thickness or liquid Reynolds number goes below this threshold value of Re*. As given in Eq. (5.5), the nucleate boiling component of HTC $h_{x \mid n b}$ becomes zero below a certain $\mathrm{Re}^{*}$ and above a particular quality for a given operating condition. Note that $\mathrm{Re}^{*}$ is expected to be a function of liquid Reynolds number at the inlet $\operatorname{Re}_{\mathrm{L}, \mathrm{in}}$.

Besides a change in Eq. (5.4), the original parameters in [38] for the above definitions of $\mathrm{h}_{\mathrm{x} \mid \mathrm{cb}}$ and $\mathrm{h}_{\mathrm{x} \mid \mathrm{nb}}$ are: $\alpha=2345, \beta=0.8, \gamma=0.7$ and $\mathrm{Re}^{*}=0$. When an optimization procedure is used to satisfy Eqs. (5.2) and (5.4), say for case 2 in Table 4.2, one finds that $\alpha=2627, \beta=1, \gamma=0.575$ and $\operatorname{Re}^{*}=22.85=0.322 * \mathrm{Re}_{\mathrm{L}, \mathrm{in}}$. The resulting "fit" satisfies both the first and second equalities in Eq. (5.2) to within $1 \%$.

Fig. 5.5a, shows a comparison of quality variation (for case 2 in Table 4.2) along the length of the channel from the experiment, and as predicted by the new proposed correlation and the correlation proposed by Kim and Mudawar [38]. Fig. 5.5b shows the variation of Nusselt number values along the length of the channel, as predicted by the new proposed correlation and the correlation proposed by Kim and Mudawar [38], based on the quality variations presented in Fig. 5.5a. 


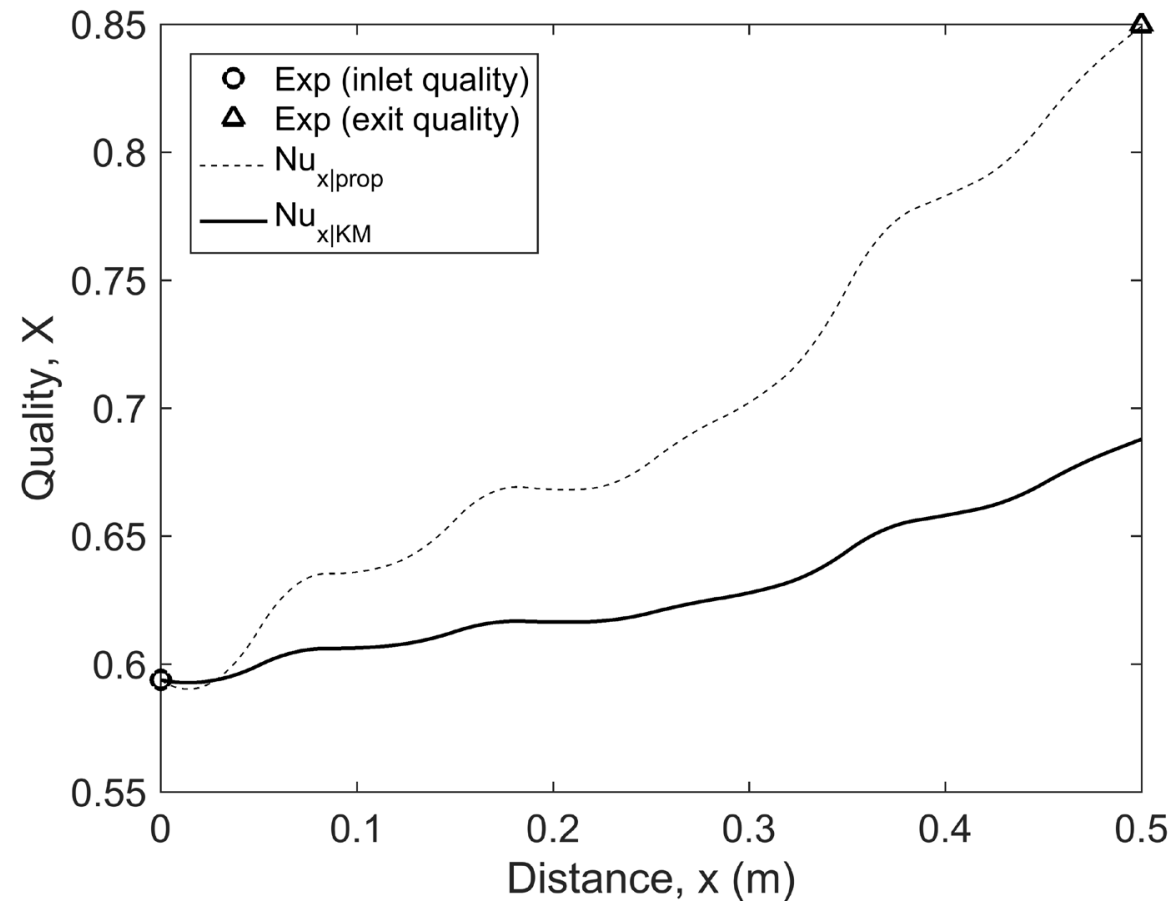

(a)

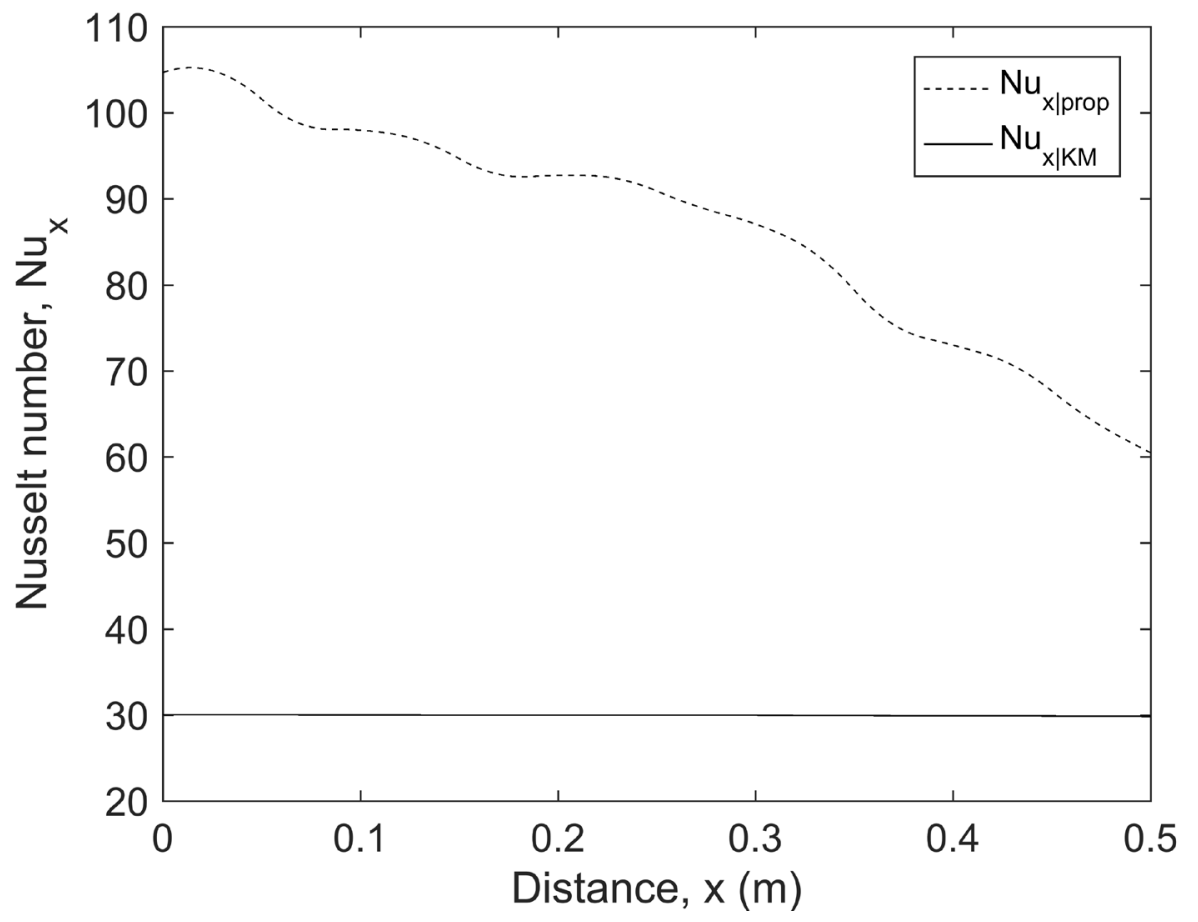

(b) 
Figure 5.5: (a) Variation of quality along the length of the channel from the experiment (Expt) and as predicted by the new proposed correlation $\left(\mathrm{Nu}_{\mathrm{x} \mid \mathrm{prop}}\right)$ and the original correlation by Kim and Mudawar $\left(\mathrm{Nu}_{\mathrm{x} \mid \mathrm{KM}}\right)$. (b) Variation of Nusselt number along the length of the channel, as predicted by the new proposed correlation $\left(\mathrm{Nu}_{\mathrm{x} \mid \text { prop }}\right)$ and the original correlation proposed by Kim and Mudawar $\left(\mathrm{Nu}_{\mathrm{x}} \mid \mathrm{KM}\right)$.

The above procedure can be further optimized covering all the cases in Tables $4.1-4.4$ for the parameter space in Eq. (4.9) and "methods of heating" in Figs. 4.2-4.3. The results are reported in [40].

In summary, the above approach and its future variations provide an excellent new approach for proposing $\mathrm{Nu}_{\mathrm{x} \text { |prop }}$ over a specified parameter range (Eq. (4.9) in this case) and a specified flow-regime (steady annular flows here). 


\section{Alternative More Efficient Ways for Realizing Enhanced Steady-in-the-mean Annular Flows}

It was not clear from the reported results on low heat-flux $\left(0.1-1 \mathrm{~W} / \mathrm{cm}^{2}\right)$ flow-boiling, if energy efficient inlet flow-rate pulsations in the liquid is the most effective way of achieving high heat-flux $\left(500-1000 \mathrm{~W} / \mathrm{cm}^{2}\right)$ annular flow-boiling realizations with all evidence pointing to a very significant role of micro-nucleation in removing heat from the boiling-surface.

It is therefore decided/recommended that Dr. Narain and his group should focus on their ongoing high heat-flux $\left(500-1000 \mathrm{~W} / \mathrm{cm}^{2}\right)$ annular flow-boiling experiments with their new and different active energization approach that they have developed to alter and control the micro-nucleation phenomena at the boiling-surface. 


\section{Conclusions}

The major conclusions of the experimental investigations, aided by contributions from the modeling/simulations group, are listed below.

Experimental and modeling support structure has been developed and synthesized to yield parameter-specific HTC correlations.

Experimental and modeling support structure has been developed and synthesized to establish the dominance of micro-scale nucleation to heat-transfer rates for laminar liquid and near-interface laminar vapor flows. The modeling support structure needs to be further developed for estimates as they relate to frequently present laminar liquid and fully turbulent (including near interface zone) vapor flows.

$>$ Pulsatile annular flow results employing inlet pulsations in the liquid and vapor flow rates show that enhancements over steady realizations are possible. Inlet liquid flow rate pulsations are most efficient and the bubble-departure diameters and associated frequencies are quite sensitive to flow conditions (and dominant frequency of noise in the steady realization is a good place to start amplification and control of micro-scale nucleation).

While liquid side pulsations' frequency synchronized to dominant noise frequencies present in steady annular realizations are found to be quite effective at thin film locations, the understanding gained from these investigations pave the way for alternative effective ways (scientific/technological breakthroughs are under development) for enhancing and controlling the dominant nucleate-boiling contributions for high heat-flux $\left(500-1000 \mathrm{~W} / \mathrm{cm}^{2}\right)$ annular flow-boiling realizations over the entire length of a flow-boiler. 


\section{References}

1. Lasance, C.J. and Simons, R.E., Advances in high-performance cooling for electronics. Electronics Cooling, 2005. 11(4).

2. Wilson, J.R. Electronics Cooling Depends on Innovative Approaches to Thermal Management. Military \& Aerospace Electronics, 2009.

3. Faghri, A., Heat Pipe Science and Technology. 1995: Taylor and Francis, Washington D. C.

4. Agostini, B., Fabbri, M., Park, J.E., Wojtan, L., Thome, J.R. and Michel, B., State of the art of high heat flux cooling technologies. Heat Transfer Engineering, 2007. 28(4): p. 258-281.

5. Ball, P., Computer engineering: Feeling the heat. Nature, 2012. 492(7428): p. 174-176.

6. Wei, J.J. and Honda, H., Effects of fin geometry on boiling heat transfer from silicon chips with micro-pin-fins immersed in FC-72. International Journal of Heat and Mass Transfer, 2003. 46(21): p. 4059-4070.

7. Kivisalu, M.T., Experimental investigation of certain internal condensing and boiling flows: Their sensitivity to pressure fluctuations and heat transfer enhancements. 2015, Michigan Technological University.

8. Bhasme, S.S., Development of and Simulation Results from: a CFD code for Steady Annular (Suppressed Nucleation) Flow Boiling. 2016, Michigan Technological University.

9. Kivisalu, M.T., Gorgitrattanagul, P. and Narain, A., Results for high heat-flux flow realizations in innovative operations of milli-meter scale condensers and boilers. International Journal of Heat and Mass Transfer, 2014. 75: p. 381-398.

10. Naik, R.R., Development of unsteady two-dimensional computational simulation tools for annular internal condensing flows--and their use for results on heattransfer rates, flow physics, flow stability, and flow sensitivity. 2015, Michigan Technological University.

11. Naik, R.R. and Narain, A., Steady and unsteady simulations for annular internal condensing flows, part II: Instability and flow regime transitions. Numerical Heat Transfer, Part B: Fundamentals, 2016: p. 1-16. 
12. Naik, R.R., Narain, A. and Mitra, S., Steady and unsteady simulations for annular internal condensing flows, part I: Algorithm and its accuracy. Numerical Heat Transfer, Part B: Fundamentals, 2016: p. 1-22.

13. Narain, A., Ranga Prasad, H. and Koca, A., Internal Annular Flow Condensation and Flow Boiling: Context, Results, and Recommendations, in Handbook of Thermal Science and Engineering, Kulacki, F.A., Editor. 2017, Springer International Publishing. p. 1-88.

14. Ranga Prasad, H., Narain, A., Bhasme, S.S. and Naik, R.R., Shear-driven Annular Flow-boiling in Millimeter-scale channels: Direct Numerical Simulations for Convective Component of the Overall Heat Transfer Coefficient. International Journal of Transport Phenomena, 2017. 15(1): p. 1-35.

15. Gerardi, C., Buongiorno, J., Hu, L.-w. and McKrell, T., Study of bubble growth in water pool-boiling through synchronized, infrared thermometry and high-speed video. International Journal of Heat and Mass Transfer, 2010. 53(19-20): p. 41854192.

16. Kim, S.-M. and Mudawar, I., Universal approach to predicting heat transfer coefficient for condensing mini/micro-channel flow. International Journal of Heat and Mass Transfer, 2013. 56(1-2): p. 238-250.

17. Kunkelmann, C., Ibrahem, K., Schweizer, N., Herbert, S., Stephan, P. and Gambaryan-Roisman, T., The effect of three-phase contact line speed on local evaporative heat transfer: Experimental and numerical investigations. International Journal of Heat and Mass Transfer, 2012. 55(7-8): p. 1896-1904.

18. McHale, J.P. and Garimella, S.V., Bubble nucleation characteristics in poolboiling of a wetting liquid on smooth and rough surfaces. International Journal of Multiphase Flow, 2010. 36(4): p. 249-260.

19. Raghupathi, P.A. and Kandlikar, S.G., Contact line region heat transfer mechanisms for an evaporating interface. International Journal of Heat and Mass Transfer, 2016. 95: p. 296-306.

20. Ghiaasiaan, S.M., Two-phase flow, boiling, and condensation: in conventional and miniature systems. 2007: Cambridge University Press.

21. Das, P.K., Chakraborty, S. and Bhaduri, S., Critical Heat Flux during Flow Boiling in Mini and Microchannel-a State of the Art Review. Frontiers in Heat and Mass Transfer, 2012. 3(1).

22. Mandhane, J., Gregory, G. and Aziz, K., A flow pattern map for gas-liquid flow in horizontal pipes. International Journal of Multiphase Flow, 1974. 1(4): p. 537553. 
23. Thome, J.R., Engineering data book III. Wolverine Tube Inc, 2004. 2010.

24. Friedel, L. Improved friction pressure drop correlations for horizontal and vertical two-phase pipe flow. in European two-phase flow group meeting, Paper E. 1979.

25. Qu, W. and Mudawar, I., Measurement and correlation of critical heat flux in two-phase micro-channel heat sinks. International Journal of Heat and Mass Transfer, 2004. 47(10-11): p. 2045-2059.

26. Grönnerud, R., Investigation of liquid hold-up, flow-resistance and heat transfer in circulation type evaporators, part IV: two-phase flow resistance in boiling refrigerants. Bull. De l'Inst. Du Froid, Annexe, 1972. 1.

27. Kim, S.-M. and Mudawar, I., Universal approach to predicting two-phase frictional pressure drop for mini/micro-channel saturated flow boiling. International Journal of Heat and Mass Transfer, 2013. 58(1-2): p. 718-734.

28. Kim, S.-M. and Mudawar, I., Review of databases and predictive methods for pressure drop in adiabatic, condensing and boiling mini/micro-channel flows. International Journal of Heat and Mass Transfer, 2014. 77: p. 74-97.

29. Lockhart, R. and Martinelli, R., Proposed correlation of data for isothermal twophase, two-component flow in pipes. Chem. Eng. Prog, 1949. 45(1): p. 39-48.

30. Zivi, S., Estimation of Steady-State Void Fraction by Means of Principle of Minimum Energy Production. ASME Journal of. Heat Transfer, 1964. 86(2): p. 247-252.

31. Bigham, S. and Moghaddam, S., Microscale study of mechanisms of heat transfer during flow boiling in a microchannel. International Journal of Heat and Mass Transfer, 2015. 88: p. 111-121.

32. Kurul, N. and Podowski, M. On the modeling of multidimensional effects in boiling channels. in ANS Proceeding of the 27th National Heat Transfer Conference. 1991. American Society of Mechanical Engineers New York.

33. Lavieville, J., Quemerais, E., Mimouni, S., Boucker, M. and Mechitoua, N., NEPTUNE CFD V1. 0 theory manual. NEPTUNE report Nept_2004_L1, 2006. 2(3).

34. Narain, A., Kivisalu, M., Naik, R., Gorgitrattanagul, N., Mitra, S., Hasan, M. M. Comparative Experimental and Computational Studies for Annular Condensing and Boiling Flows in Milli-meter Scale Horizontal Ducts. in Proceedings of ASME 2012 Summer Heat Transfer Conference. 2012. Rio Grande, Puerto Rico, USA: ASME. 
35. Kivisalu, M.T., Experimental Investigation of Internal Condensing Flows, Their Sensitivity to Pressure Fluctuations and Heat Transfer Enhancements, in Mechanical Engineering 2013, Michigan Technological University.

36. Kivisalu, M.T., Gorgitrattanagul, P., Narain, A., Naik, R. and Hasan, M., Sensitivity of shear-driven internal condensing flows to pressure fluctuations and its utilization for heat flux enhancements. International Journal of Heat and Mass Transfer, 2013. 56(1-2): p. 758-774.

37. Moffat, R.J., Describing the uncertainties in experimental results. Experimental thermal and fluid science, 1988. 1(1): p. 3-17.

38. Kim, S.-M. and Mudawar, I., Universal approach to predicting saturated flow boiling heat transfer in mini/micro-channels - Part II. Two-phase heat transfer coefficient. International Journal of Heat and Mass Transfer, 2013. 64: p. 12391256.

39. Sepahyar, S., Flow-boiling of water under innovative operations that lead to experimental realization of annular flows in millimeter scale ducts. 2018, Michigan Technological University.

40. Narain, A., Ranga Prasad, H., Gorgitrattanagul, P. and Mehendale, S., Investigations of Temperature Controlled Innovative Annular Flow-boiling of FC72 in Millimeter Scale Ducts - Part II: Modeling/simulations for heat transfer coefficient correlations and assessment of convective and nucleate boiling contributions. International Journal of Heat and Mass Transfer, 2018: p. To Be Submitted.

41. Ranga Prasad, H., Assessment of Annular Flow Boiling in the Context of CFD Simulations, Experiments and Existing Correlations. 2017, Michigan Technological University.

42. Mitra, S., Narain, A., Naik, R. and Kulkarni, S.D., A quasi one-dimensional method and results for steady annular/stratified shear and gravity driven condensing flows. International Journal of Heat and Mass Transfer, 2011. 54(1516): p. 3761-3776.

43. Carey, V.P., Liquid-Vapor Phase-Change Phenomena. Series in Chemical and Mechanical Engineering, Hemisphere Publishing Corporation, 1992. 


\section{A Appendix A: Flow-loop Modifications Undertaken for this Thesis}

\section{A.1 Description of Existing Apparatus/Equipment}

The original flow boiling loop is described in Fig. A.1 below. The list below give the salient components used in this flow-loop as well as for the reported flow boiling experiments.

- Test-Section

- Pool-boiler

- Peristaltic/Displacement pumps

- Compressor with Magnetic-Coupling Levitated Shaft

- LabVIEW and DAQ

- Absolute Pressure Transducers

- Differential Pressure Transducers

- Coriolis Flow Meters

- Vapor Pulsator

- Auxiliary Condenser

The changes made to the experimental flow-loop shown in Fig. A.1 are incorporated in the modified flow-loop shown in Fig. 3.2. The key activities that have been completed to obtain the modified flow-loop in Fig. 3.2 are described later on in section A.2 onwards. In this section we review the features of the salient components in the original flow-loop shown in Fig. A.1.

Test-Section:

The earlier test-section [7,9] used a stainless steel plate as a heat exchange surface and it had a machined plastic channel (forming the other three sides of the rectangular crosssection channel) fastened on top of it [7,9]. The stainless steel is heated via reversed thermo-electric modules (TECs). The electrical control and heat source arrangements for 
the reversed TECs allow a temperature-controlled heating of the boiling-surface. The plastic channel is machined to have a channel width and height of $15 \mathrm{~mm}$ and $2 \mathrm{~mm}$, respectively. The earlier experiments in [7,9] had a channel length of $1 \mathrm{~m}$, but the new forthcoming experiments have a test-section channel length of $0.5 \mathrm{~m}$.

Pool-boiler:

The pool-boiler is used to initially supply the flow-loop and the test-section with the requisite starting vapor flow rates of the working fluid. After start-up conditions have been achieved and the system reaches quasi-steady (approximately steady-in-the-mean) conditions within the test-section, the pool-boiler is cut-off from the rest of the flow-loop. This is done by closing suitable ball valves.

\section{Peristaltic/Displacement Pumps:}

The pumps within the system are controlled through actuating milli-Amp signals (via pulse-width management) into the pump that moves the liquid through the liquid lines in its vicinity.

\section{Levitated Magnetic Coupling Oil-Free RPM Controlled Compressor:}

The compressor is used to move a fraction of the exiting vapor from the exit of the testsection back to its inlet (see Figs. 3.2 and A.1). The control of the compressors RPM, is used to assist in controlling the recirculating vapor's mass flow rate.

\section{LabVIEW and DAQ:}

LabVIEW is used to assist with data collection and in controlling of various controllable devices/equipment within the flow-loop.

\section{Absolute Pressure Transducers (APTs):}

Various APTs are used in the flow-loop to electronically record the pressure at suitable locations within the flow-loop. Their placements are not shown in Figs. A.1 or 3.2, but a 
couple of placements allowing key measurements are: the pool-boiler pressure, the pressure at the inlet of the test-section, etc.

Differential Pressure Transducers (DPTs):

Two DPTs are used across the test-section (of Fig. A.1) to measure and record the pressure difference across the test-section lengths of 0 to $40 \mathrm{~cm}$ and 40 to $90 \mathrm{~cm}$. Because of the shorter channel length in the new design, the new experiments replace these 2 DPTs with a single DPT across test-section lengths of 10 to $40 \mathrm{~cm}$.

\section{Coriolis Flow Meters:}

Two Coriolis flow meters are used to measure the mass flow rates of the liquid and vapor flows being introduced at the innovative flow-boiler test-section's inlet. The flow meters' readings are also used to assist in the feedback control of pumps and compressor to suitably direct attainment $[7,9]$ of approximate steady flow conditions.

\section{Vapor Pulsator:}

The vapor pulsator is a modified pump that does not work as a pump because its inlet and outlet are connected together (see descriptions in [7,9]). This configuration causes a "pull and push" pressure superposition in the pulsator line - connected to the vapor line of the flow-loop through a T-junction connection. Therefore, this pulsator also imposes pressure fluctuations within the flow-loop's vapor line - establishing a pulsatile "steady-in-themean" liquid-vapor flow within the test-section. The speed of the pulsator motor controls the frequency of the imposed pulsations, and a throttling valve in the pulsator line independently controls the amplitude of the imposed pulsations.

\section{Auxiliary Condenser:}

The auxiliary condenser in Fig. 3.1 is a vertical tube-in-tube heat exchanger that condenses, in its inner tube, part of the vapor (the portion that is not recirculated) created in the testsection. The outer tube is cooled by a controlled flow rate and controlled inlet temperature 
water-flow arrangement (through a market available chiller, not shown in Figs. 3.1 and A.1).

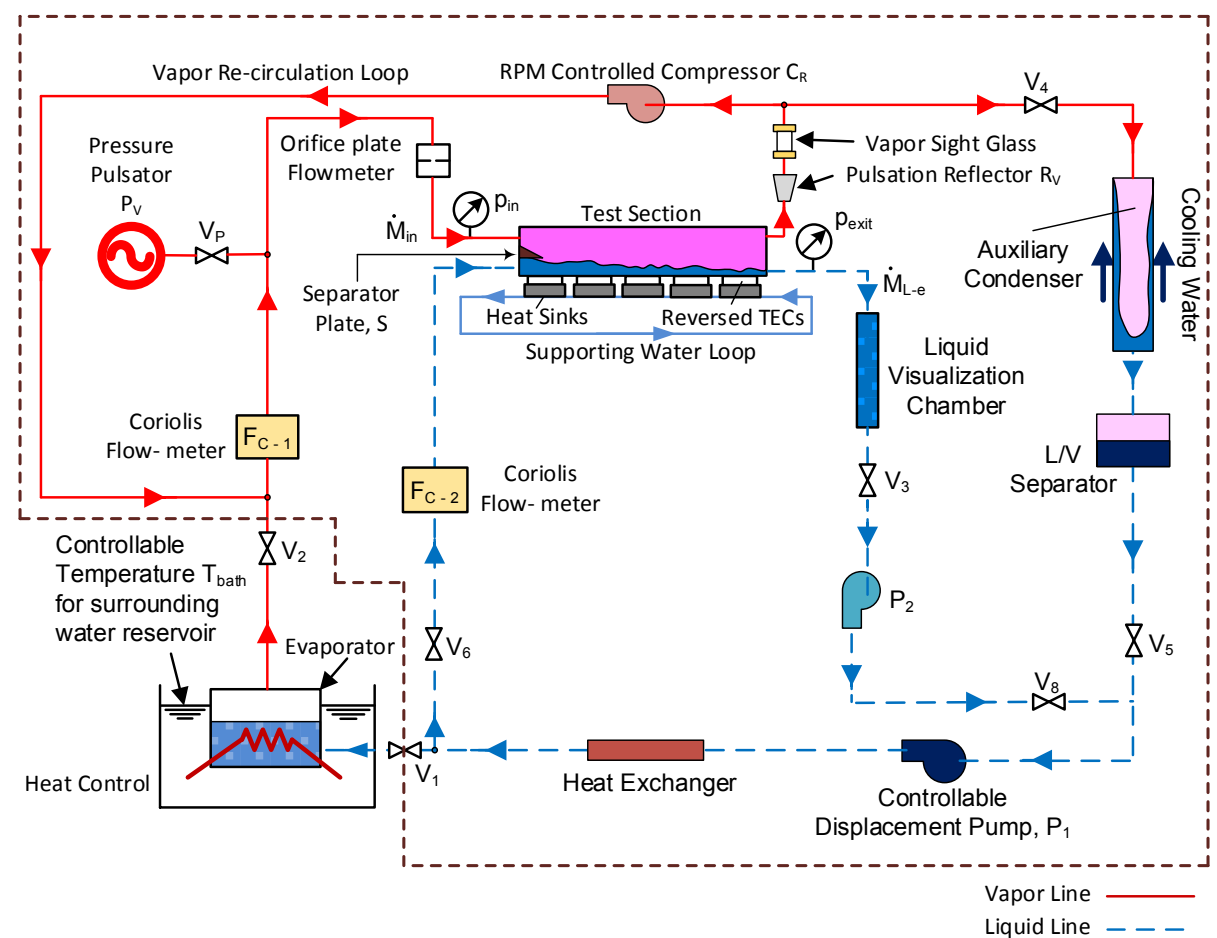

Figure A.1: Original flow-loop structure used in previous experiments.

\section{A.2 Modified Flow-Loop and Its New Components}

For the modified flow-loop, shown in Fig. 3.2, we describe the following key new components:

- Shorter New Test-Section

- New Heat Exchanger

- New Liquid Pulsator

- New Liquid Exit Fitting and Visualization Chamber

- New Liquid Pulsation Damper

- New Turbine Flow Meter 
- New Imbedded Thermocouples

Shorter New Test-Section:

The new test-section is redesigned, fabricated, and instrumented in a manner similar to the flow-boiler test-section described earlier in [7,9]. This is to avoid complete boil off (necessary for the proposed innovative flow-boilers [7, 9]) - or dry-out within the testsection - for a larger number of test runs as well as to allow measurements of the overall heat transfer rate (by measuring the exiting liquid flow rate). This ensures that the liquid flow in the new test-section (see Fig. 3.1) is over a shorter length (it has a width of $15 \mathrm{~mm}$, height of $2 \mathrm{~mm}$, and length of $0.5 \mathrm{~m}$ ). The new test-section continues to have a dynamic/steady heat-flux measurement capability at $\mathrm{x}=40 \mathrm{~cm}$ location. 


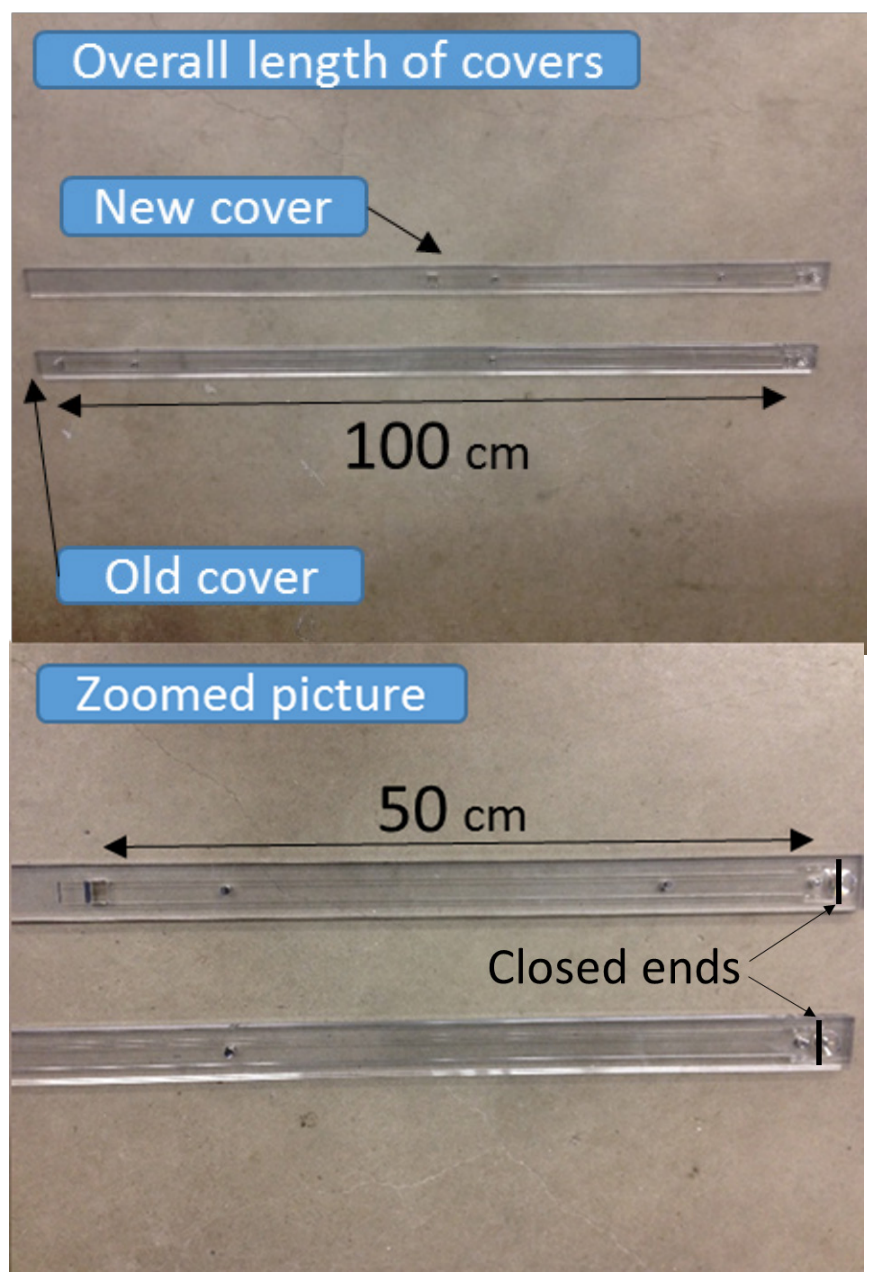

Figure A.2: A picture shows a comparison of the test-section channel lengths. On the bottom steel plate, there is a liquid drainage outlet near the "closed end" markings.

Heat Exchanger:

The heat exchanger in Fig. A.1 (between $\mathrm{V}_{6}$ and pump $\mathrm{P}_{2}$ ) has been moved, modified, and inserted prior to the liquid test-section inlet (but before the liquid pulsator) in Fig. 3.2. This heat-exchanger movement and modification is to ensure that the liquid entering the testsection has a temperature much closer to its saturation temperature (at the test-section operating pressure) than the previous design and location allowed. This is important because many innovative vapor compression cycle designs being recommended by our group cannot allow significant sub-cooling. 
Liquid Pulsator:

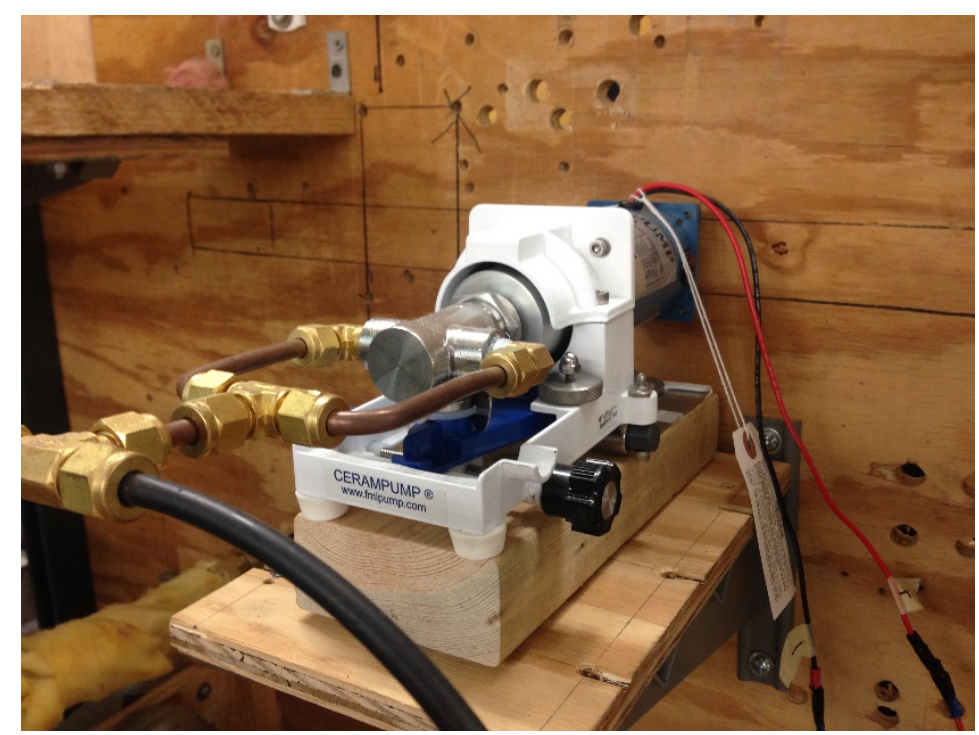

Figure A.3: A photograph of a liquid pulsator.

The liquid pulsator has been inserted immediately after the liquid Coriolis flow meter and heat exchanger, and right before the test-section inlet in Fig. 3.2. It is a variable speed and displacement piston pump whose inlet and outlet lines are connected to each other - and to the liquid line through the single branch line shown in Fig. 3.2. The new "liquid pulsator" serves a similar purpose to the vapor pulsator shown in Fig. 3.2, except that its use at the same frequency as the vapor pulsator is expected to significantly decrease the total pulsatile energy (considering both the pulsators) needed for high heat-flux performance of the innovative steady-in-the-mean flow-boiler operations [7,9]. This device is central to expanding our understanding the benefits of our earlier findings [7,9] - with regard to best ways of achieving enhanced steady-in-the-mean annular flow-boiling. 
Exit Fittings and Visualization Chamber:

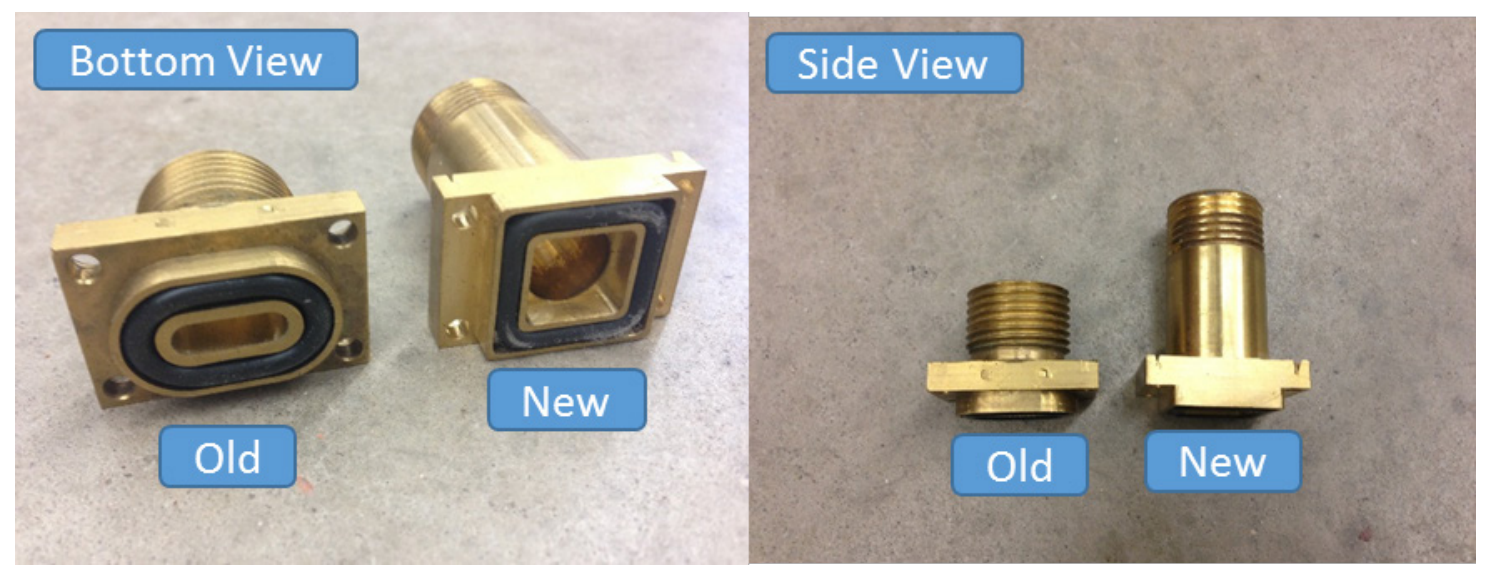

Figure A.4: A comparison of the old and new exit fittings.

A new vapor exit fitting (at the upper part of the test-section) was designed, machined, and positioned near the "closed end" at 50 centimeter length location of the test-section in Fig. 3.1. Also, the visualization chamber downstream of the fitting (not shown in Fig. A.4 bit shown in the schematics of Figs. A.1 and 3.1) has been change to a smaller size to allow less liquid to accumulate in the visualization chamber itself. Moreover, the gap between the test-section and the sight-glass has been reduced significantly to help assure appropriate liquid level at the test-section exit. 
Pulsation Damper:
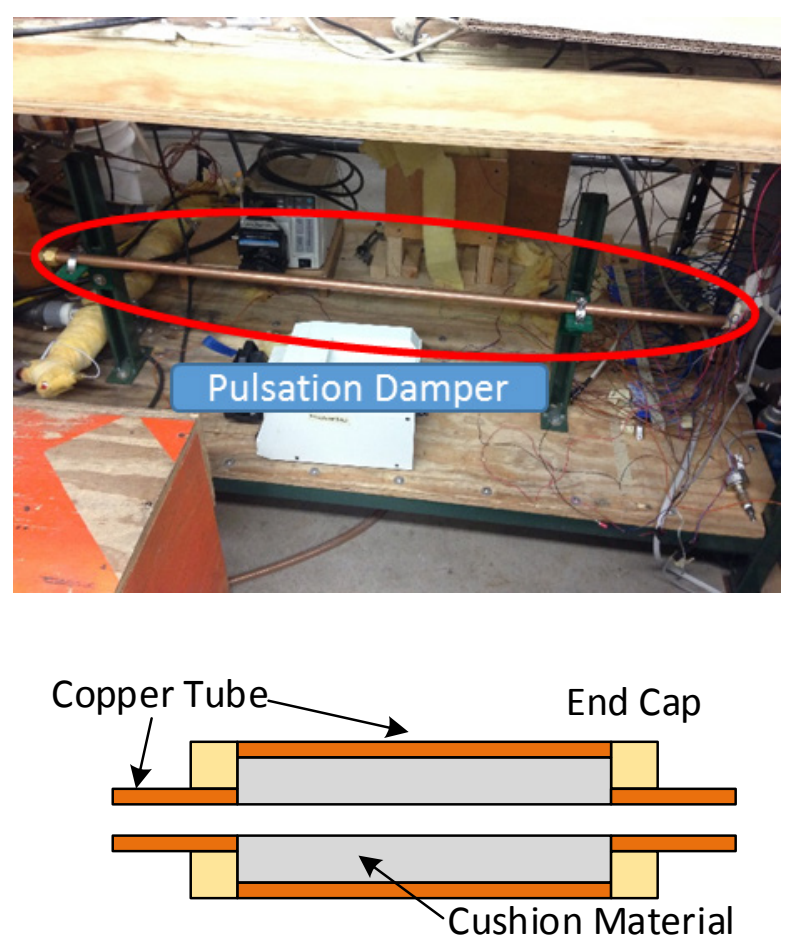

Figure A.5: A photograph of a pulsation dampener and its schematic.

The pulsation damper shown in Fig. A.5 has been inserted immediately downstream of the liquid line displacement pump $\mathrm{P}_{1}$ shown in Fig. 3.2. The displacement pump is a peristaltic pump that moves liquid based on periodic squeezing of a flexible tube. This pump induces pulsations within the liquid line - and was providing useful fixed frequency pulsations in the earlier Fig. A.1 flow-loop's innovative operations [7, 9] for any given liquid flow rate at the test-section inlet. The very same pulsations are now unwanted in the new operations - because we want to have choice and control on the liquid line pulsations and we do not want pump $\mathrm{P}_{1}$ induced pulsations to interfere with the more controllable (both in frequency and amplitude) pulsations from the new liquid pulsator $\mathrm{P}_{\mathrm{L}}$. The damper is therefore inserted to stifle the peristaltic pump generated pulsations. 
Turbine Flow Meter:

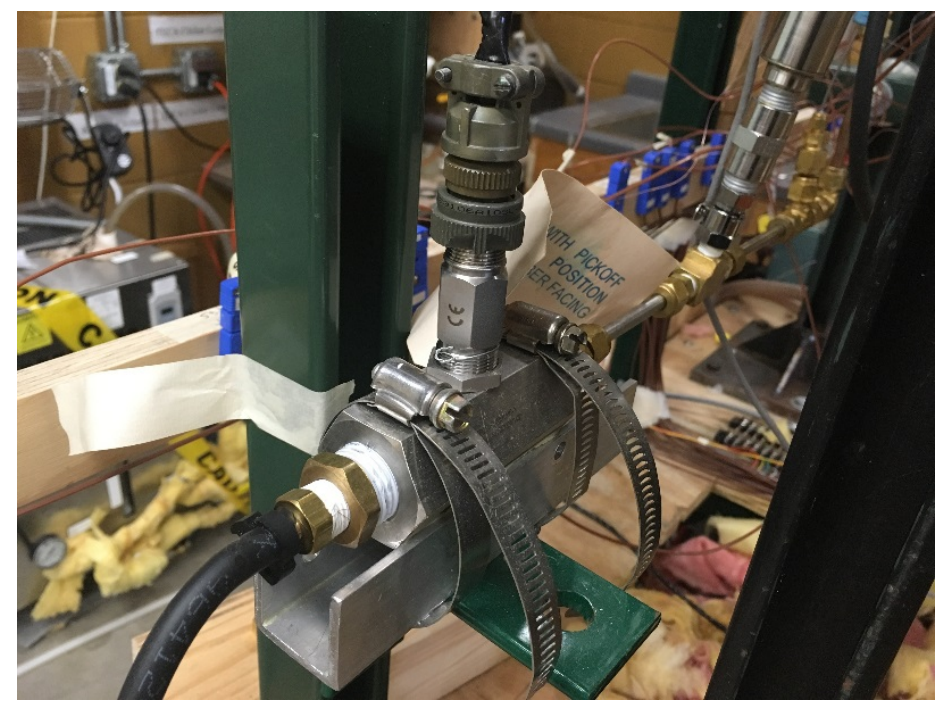

Figure A.6: A picture of a turbine flow meter.

The turbine flow meter has been inserted after the liquid exits the liquid pump $\mathrm{P}_{2}$ in Fig. 3.2. Between pump $P_{2}$ and the turbine flow meter, there is a filter (not shown in Fig. 3.2) which protects the turbine flow meter from being plugged with particles in the liquid flow. The turbine flow meter measures the flow rate of liquid exiting the test-section and has been calibrated (with the help of a Coriolis Meter) to measure liquid flow rates (around a range of liquid temperatures in the vicinity of certain expected liquid lines temperatures of interest). 
New Imbedded Thermocouples:
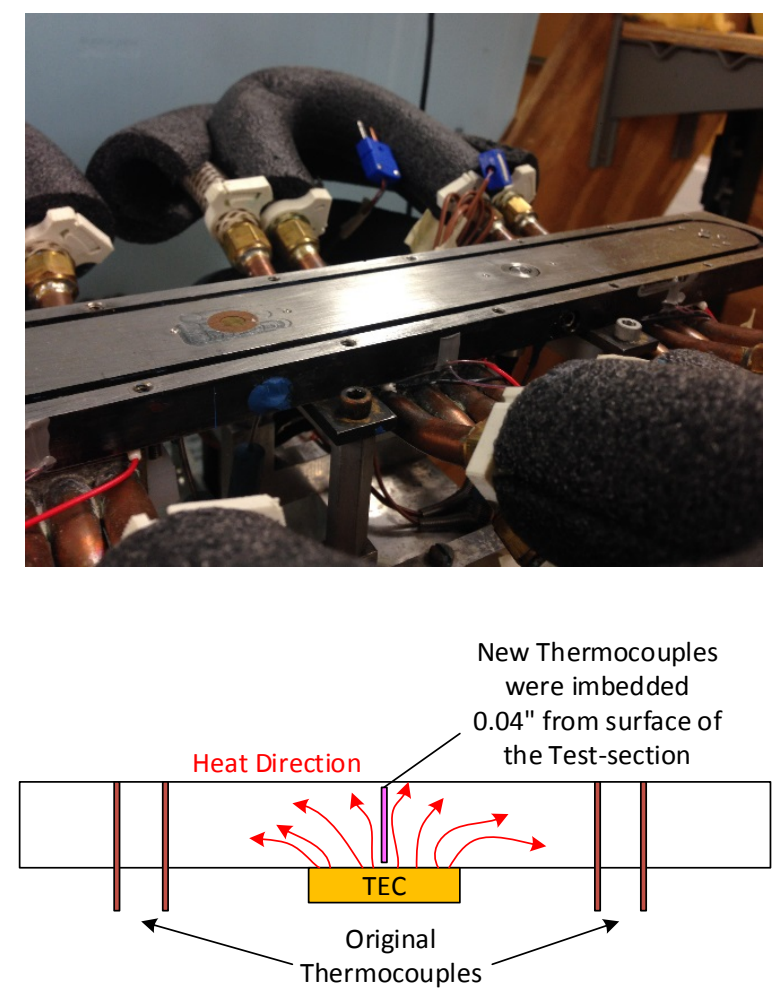

Figure A.7: An illustration of imbedded thermocouples and their schematic.

Small thermocouples (40 AWG, bare tip) were imbedded into the stainless steel test-section and potted with an epoxy that has thermal conductivity close to stainless steel. The tips of thermocouples were 0.02 " away from the boiling surface directly on top of TECs - as they were missing in the earlier Fig. A.1 flow-loop - to give a better and more precise wall temperature measurement towards defining the "method of heating (see section 4)" profile. These measured wall temperature "profiles" are critical to the planned synthesis of modeling with experiments as discussed in sections 4 and 5 . 


\section{B Appendix B: Full raw data of section 4}

\section{Table B.1}

Raw $\mathrm{T}_{\mathrm{w}}(\mathrm{x})$ data for Table 4.1 where $\{\mathrm{x}(\mathrm{cm})\} \equiv\{0,5,8.5,11.5,15,18.5,21.5,25,28.5$, $31.5,35,38.5,41.5,45,48.5\}$.

\begin{tabular}{|c|c|c|c|c|c|c|c|c|c|c|c|c|c|c|c|c|}
\hline \multirow{2}{*}{ Case } & $\mathrm{T}_{\mathrm{W}}\left(\mathrm{x}_{1}\right)$ & $\mathrm{T}_{\mathrm{W}}\left(\mathrm{x}_{2}\right)$ & $\mathrm{T}_{\mathrm{W}}\left(\mathrm{x}_{3}\right)$ & $\mathrm{T}_{\mathrm{W}}\left(\mathrm{x}_{4}\right)$ & $\mathrm{T}_{\mathrm{W}}\left(\mathrm{x}_{5}\right)$ & $\mathrm{T}_{\mathrm{W}}\left(\mathrm{x}_{6}\right)$ & $\mathrm{T}_{\mathrm{W}}\left(\mathrm{x}_{7}\right)$ & $\mathrm{T}_{\mathrm{W}}\left(\mathrm{x}_{8}\right)$ & $\mathrm{T}_{\mathrm{W}}\left(\mathrm{x}_{9}\right)$ & $\mathrm{T}_{\mathrm{W}}\left(\mathrm{x}_{10}\right)$ & $\mathrm{T}_{\mathrm{W}}\left(\mathrm{x}_{11}\right)$ & $\mathrm{T}_{\mathrm{W}}\left(\mathrm{x}_{12}\right)$ & $\mathrm{T}_{\mathrm{W}}\left(\mathrm{x}_{13}\right)$ & $\mathrm{T}_{\mathrm{W}}\left(\mathrm{x}_{14}\right)$ & $\mathrm{T}_{\mathrm{W}}\left(\mathrm{x}_{15}\right)$ \\
\hline & $\left( \pm 1^{\circ} \mathrm{C}\right)$ & $\left( \pm 1^{\circ} \mathrm{C}\right)$ & $\left( \pm 1^{\circ} \mathrm{C}\right)$ & $\left( \pm 1^{\circ} \mathrm{C}\right)$ & $\left( \pm 1^{\circ} \mathrm{C}\right)$ & $\left( \pm 1{ }^{\circ} \mathrm{C}\right)$ & $\left( \pm 1^{\circ} \mathrm{C}\right)$ & $\left( \pm 1^{\circ} \mathrm{C}\right)$ & $\left( \pm 1^{\circ} \mathrm{C}\right)$ & $\left( \pm 1^{\circ} \mathrm{C}\right)$ & $\left( \pm 1^{\circ} \mathrm{C}\right)$ & $\left( \pm 1^{\circ} \mathrm{C}\right)$ & $\left( \pm 1^{\circ} \mathrm{C}\right)$ & $\left( \pm 1^{\circ} \mathrm{C}\right)$ & $\left( \pm 1^{\circ} \mathrm{C}\right)$ \\
\hline 1 & 58.16 & 61.50 & 59.26 & 59.87 & 60.50 & 59.58 & 59.76 & 60.00 & 60.59 & 61.55 & 63.50 & 60.72 & 61.31 & 63.00 & 63.15 \\
\hline 2 & 58.19 & 62.50 & 59.33 & 59.94 & 61.50 & 59.15 & 59.47 & 61.00 & 60.39 & 61.15 & 64.00 & 60.40 & 60.66 & 63.00 & 61.85 \\
\hline 3 & 58.17 & 61.50 & 59.29 & 59.93 & 60.50 & 59.60 & 59.77 & 60.00 & 60.59 & 61.33 & 63.50 & 60.55 & 61.00 & 63.00 & 63.31 \\
\hline 4 & 58.29 & 61.50 & 59.29 & 59.89 & 60.50 & 59.59 & 59.74 & 60.00 & 60.58 & 61.28 & 63.50 & 60.56 & 60.89 & 63.00 & 63.28 \\
\hline 5 & 58.60 & 61.50 & 59.36 & 59.99 & 60.50 & 59.70 & 59.85 & 60.00 & 60.65 & 61.40 & 63.50 & 60.69 & 60.95 & 63.00 & 63.42 \\
\hline 6 & 58.18 & 61.50 & 59.27 & 59.86 & 60.50 & 59.62 & 59.73 & 60.00 & 60.52 & 61.30 & 63.50 & 60.54 & 60.82 & 63.00 & 63.24 \\
\hline 7 & 57.83 & 61.50 & 59.22 & 59.70 & 60.50 & 59.51 & 59.60 & 60.00 & 60.29 & 61.17 & 63.50 & 60.37 & 60.68 & 63.00 & 62.99 \\
\hline 8 & 57.86 & 61.50 & 59.23 & 59.72 & 60.50 & 59.46 & 59.55 & 60.00 & 60.12 & 61.04 & 63.50 & 60.40 & 60.54 & 63.00 & 62.87 \\
\hline 9 & 57.97 & 61.50 & 59.15 & 59.60 & 60.50 & 59.37 & 59.41 & 60.00 & 59.84 & 60.85 & 63.50 & 60.21 & 60.26 & 63.00 & 62.52 \\
\hline 10 & 57.14 & 61.50 & 59.11 & 59.54 & 60.50 & 59.31 & 59.36 & 60.00 & 59.81 & 60.84 & 63.50 & 60.11 & 60.15 & 63.00 & 62.30 \\
\hline 11 & 57.13 & 61.50 & 59.02 & 59.54 & 60.50 & 59.21 & 59.20 & 60.00 & 59.38 & 60.47 & 63.50 & 59.85 & 60.03 & 63.00 & 61.41 \\
\hline
\end{tabular}




\section{Figure B.1}

Raw temperature profile of Table 4.1

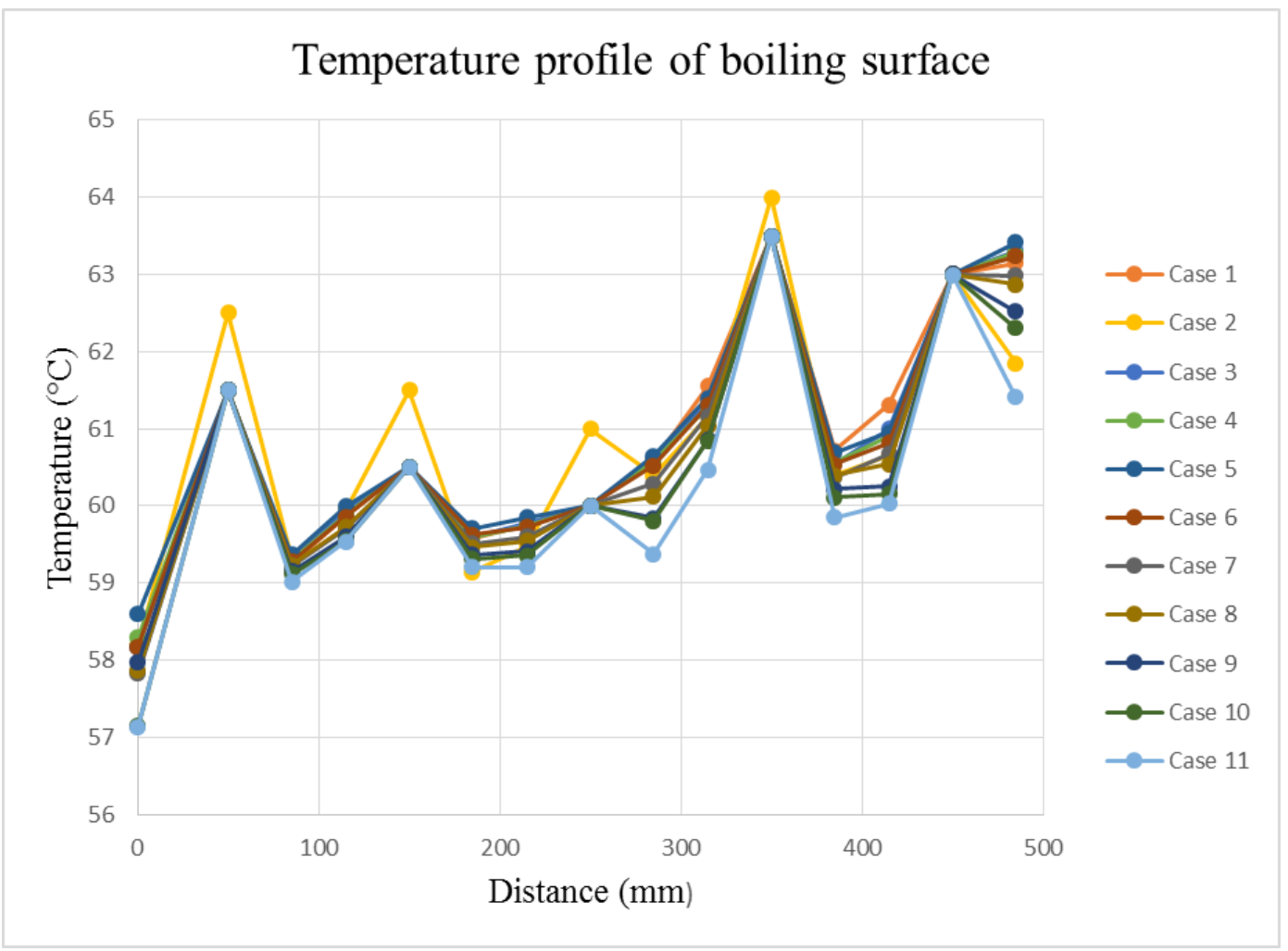


Figure B.2

Raw non-dimensionalized temperature profile of Table 4.1 and Figure 4.2

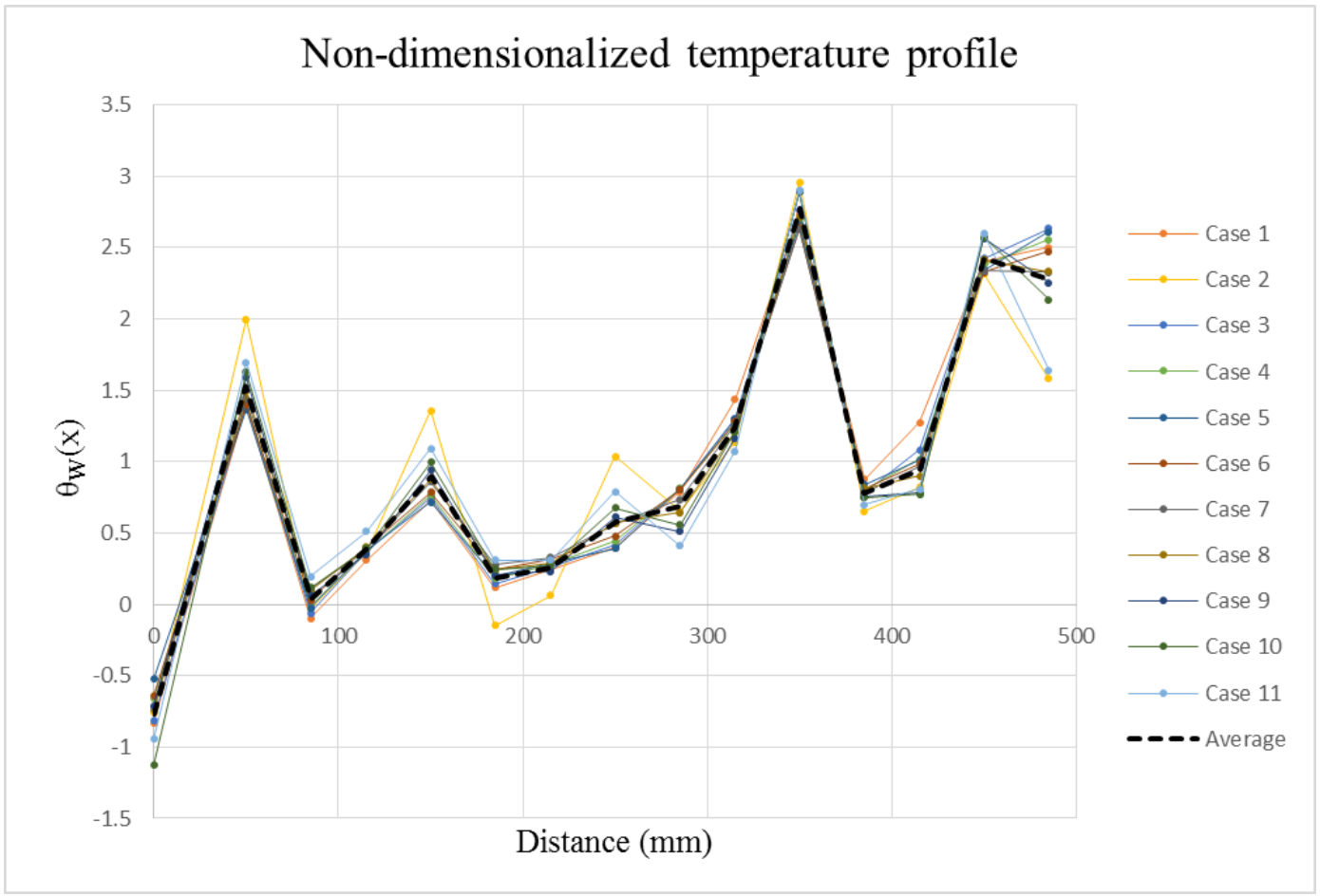




\section{Table B.2}

Raw $\mathrm{T}_{\mathrm{w}}(\mathrm{x})$ data for Table 4.3 where $\{\mathrm{x}(\mathrm{cm})\} \equiv\{0,5,8.5,11.5,15,18.5,21.5,25,28.5$, $31.5,35,38.5,41.5,45,48.5\}$.

\begin{tabular}{|c|c|c|c|c|c|c|c|c|c|c|c|c|c|c|c|}
\hline \multirow{2}{*}{ Case } & $\mathrm{T}_{\mathrm{W}}\left(\mathrm{x}_{1}\right)$ & $\mathrm{T}_{\mathrm{W}}\left(\mathrm{x}_{2}\right)$ & $\mathrm{T}_{\mathrm{W}}\left(\mathrm{x}_{3}\right)$ & $\mathrm{T}_{\mathrm{W}}\left(\mathrm{x}_{4}\right)$ & $\mathrm{T}_{\mathrm{W}}\left(\mathrm{x}_{5}\right)$ & $\mathrm{T}_{\mathrm{W}}\left(\mathrm{x}_{6}\right.$ & $\mathrm{T}_{\mathrm{W}}\left(\mathrm{x}_{7}\right)$ & $\mathrm{T}_{\mathrm{W}}\left(\mathrm{x}_{8}\right)$ & $\mathrm{T}_{\mathrm{W}}\left(\mathrm{x}_{9}\right)$ & $\mathrm{T}_{\mathrm{W}}\left(\mathrm{x}_{10}\right)$ & $\mathrm{T}_{\mathrm{W}}\left(\mathrm{x}_{11}\right)$ & $\mathrm{T}_{\mathrm{W}}\left(\mathrm{x}_{12}\right)$ & $\mathrm{T}_{\mathrm{W}}\left(\mathrm{x}_{13}\right)$ & $\mathrm{T}_{\mathrm{W}}\left(\mathrm{x}_{14}\right)$ & $\mathrm{T}_{\mathrm{W}}\left(\mathrm{x}_{15}\right)$ \\
\hline & $\left( \pm 1^{\circ} \mathrm{C}\right)$ & $\left( \pm 1^{\circ} \mathrm{C}\right)$ & $\left( \pm 1^{\circ} \mathrm{C}\right)$ & $\left( \pm 1^{\circ} \mathrm{C}\right)$ & $\left( \pm 1^{\circ} \mathrm{C}\right)$ & $\left( \pm 1^{\circ} \mathrm{C}\right)$ & $\left( \pm 1^{\circ} \mathrm{C}\right)$ & $\left( \pm 1^{\circ} \mathrm{C}\right)$ & $\left( \pm 1^{\circ} \mathrm{C}\right)$ & $\left( \pm 1^{\circ} \mathrm{C}\right)$ & $\left( \pm 1^{\circ} \mathrm{C}\right)$ & $\left( \pm 1^{\circ} \mathrm{C}\right)$ & $\left( \pm 1^{\circ} \mathrm{C}\right)$ & $\left( \pm 1^{\circ} \mathrm{C}\right)$ & $\left( \pm 1^{\circ} \mathrm{C}\right)$ \\
\hline 1 & 56.42 & 64.00 & 61.06 & 61.32 & 64.00 & 62.32 & 61.62 & 64.00 & 61.89 & 61.93 & 64.00 & & 61.73 & 64.00 & 63.79 \\
\hline 2 & 56.39 & 64.00 & & 61.51 & 64.00 & & 61. & 64.00 & 61.99 & .07 & 64.00 & & & 4.00 & 3.93 \\
\hline 3 & 6.34 & .00 & & 61 & 6 & & & & & & & & & & \\
\hline 4 & 56.23 & 6 & & 61.42 & 64.0 & & & 6 & & & & & & & .77 \\
\hline 5 & 56.47 & 65.75 & 62.42 & 62.67 & 65.75 & 63.18 & 62.65 & 65.75 & 62.82 & 62.89 & 65.75 & 23 & 22.49 & 5.75 & 5.21 \\
\hline 6 & 57.90 & 64.50 & 61.6 & 62.08 & 64.50 & 62.97 & 62.41 & 64.50 & 62.60 & 69 & 64.50 & & 2.39 & 4.50 & 4.06 \\
\hline 7 & 57.85 & 66.00 & 62.80 & 63.05 & 66.00 & 63.69 & 63. & 66.00 & 63.32 & .45 & 66.00 & .74 & & 6.00 & 65.39 \\
\hline 8 & 58.77 & 66.50 & & 63.38 & 66.50 & 63. & & 5.50 & 63.46 & & 0 & & & 5.50 & 88 \\
\hline 9 & 59.18 & 68.00 & & 64.38 & 68.00 & 64.95 & & 68.00 & 64.47 & 64.62 & & & & 68.00 & 66.68 \\
\hline 10 & 60.15 & 69.00 & 65.09 & 65.29 & 69.00 & 65.74 & 65.34 & 69.00 & 65.15 & 65.42 & 69.00 & 65.09 & 65.28 & 69.00 & 67.48 \\
\hline
\end{tabular}




\section{Figure B.3}

Raw temperature profile of Table 4.3

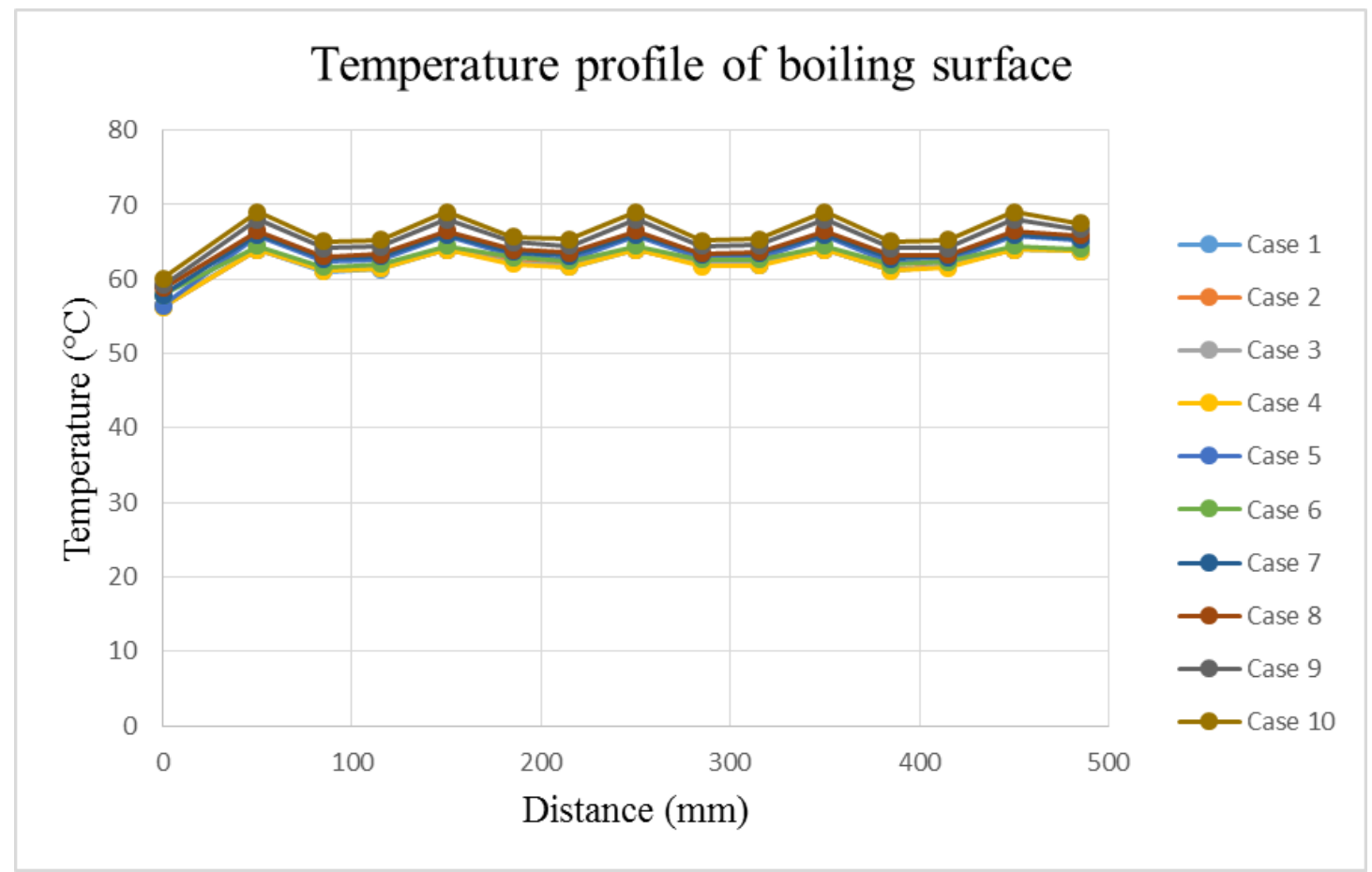




\section{Figure B.4}

Raw non-dimensionalized temperature profile of Table 4.3 and Figure 4.3

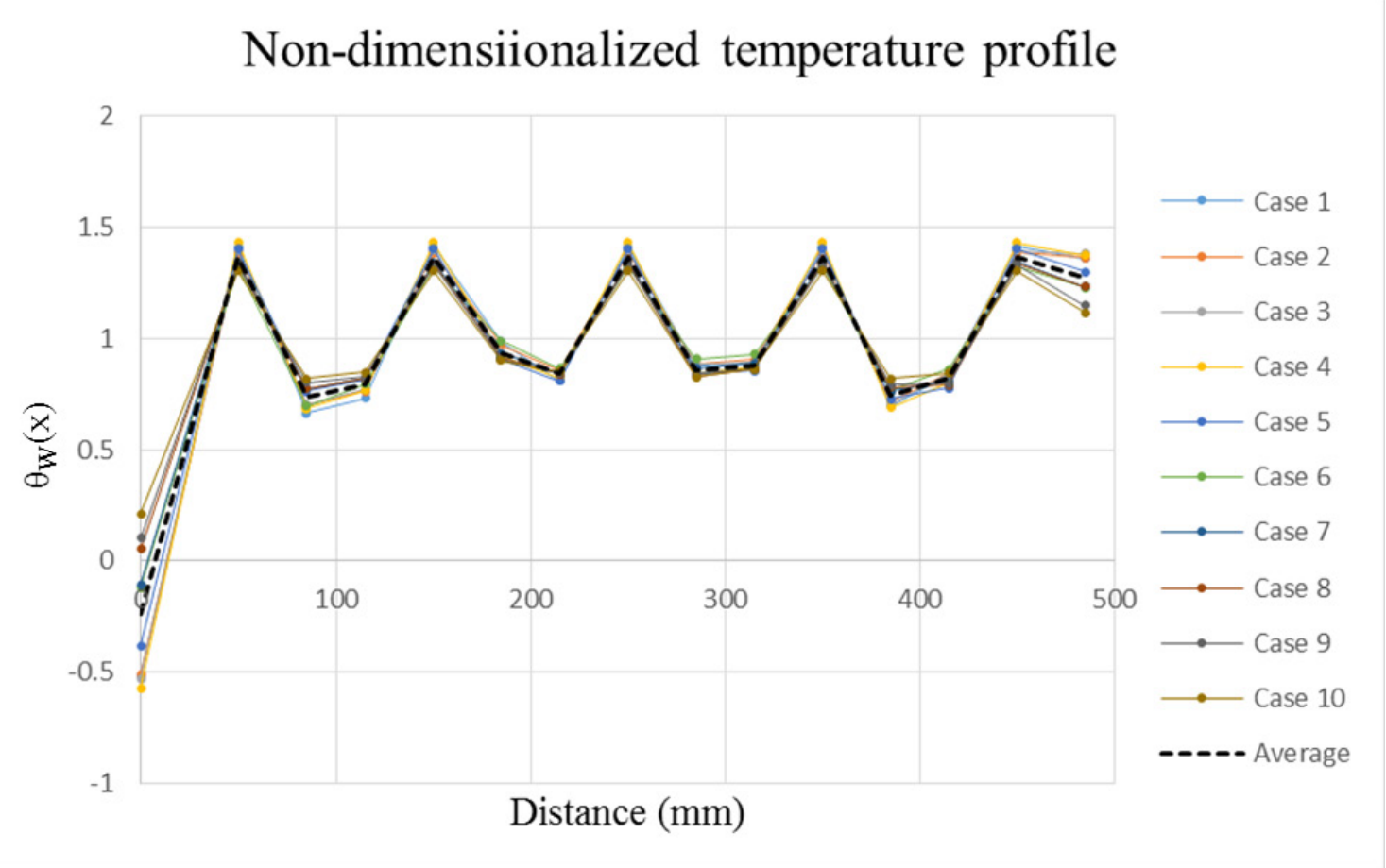




\section{Table B.3}

Raw $\mathrm{T}_{\mathrm{w}}(\mathrm{x})$ data for Table 4.5 where $\{\mathrm{x}(\mathrm{cm})\} \equiv\{0,5,8.5,11.5,15,18.5,21.5,25,28.5$, $31.5,35,38.5,41.5,45,48.5\}$.

\begin{tabular}{|c|c|c|c|c|c|c|c|c|c|c|c|c|c|c|c|}
\hline \multirow{2}{*}{ Case } & $\mathrm{T}_{\mathrm{W}}\left(\mathrm{x}_{1}\right.$ & $\mathrm{T}_{\mathrm{W}}\left(\mathrm{x}_{2}\right.$ & $\mathrm{T}_{\mathrm{W}}(\mathrm{x}$ & ${ }_{N}\left(\mathrm{x}_{4}\right.$ & $\mathrm{T}_{\mathrm{W}}\left(\mathrm{x}_{5}\right)$ & $\mathrm{T}_{\mathrm{W}}(\mathrm{x}$ & $\mathrm{T}_{\mathrm{w}} \mathrm{C}$ & $\mathrm{T}_{\mathrm{W}}\left(\mathrm{x}_{8}\right.$ & $\mathrm{T}_{\mathrm{W}}\left(\mathrm{x}_{9}\right)$ & $\mathrm{T}_{\mathrm{W}}\left(\mathrm{x}_{10}\right.$ & $\mathrm{T}_{\mathrm{W}}\left(\mathrm{x}_{11}\right)$ & $\mathrm{T}_{\mathrm{W}}\left(\mathrm{x}_{12}\right)$ & $\mathrm{T}_{\mathrm{W}}\left(\mathrm{x}_{13}\right.$ & $\mathrm{T}_{\mathrm{W}}\left(\mathrm{x}_{14}\right)$ & \\
\hline & $\left( \pm 1^{\circ} \mathrm{C}\right)$ & $\left( \pm 1^{\circ} \mathrm{C}\right)$ & $\left( \pm 1^{\circ} \mathrm{C}\right)$ & $\left( \pm 1^{\circ} \mathrm{C}\right)$ & $\left( \pm 1^{\circ} \mathrm{C}\right)$ & $\left( \pm 1^{\circ} \mathrm{C}\right)$ & $\left( \pm 1^{\circ} \mathrm{C}\right)$ & $\left( \pm 1^{\circ} \mathrm{C}\right)$ & $\left( \pm 1^{\circ} \mathrm{C}\right)$ & $\left( \pm 1^{\circ} \mathrm{C}\right)$ & $\left( \pm 1^{\circ} \mathrm{C}\right)$ & $\left( \pm 1^{\circ} \mathrm{C}\right)$ & $\left( \pm 1^{\circ} \mathrm{C}\right)$ & $\left( \pm 1^{\circ} \mathrm{C}\right)$ & C) \\
\hline & 59.95 & 68 & 62.95 & 63.53 & 68.00 & & 3.24 & 69.00 & & & & & & & 3.49 \\
\hline lsatile & 62.00 & 68.04 & 62.91 & 63.57 & 68.03 & 63.17 & 63.20 & 69.01 & 63.42 & 64.46 & 72.04 & 66.46 & 66.59 & 72.01 & 63.95 \\
\hline
\end{tabular}




\section{Figure B.5}

Raw temperature profile of Table 4.5

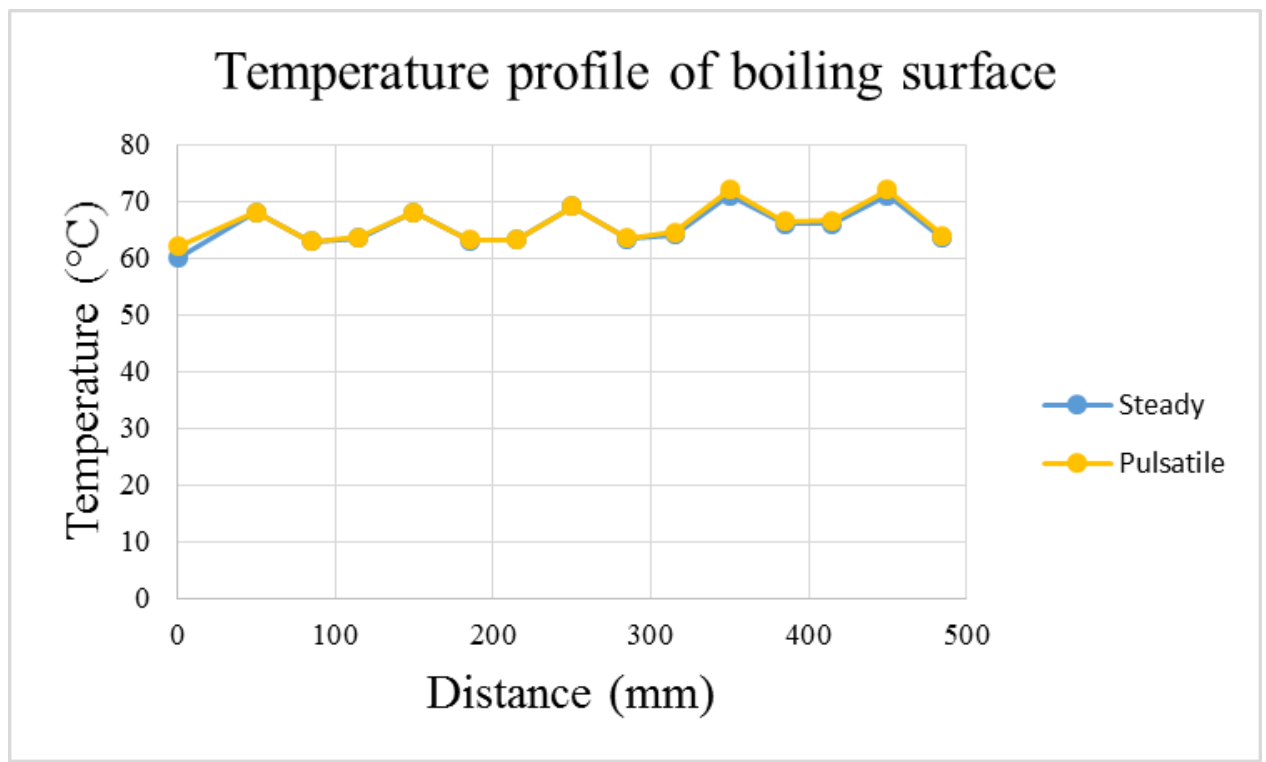


Figure B.6

Raw non-dimensionalized temperature profile of Table 4.5 and Figure 4.6

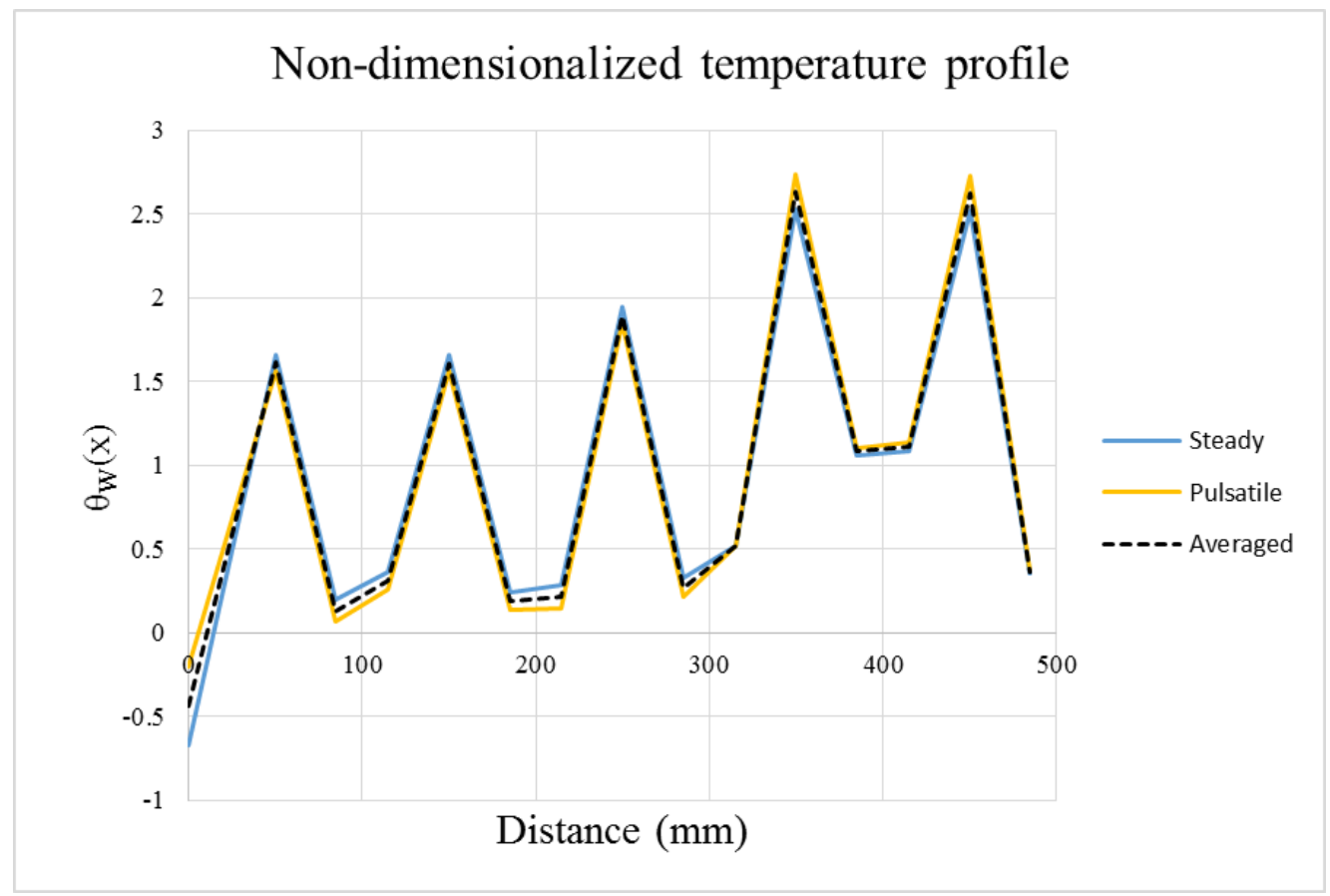




\section{Table B.4}

Raw $\mathrm{T}_{\mathrm{w}}(\mathrm{x})$ data for Table 4.6 where $\{\mathrm{x}(\mathrm{cm})\} \equiv\{0,5,8.5,11.5,15,18.5,21.5,25,28.5$, $31.5,35,38.5,41.5,45,48.5\}$.

\begin{tabular}{|c|c|c|c|c|c|c|c|c|c|c|c|c|c|c|c|}
\hline \multirow{2}{*}{ Case } & $\mathrm{T}_{\mathrm{W}}\left(\mathrm{x}_{1}\right)$ & $\mathrm{T}_{\mathrm{W}}\left(\mathrm{x}_{2}\right.$ & $\mathrm{T}_{\mathrm{W}}\left(\mathrm{x}_{3}\right)$ & $\mathrm{T}_{\mathrm{W}}\left(\mathrm{x}_{4}\right)$ & & $\mathrm{T}_{\mathrm{W}}\left(\mathrm{x}_{6}\right)$ & $\mathrm{T}_{\mathrm{W}}\left(\mathrm{x}_{7}\right.$ & $\mathrm{T}_{\mathrm{W}}\left(\mathrm{x}_{8}\right)$ & $\mathrm{T}_{\mathrm{W}}\left(\mathrm{x}_{9}\right)$ & $\mathrm{T}_{\mathrm{W}}\left(\mathrm{x}_{10}\right)$ & $\mathrm{T}_{\mathrm{W}}\left(\mathrm{x}_{11}\right)$ & $\mathrm{T}_{\mathrm{W}}\left(\mathrm{x}_{12}\right)$ & $\mathrm{T}_{\mathrm{W}}\left(\mathrm{x}_{13}\right.$ & $\mathrm{T}_{\mathrm{W}}\left(\mathrm{x}_{14}\right.$ & $\mathrm{T}_{\mathrm{W}}\left(\mathrm{x}_{15}\right)$ \\
\hline & $\left( \pm 1^{\circ} \mathrm{C}\right)$ & $\left( \pm 1^{\circ} \mathrm{C}\right)$ & $\left( \pm 1^{\circ} \mathrm{C}\right)$ & $\left( \pm 1^{\circ} \mathrm{C}\right)$ & $\left( \pm 1^{\circ} \mathrm{C}\right)$ & $\left( \pm 1^{\circ} \mathrm{C}\right)$ & $\left( \pm 1^{\circ} \mathrm{C}\right)$ & $\left( \pm 1^{\circ} \mathrm{C}\right)$ & $\left( \pm 1^{\circ} \mathrm{C}\right)$ & $\left( \pm 1^{\circ} \mathrm{C}\right)$ & $\left( \pm 1^{\circ} \mathrm{C}\right)$ & $\left( \pm 1^{\circ} \mathrm{C}\right)$ & $\left( \pm 1^{\circ} \mathrm{C}\right)$ & $\left( \pm 1^{\circ} \mathrm{C}\right)$ & $\left( \pm 1^{\circ} \mathrm{C}\right)$ \\
\hline 1 & 59.47 & 67.00 & 63.56 & 63.98 & 67.00 & 64.36 & 64.18 & 67.00 & 64.61 & & & & & & 66.49 \\
\hline 2 & 59.18 & 67.00 & 63.59 & 63.88 & 7.00 & 64.13 & 63.85 & 67.00 & 63.93 & 64.23 & 7.00 & 3.34 & 3.42 & 1.0 & 6.46 \\
\hline 3 & 43 & 7.00 & 63.72 & 4.04 & & 31 & .11 & 67.00 & 64.07 & & & & .73 & & .71 \\
\hline 4 & 59.41 & 67.00 & 63.80 & 64.15 & 67.00 & 64.33 & 64.16 & 67.00 & 64.33 & .53 & 7.00 & 57 & 3.72 & 7.00 & 6.69 \\
\hline 5 & 59.49 & 67.00 & 63.94 & 64.22 & 67.00 & 64.41 & 64.24 & 67.00 & 64.42 & 64.65 & 67.00 & 63.69 & 63.79 & 67.00 & 66.83 \\
\hline 6 & 59.74 & 67.00 & 63.95 & 64.22 & 67.00 & 64.43 & 64.27 & 67.00 & 64.35 & & 00 & .73 & 63.81 & 7.00 & 7.00 \\
\hline 7 & 59.65 & 67.00 & 64.01 & 4.35 & & 64.48 & 64. & 67.00 & & & & & & & 6.81 \\
\hline 8 & 59.64 & 67.00 & 64.05 & 64.31 & 67.00 & 64.52 & 64.37 & 67.00 & 64.61 & 64.70 & 7.00 & 63.80 & 63.83 & 67.00 & 6.89 \\
\hline 9 & 59.56 & 67.00 & 63.89 & 64.29 & 67.00 & 64.45 & 64.31 & 67.00 & 64.35 & 64.66 & 67.00 & 63.73 & 63.80 & 67.00 & 66.77 \\
\hline 10 & 59.11 & 67.00 & 63.42 & 63.76 & 67. & 64.00 & 63.71 & 67.00 & 63.82 & & & .20 & 63.42 & 7.00 & 6.44 \\
\hline 11 & 58.97 & 67.00 & 63.49 & 63.80 & 6 & 64.07 & 63.79 & 67.00 & 63.65 & & & .25 & 63.58 & 7.01 & 6.48 \\
\hline 12 & 58.90 & 67.00 & 63.46 & 63.75 & 67.00 & 64.04 & 63.76 & 67.00 & 63.60 & 64.20 & 67.00 & 63.23 & 63.51 & 67.00 & 66.43 \\
\hline 13 & 58.95 & 67.00 & 63.44 & 63.73 & 67.00 & 64.01 & 63.73 & 67.00 & 63.58 & 64.22 & .00 & 63.23 & 63.43 & 77.00 & 66.46 \\
\hline 14 & 59.20 & 66.99 & 63.57 & 63.89 & 7.00 & 64.16 & 63.91 & 67.00 & 64.07 & $\begin{array}{l}4.30 \\
\end{array}$ & 00 & 63.34 & 63.52 & 7.00 & 6.47 \\
\hline 15 & 59.13 & 67.00 & 63.60 & 63.87 & 67.00 & 64.18 & 63.92 & 67.00 & 63.87 & & & 63.33 & 63.63 & 7.00 & 66.54 \\
\hline 16 & 59.12 & 67.00 & 63.53 & 63.87 & 67.00 & 64.12 & 63.85 & 67.00 & 63.67 & & & 63.29 & 63.53 & 7.00 & 66.44 \\
\hline 17 & 59.11 & 67.00 & 63.49 & 63.80 & 67.00 & 64.08 & 63.82 & 67.00 & 63.71 & 64.29 & 67.00 & 63.30 & 63.46 & 67.00 & 66.44 \\
\hline 18 & 59.09 & 67.00 & 63.47 & 63.83 & 67. & 64.06 & 63. & 67.00 & 63.87 & & & 63.29 & 63.42 & 7.00 & 66.43 \\
\hline 19 & 59.05 & 67.00 & 63.42 & 63.78 & 67.00 & 64.00 & 63.72 & 67.00 & 63.97 & 64.18 & 67.00 & 63.23 & 63.36 & 67.00 & 66.43 \\
\hline
\end{tabular}


Figure B.7

Raw temperature profile of Table 4.6

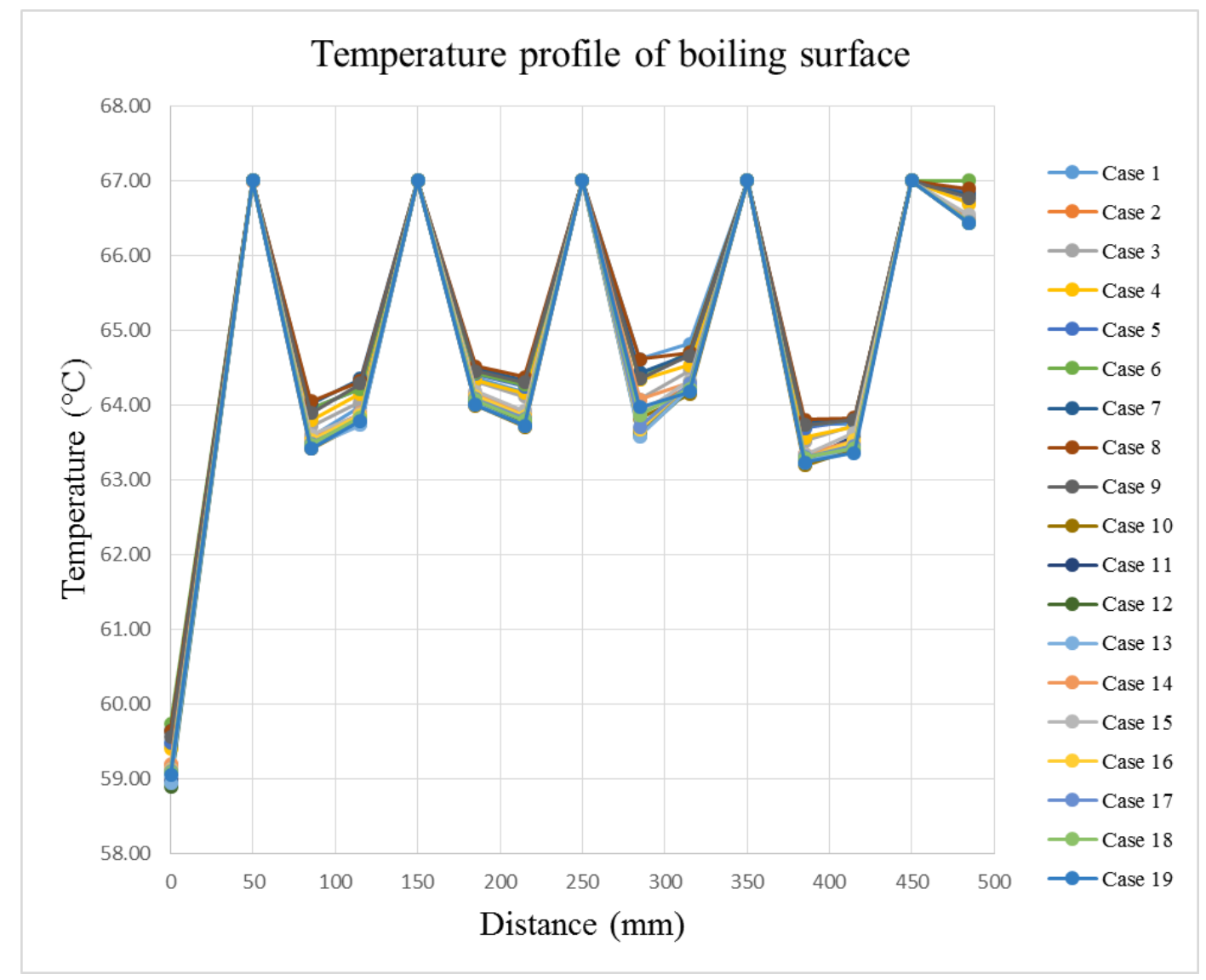




\section{Figure B.8}

Raw non-dimensionalized temperature profile of Table 4.6 and Figure 4.11

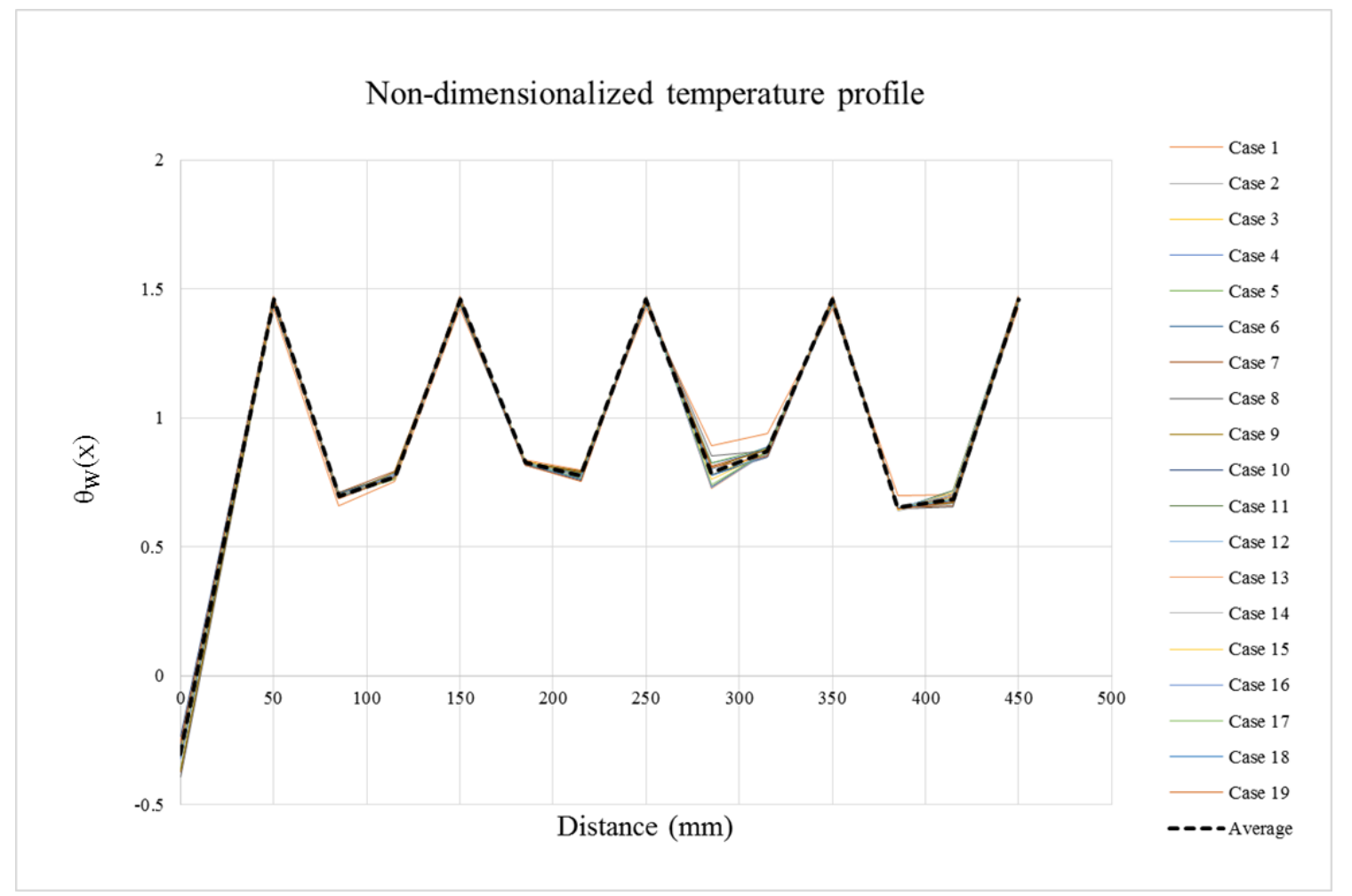




\section{Appendix C: Copyright documentation}

Permission for Figure 4.5b and c from Elsevier publishing:

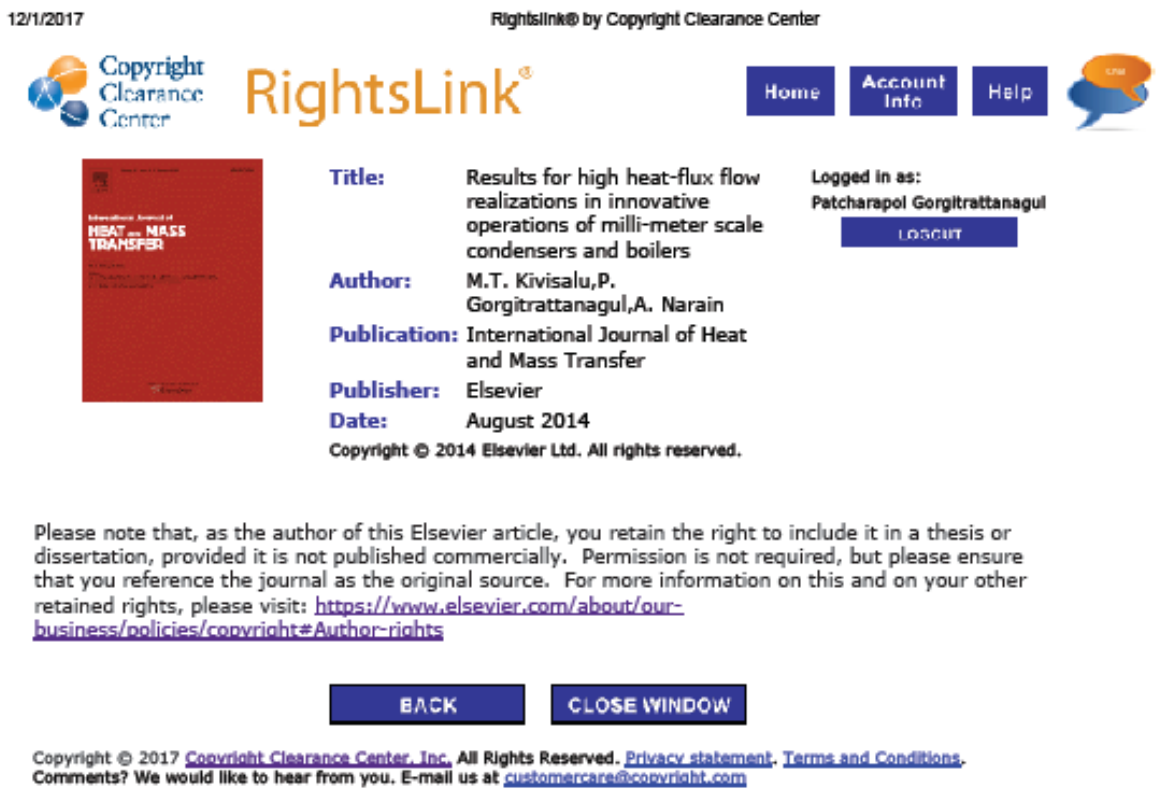


Permission for Figure 5.3 from Springer International Publishing:

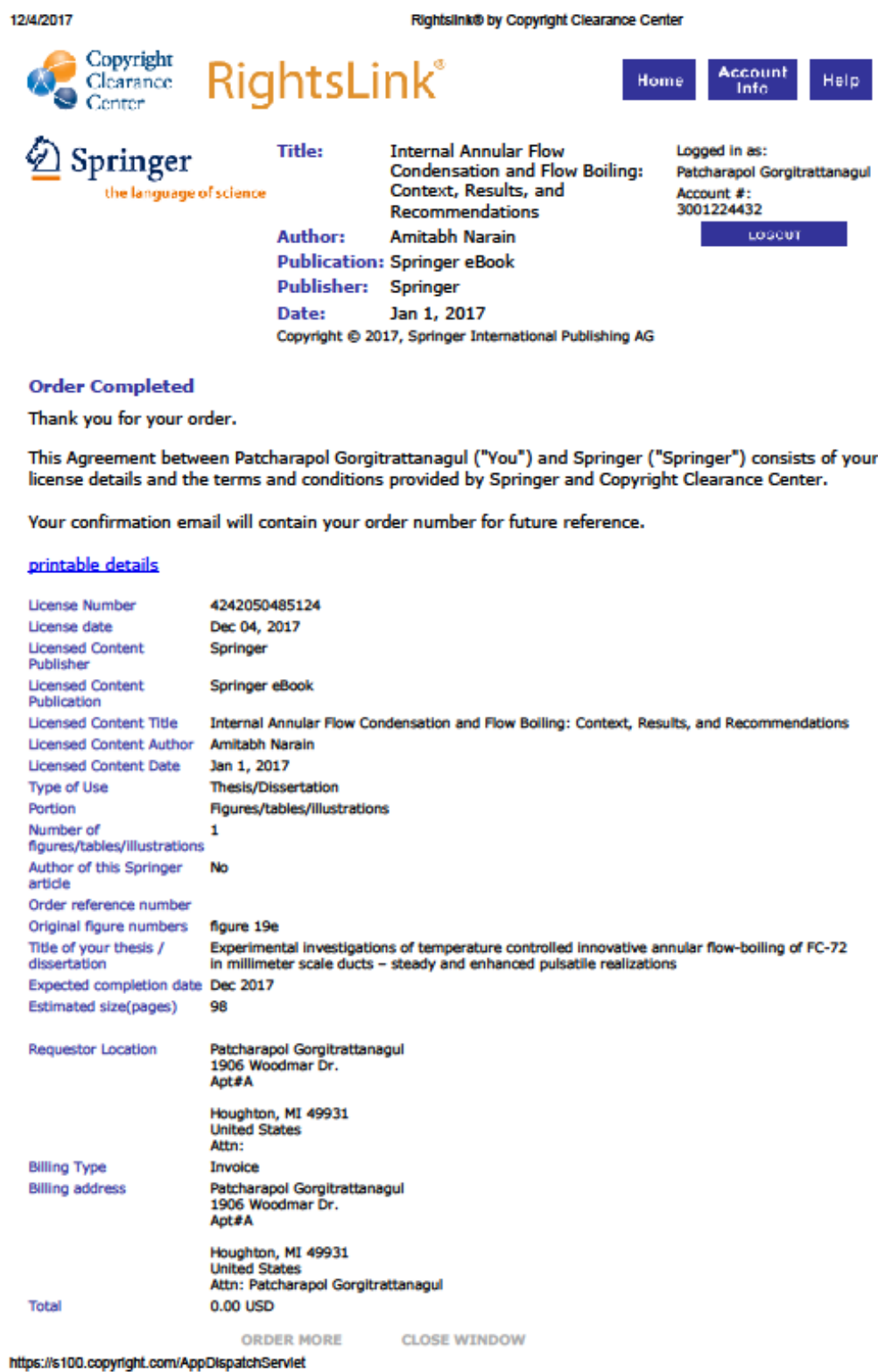

Copyright 92017 , Springer International Publishing AG

Logged in as: Patcharapol Gorgitrattanagul Account : : Loseur

Order Completed

Thank you for your order.

This Agreement between Patcharapol Gorgitrattanagul ("You") and Springer ("Springer") consists of your license details and the terms and conditions provided by Springer and Copyright Clearance Center.

Your confirmation email will contain your order number for future reference.

printable details

Uicense Number

Ucense date

Ucensed Content

Publisher

Uicensed Content

Uicensed Content Tule

Uicensed Content Author

Ucensed Content Date

Type of Use

Portion

Number of

Number of
Agures/tables/llustrations

Auther of this Springer

Author of this
artide

Order reference number

Original figure numbers ngure 19e

nile of your

dissertation

Expected completion dot Dec 2017

Estimated size(pages) $\quad 98$

Requestor Location

4242050485124

Dec 04, 2017

Springer ebook

Internal Annular Flow Condensation and Flow Bolling: Context, Results, and Recommendations

Amitabh Narain

Thesis/Dissertation

perimental investigations of temperature controlled innovative annular fow-boliting of FC-72

2017

Patcharapol Gorgitrattanagul

1906 Wo

Houghton, MI 49931

United States

Attr:

Billing Type Invoice

Billing address Patcharapol Gorgitrattanagul

1906 Woodmar Dr.

Apt:A

Houghton, MI 49931

Attn: Patcharapol Gorgitrattanagul

Total

0.00 USD

ORDER MORE CLOSE WINDOW

Intp6:/15100.copynght.com/AppDispatchServet 